\title{
A New Era in Radio Astronomy
}

By the early 1950s the US Department of Defense, especially the Navy, and the newly created National Science Foundation (NSF) began to play a major role in American science, especially in astronomy. Meanwhile, Associated Universities, Inc. (AUI), which founded and operated the Brookhaven National Laboratory, was looking for new business. During these Cold War times, the United States could not afford to fall behind in the exciting and rapidly developing new area of radio astronomy. Caltech, MIT, Harvard, and Naval Research Laboratory scientists discussed how to get the United States more involved in this emerging field that had clear commercial and military applications as well as extraordinary opportunities for basic research. Two key conferences held at the end of 1953 and the start of 1954 provided the catalyst for an NSF-funded feasibility study aimed toward the goal of establishing a national radio astronomy facility.

After an exhaustive search, a site was chosen in a remote part of West Virginia between the small hamlets of Arbovale and Green Bank. Following more than two years of confrontational discussions about the nature of the proposed national radio astronomy facility and how it would be managed, the NSF awarded a contract in November 1956 to AUI to manage the construction and operation of the National Radio Astronomy Observatory.

\subsection{The Business of SCIEnCE}

As a result of their widely recognized contribution to the development of nuclear weapons and radar, American scientists emerged from WWII with a prestige that afforded them great influence during the post-war decades of the Cold War. Their influence increased after the 1957 Soviet launch of Sputnik as more money started flowing to US science and technology. Prior to the war, the center of physics was in Europe, but as a result of the physical devastation in Europe brought about by six years of conflict and the migration of many 
eminent scientists from Europe to the United States, the US emerged after 1945 as the dominant scientific power in the world, fueled by unprecedented government spending on science. Although research was mostly concentrated at the universities, the generous government financial support, which had been prompted by the urgencies of the war, continued during the post-war period. Initially much of the federal support for science came from the military for defense of the country, driven, at least in part, by competition among the services. At this time, federal leadership in science fell to the Atomic Energy Commission (AEC), the National Bureau of Standards (NBS), and the military services. The Office of Naval Research (ONR), in particular, developed close ties with American universities to support a variety of basic and applied research programs, even those that had no direct bearing on defense programs.

The National Science Foundation ${ }^{1}$ As early as 1942, Senator Harley Kilgore from West Virginia introduced a bill to create a National Science Foundation to distribute grants and contracts supporting both basic and applied research. Kilgore's bill paid particular attention to a broad geographic distribution of the funds. By contrast, the Vannevar Bush (1945) classic report, Science-The Endless Frontier, which argued for continued federal support for research, was more elitist than the Kilgore bill, and argued that the most public good would come from supporting only the best scientists and the best universities and laboratories.

It would be eight years before Congress and the Truman administration could agree on language addressing issues such a geographic diversity, the inclusion of the social sciences, applied research, patent rights, and administrative control. A 1947 bill, giving control to a board of scientists that appointed a director who reported to the board, was vetoed by President Truman, who wanted to appoint the director himself, with the board acting only in an advisory capacity.

The National Science Foundation was finally established in 1950. Alan Waterman, former Chief Scientist at ONR, was appointed as the first NSF director and recruited other senior ONR personnel to fill key positions at the new organization. In particular, Admiral Tom Owen, who later became Assistant Director for the Division of Astronomy, Atmospheres, Earth, and Oceans (AAEO), colloquially referred to as "Earth, Air, Fire, and Water," later played a major role in funding the Very Large Array (Chap. 7). Dan Hunt, who was a former Navy Captain, headed the NSF National Centers and then later the Astronomy Division. Although the 1950 NSF enabling act authorized an annual budget of $\$ 15,000,000$, the initial budget for fiscal year 1951 was only $\$ 224,000$. By 1951, the Korean War had begun and national priorities were turning elsewhere. The NSF budget was increased to $\$ 3.5$ million for fiscal year 1952, still well below the authorization level, but sufficient to begin a modest grant program to support individual investigators. But with the limited NSF funds, many highly qualified proposals were left unfunded. 
Waterman was looking for ways to enable the new NSF to make an impact on American science beyond just supporting research grants for individual investigators. Coming from ONR, he was aware of the emerging opportunities in radio astronomy, with its obvious cutting edge commercial and military applications and its potential impact on basic research. He was also aware of the ambitious plans in the UK and Australia to construct large new facilities for radio astronomy research and the potential for important new discoveries. Under Waterman's leadership, the NSF gave early support to the construction of the Harvard 24 foot and then 60 foot radio telescopes, as well as to Ohio State University for John Kraus's helical array. But the bulk of federal support for radio astronomy still came from the defense related programs at ONR and the Air Force Office for Scientific Research (AFOSR), as well as the privately funded program at the Carnegie Institution's Department of Terrestrial Magnetism (DTM).

An important NSF policy change occurred in May 1955 when the National Science Board (NSB) issued a statement declaring that ${ }^{2}$ :

1. The NSF should recommend as a national policy the desirability of government support of large-scale basic scientific facilities when the need is clear, and it is the national interest, when the merit is endorsed by panels of experts, and when the funds are not readily available from other sources,

2. A national astronomical observatory, a major radio astronomy facility, and university research installations of computers, accelerators and reactors are examples of such desirable activities for the NSF.

Although there was no specific Congressional authorization for the NSF to use its funds to pay for scientific equipment and facilities, apparently Congress did not object (Lomask 1976, p. 139). More importantly, the NSF was explicitly forbidden by law to operate any facilities or laboratories, ${ }^{3}$ so any funds used for this purpose had to be routed through a university or other research institution. What was not specified, however, was the degree of control that the NSF would have over the construction, operation and maintenance of any facility that they might fund.

Recognizing that there might be opposition to the diversion of funds from the NSF mandate to support individual investigators to the funding of construction and operation of large scale facilities, the NSB further stipulated that "Funds for such large-scale projects should be handled under special budgets."4 In August, NSF Director Alan Waterman informed the White House that the "1957 NSF budget request will include an item for support of certain research facilities now urgently needed," and that "this item is in addition to the established program of the foundation in support of research by grants for basic research." Unfortunately, the separation of research grants and facility funding was never firmly implemented at the NSF and remained a matter of contention for many decades. 
The establishment of the 1995 Major Research Equipment or MRE (later Major Research Equipment and Facilities Construction or MREFC) funding line (Sects. 9.6 and 10.7) somewhat addressed the problem of funding the construction of new facilities, but left unresolved the source of annual funding to operate these large and expensive facilities, leading to increased tensions and competition for funds between facilities and investigators.

The Association of Universities for Research in Astronomy (AURA) and the National Astronomy Observatory ${ }^{6}$ The broad ranging 1955 NSF policy decision was motivated largely by the growing demands of astronomy. Even before radio astronomers had begun to rally around the construction of one or more large (and expensive) radio telescopes to be located at a national radio astronomy facility, optical astronomers began what would be a parallel effort leading toward a National [Optical] Astronomy Observatory. At the time, the major US optical astronomy facilities, which were constructed largely through philanthropic support, were available primarily to scientists located only at those institutions that owned and operated the telescope, such as the Caltech Mt. Wilson and Palomar Observatories (MWPO), the University of California (Lick Observatory) and the Universities of Texas and Chicago (McDonald and Yerkes Observatories). Astronomers from other universities, particularly from the East Coast or Midwest, had at best access to smaller less competitive facilities and unfavorable skies. Indeed, with only limited opportunities for research in observational astronomy, universities were not able to attract the most talented students. Even at Harvard University, which once had the largest telescope in the world and probably the largest astronomy faculty in the US, the instrumentation had deteriorated, and the site 25 miles from Boston suffered from light pollution and poor weather.

Concerned about the lack of opportunity for the disenfranchised astronomers from the East and Midwest, John Irwin (1952) suggested that a clear site should be found in Arizona for photoelectric photometry that could be used by all astronomers. In August 1952, NSF convened an "Ad Hoc Meeting of Astronomical Consultants," which was later constituted as the NSF Advisory Panel for Astronomy with Jesse Greenstein from Caltech as the Chair. ${ }^{7}$ However, apparently concerned that a search for a site would not yield any astronomical research results, a joint \$21,200 proposal from Ohio State University and the Universities of Arizona and Indiana to search for a suitable location was not approved by Greenstein's Committee (Edmondson 1991; Goldberg 1983). The following year, during a meeting at Lowell Observatory on photoelectric photometry, Leo Goldberg stressed the need for a co-operative center for astronomy located at a good site with a 100-inch-class telescope to provide better opportunities for all optical observing, not just photometry, particularly for those without other access to competitive facilities and clear skies. In January 1954, following a recommendation from the NSF Advisory Panel for Astronomy, Waterman appointed an additional Advisory Panel for a National Astronomical Observatory with Robert McMath, Director of the University of Michigan's McMath-Hulbert Observatory as the Chair (England 1982, 
p. 281). ${ }^{8}$ As conceived, the national observatory would be owned by the US government but operated by a consortium of private universities. ${ }^{9}$ With grants totaling $\$ 818,400$ to the University of Michigan, Aden Meinel and Helmut Abt studied some 150 potential sites located throughout the Southwest leading to the choice of Kitt Peak, Arizona, some 60 miles west of Tucson (Goldberg 1983).

The McMath Panel proceeded with ambitious plans to construct a 30 inch telescope within 18 months, to be followed by an 84 inch telescope and also a large telescope dedicated to solar observations. The proposed 1957 NSF budget included funding for what was called the "American Astronomical Observatory," and the NSF wrote to McMath that "the Foundation would welcome a proposal from a group of universities organized for the purpose of managing and operating an astronomical observatory facility" (Goldberg 1983). Following an organizational meeting in March 1957, the Association of Universities for Research in Astronomy (AURA) was incorporated. Seven universities, California, Chicago, Harvard, Indiana, Michigan, Ohio State, and Wisconsin, became charter members of AURA, and the first contract with the NSF to operate the national observatory was signed in December 1957. Although the McMath Panel initially anticipated that the new observatory would be federally funded but privately owned, the NSF decided that the federal government would maintain ownership.

Princeton, citing their commitment to space astronomy, and Caltech, with their own 100 and 200 inch telescopes, did not initially join AURA. ${ }^{10}$ In March 1958, Kitt Peak was selected as the site of the Kitt Peak National Observatory (KPNO) which was soon to house 36 inch, 84 inch, and 158 inch telescopes, and later the McMath Solar Telescope. Nicholas Mayall was appointed as the first Director of KPNO, and when he retired in 1971, Leo Goldberg became KPNO Director. In 1963, AURA formed the Cerro Tololo Inter-American Observatory (CTIO) in Chile and purchased the land surrounding the Observatory as well as land in the nearby town of La Serena to house the Observatory headquarters. In 1983, AURA reorganized their observatories to include the KPNO, CTIO, and the National Solar Observatory as parts of the National Optical Astronomy Observatory (NOAO). AURA moved their corporate offices from Tucson to Washington to be closer to the political action, and John Jefferies became the new director of NOAO.

Associated Universities Inc. ${ }^{11}$ Following the end of the Second World War, American research in nuclear physics was concentrated at the University of California Radiation Laboratory at Berkeley, Los Alamos, the University of Chicago Argonne Laboratory, and at the Oak Ridge National Laboratory in Tennessee. Scientists from the Northeast felt excluded from pursuing the rapidly developing opportunities in nuclear and high energy particle physics, in spite of the earlier pioneering work at Harvard, MIT, and Columbia University. Following separate initiatives to develop two new regional centers for nuclear physics in the New York and Cambridge areas, it became clear that the newly 
created Atomic Energy Commission would not fund more than one new center, and if the two groups could not agree, there would be no new nuclear physics laboratory in the Northeast. On 23 March 1946, scientific and administrative representatives of nine Northeast universities ${ }^{12}$ assembled at Columbia to promote the establishment of a government facility for nuclear physics. Lee DuBridge from Rochester, former Director of the MIT Radiation Laboratory, was chosen to lead the discussion which culminated in a resolution to join together to further their mutual interests.

The group wisely rejected a suggested name, PYJOHMITCH, based on the initials of the nine founding universities, and instead adopted the name of "Associated Universities Incorporated" (AUI). Except for Harvard, each AUI member university agreed to contribute $\$ 25,000$ toward the new laboratory. When it was pointed out to George Kistiakowski, the Harvard representative, that Harvard was the richest of the nine institutions, Kistiakowski quickly retorted, "How do you think it got that way?"13

Initially AUI was incorporated in New Jersey, since it was thought that the new nuclear physics laboratory would be located in New Jersey, but when it was decided to locate the laboratory at Camp Upton on Long Island, Associated Universities Inc. was created as a New York corporation on 18 July 1946. The 18-member Board of Trustees included one administrator and one scientist from each member university (Fig. 3.1). Edward Reynolds, Vice President for

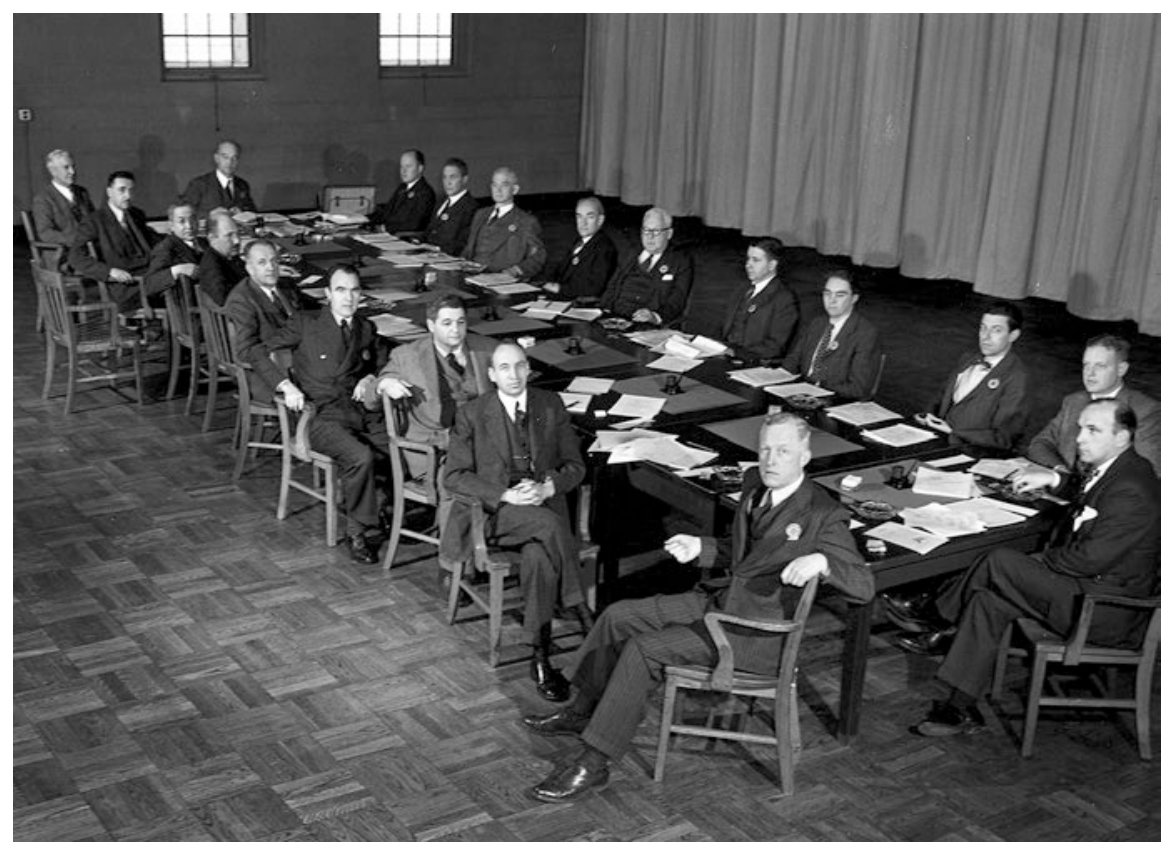

Fig. 3.1 First meeting of the AUI Board of Trustees in 1947. Credit: NRAO/AUI/ NSF 
Administration at Harvard and retired Brigadier General in the Army Medical Supply Services, was elected as the first Chairman of the Board and President of AUI, while MIT Professor Philip Morse was named as the first Director of the new Brookhaven National Laboratory. AUI Secretary Norman Ramsey later noted that "initially almost all the details and plans had to be made by the Trustees themselves. After there existed a Brookhaven staff, it was a somewhat difficult transition for the Trustees to acquire the confidence in the Brookhaven staff and to allocate to that staff its full responsibility." ${ }^{14}$ Many of the same issues were to arise a decade later with the newly formed NRAO.

For the first five years, AUI did not have a separate President. Rather the position of President was assumed by the Chairman of the Board of Trustees. But, wanting to expand its activities beyond Brookhaven, AUI recruited Lloyd Berkner (Fig. 3.2), who started as its full time President in February 1951. His mandate was to bring in new business needed to smooth out the financial fluctuations in the AEC Brookhaven contract, new business which might also act as a deterrent to AUI micromanagement of Brookhaven. ${ }^{15}$ Berkner was on the short list, and apparently the choice to be the first NSF Director, but withdrew from consideration to accept the AUI appointment (England 1982, p. 124).

Fig. 3.2 AUI President Lloyd V. Berkner led the effort to establish a national radio astronomy facility managed by AUI. Credit: NRAO/ AUI/NSF

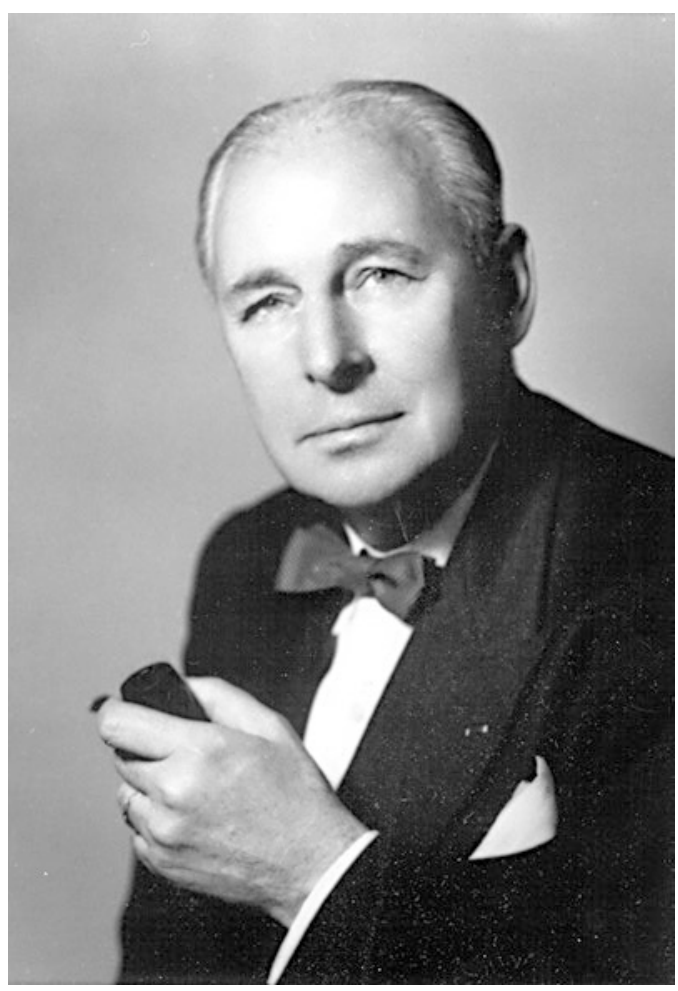


Lloyd Viel Berkner ${ }^{16}$ was born in 1905 in Milwaukee, Wisconsin, and grew up in Sleepy Eye, Minnesota and in North Dakota. Like many youths of the time, Berkner became fascinated with airplanes and radio, and held an amateur radio license, 9AWM. Following a year spent as a shipboard radio operator, he attended the University of Minnesota where he received his bachelor's degree in electrical engineering in 1927. One of his professors was Curtis M. Jansky, who had worked hard to persuade Bell Labs to hire his younger brother Karl in spite of Karl's chronic illness (Sect. 1.1). After graduation, Berkner worked on developing aircraft VHF radio navigation systems. Later, while working at the Bureau of Standards, he provided communications support for Admiral Richard E. Byrd and accompanied Byrd on his first Antarctic expedition as the expedition's radio engineer. His contributions were later recognized by the naming of what was then the most southerly known island in the world as Berkner Island. With perhaps somewhat less success, Berkner also became involved in assisting with radio support for Amelia Earhart on her airplane adventures. While at the Bureau of Standards, Berkner began his long research program in ionospheric physics, leading to the discovery of the $\mathrm{F}$ layer of the ionosphere responsible for long distance short wave radio propagation. Moving to the Carnegie Institution's Department of Terrestrial Magnetism (DTM), and building on techniques developed earlier by Merle Tuve, Berkner developed an advanced ionospheric sounding system which he deployed in Washington, DC, at Huancayo, Peru, at Watheroo in Western Australia, and near Fairbanks, Alaska to help predict optimum frequencies for short wave radio communication. During this period, he also worked with Tuve in the development of the proximity fuse, which was to play a critical role during WWII.

Tuve, who later started a radio astronomy program at DTM (Needell 2000, p. 265) is credited with having developed ionospheric sounding techniques, and, along with James Van Allen, for the WWII invention of the proximity fuse. But by this time, according to Needell (1987 p. 267), Tuve had become concerned about the growth of Federal investments in "big science" and the justification of basic research "as a basis for the defense of the free world," which he argued compromised individual creativity. Prior to the War, Tuve was Lloyd Berkner's boss at DTM, where their very different research styles led to conflicts and lasting tensions. Moreover, questions of priority and credit surrounding Berkner's contribution to both ionospheric sounding and the proximity fuse may have contributed to their subsequent confrontations around the establishment of NRAO a decade later.

During the War, Berkner had served as head of the Radar Section in the Navy Bureau of Aeronautics, where he developed aircraft radar systems and was instrumental in starting a program at the MIT Radiation Laboratory to protect American ships from Japanese attacks. It was in this capacity that he got to know I. I. Rabi and others who later became leaders of AUI. ${ }^{17}$ As a result of his continuing work on naval electronics, Berkner rose to the rank of Rear Admiral within the Naval Reserve and was recognized by the British Government with the "Order of the British Empire." 
Following the end of WWII, Berkner became head of the DTM Section for Exploratory Geophysics of the Atmosphere and also led DTM's fledging radio astronomy program. He was an active member of URSI Commission $\mathrm{V}$ on "Extraterrestrial Radio Noise" (later changed to "Radio Astronomy") as well as Chair of the US National Committee for URSI. As a regular advisor to the Department of Defense and to NATO, Berkner was instrumental in establishing the Distant Early Warning (DEW) line radar system and in organizing the NATO Military Assistance Program. From 1956 to 1959, he served as a member of the President's Scientific Advisory Committee (PSAC) where he led a study leading to the detection of underground nuclear tests and helped draft the 1959 Antarctic Treaty. He was a Fellow of the Arctic Institute, a Member of the National Academy of Sciences, and a Fellow of the American Philosophical Society. He was rumored to be part of a 1947 alleged secret group, known as the Majestic-12, appointed by President Truman to investigate the nature of UFOs. Later, he became Treasurer of the National Academy of Sciences, and was the founder and Chair of the 1957 International Geophysical Year, president of the International Council of Scientific Unions (1955) where he led the effort to found COSPAR, the joint IAU/URSI Committee on Space Science, president of the American Geophysical Union (1959), and president of the Institute of Radio Engineers (1961).

In 1958, Berkner became the first Chair of the National Academy of Science Space Studies Board (SSB). Following a three-year study, on 31 March 1961, on behalf of the SSB he sent a strongly worded memorandum to NASA Administrator James Webb stating that ${ }^{18}$ :

Scientific exploration of the Moon and planets should be clearly stated as the ultimate objective of the U.S. space program. ... Scientific exploration of the Moon and planets must at once be developed on the premise that man will be included. Failure to adopt and develop our national program upon this premise will inevitably prevent man's inclusion, and every effort should be made to establish the feasibility of manned space flight at the earliest opportunity. ... The Board strongly urges official adoption and public announcement of the foregoing policy and concepts by the U.S. government.

Less than two months later, in a special address to joint session of Congress, President John F. Kennedy conveyed Berkner's message stating that "this nation should set as a goal before this decade is out, of landing of a man on the moon and returning him safely to the Earth." 19

Although Berkner may not have the name recognition as some of the other American post-war science policy leaders such as Vannevar Bush, Robert Oppenheimer, or I. I. Rabi, perhaps no one had a broader impact on midtwentieth century science policy than Lloyd Berkner. He held numerous high level national and international positions which he was able to use to promote the case for increased Federal government funding of science. He died on 4 
Fig. 3.3 AUI Assistant to the President, Richard M. Emberson, ca. 1962. Credit: (C) 1962 IEEE; used with permission

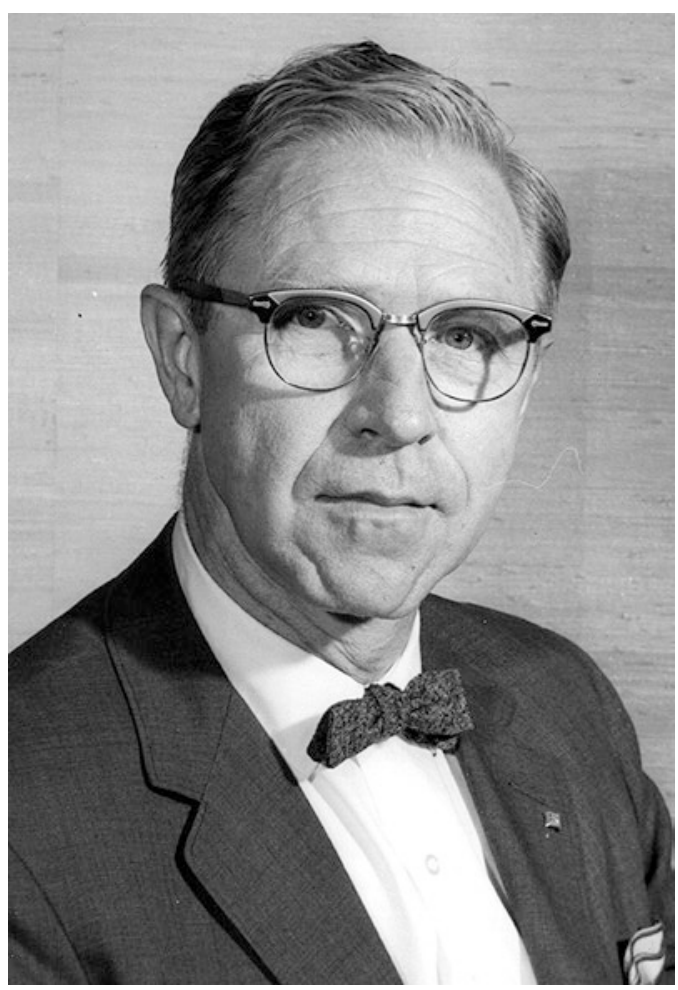

June 1967, following a heart attack suffered while attending a meeting of the Council of the National Academy of Sciences.

Among Berkner's first moves as AUI President was to transfer the AUI office from Brookhaven to the Empire State Building in New York City to escape the day-to-day issues surrounding the operation of this complex operation and to hire Richard (Dick) Emberson (Fig. 3.3) as Assistant to the President. A year later Emberson also became Assistant Secretary of the AUI Corporation. After receiving his PhD in Physics from the University of Missouri in 1936, Emberson spent three years building infrared detectors at the Harvard College Observatory. He was at the MIT Radiation Laboratory during the War, then at NRL. Immediately before joining AUI, Emberson spent five years at the Department of Defense Research and Development Board.

\subsection{First Steps Toward a National Radio Astronomy Facility ${ }^{20}$}

Oddly, the first stimulus toward creating a national radio astronomy facility in the US, came not from American scientists, but from Australia. By the late 1950s it was becoming clear that Australia could no longer remain competitive 
Fig. 3.4 Chief of the CSIRO Division of Radiophysics, E.G. (Taffy) Bowen played a major role in alerting US scientific leaders to the growing opportunities in radio astronomy. Credit: CSIRO Radio Astronomy Image Archive

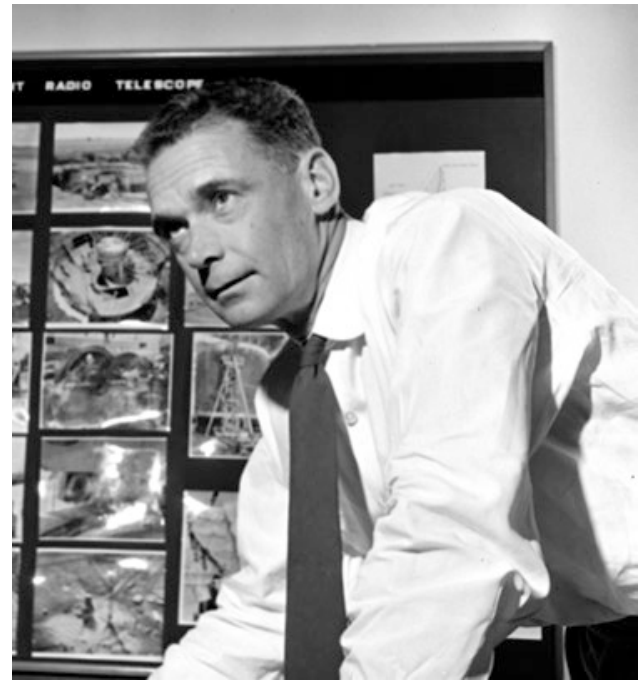

in the rapidly growing field of radio astronomy by simply continuing their modest individual investigator-initiated programs discussed in Chap. 2. While a small country like Australia could not compete in popular, but expensive scientific research areas such as nuclear or high energy physics, the modest CSIRO radio astronomy program was probably the most successful area of scientific research in Australia, and one that had brought considerable visibility and prestige to this country of only ten million people. CSIRO Radiophysics Chief Edward (Taffy) G. Bowen (Fig. 3.4) wanted to maintain the prominence of Australian radio astronomy, but was aware of the growing radio astronomy programs in the UK and in Europe. He wanted to make an impact, and in particular not be outdone by Bernard Lovell's planned 250 foot radio telescope under construction in the UK. But he knew that he would need to look beyond Australia for the kind of funding he needed to compete with Lovell at Jodrell Bank and Martin Ryle at Cambridge.

Bowen had been a key player in the British and later Allied radar effort during WWII. He was part of the secret 1940 Tizard Mission to the United States to discuss British radar developments, and carried plans and a prototype for a cavity magnetron, a key component to the development of microwave wavelength radar (Bowen 1987). During the following War years, Bowen spent considerable time in the US acting as liaison between the US and UK efforts to develop microwave radar systems. He helped set up the MIT Radiation Laboratory, which became the center for American radar development. During a three year stay at MIT he became close friends with influential American radar scientists, including Radiation Lab director Lee DuBridge, Robert Bacher, Alfred Loomis, Chair of the American Microwave Committee, and Vannevar Bush, later to become President of the Carnegie Institution and probably the most influential science policy maker in the post-war period. During this time, 
Bowen visited a number of laboratories involved in radar development, including Bell Laboratories where he met Karl Jansky (Bowen 1987, p. 170). In 1944, Bowen joined the Australian Council for Scientific and Industrial Research (CSIR, reorganized in 1949 as Commonwealth Scientific and Research Organization, CSIRO) to help develop Australia's radar defenses. In 1946, he became Chief of the Division of Radiophysics where he led the transition from wartime radar toward a variety of peaceful programs, including radio astronomy in which Australia quickly became a world power (Hanbury Brown et al. 1992).

Following the War, Lee DuBridge became president of the California Institute of Technology (Caltech), and Robert Bacher head of the Caltech Division of Physics, Mathematics, and Astronomy. Caltech operated the Mt. Wilson and Palomar Observatories (MWPO) together with the Carnegie Institution of Washington (CIW), but Caltech had no formal astronomy program in spite of owning the largest and most powerful telescope in the world, the 200 inch Mt. Palomar telescope. Soon after he took over at Caltech, DuBridge hired Jesse Greenstein, then a young but already highly respected astronomer, away from the Yerkes Observatory to begin an astronomy program at Caltech and to train students in astronomy. Greenstein quickly recruited a strong faculty, and the department started to turn out a series of very successful $\mathrm{PhD}$ graduates. Their work was all based on research done at the MWPO's 60 and 100 inch telescopes on Mt. Wilson and the 200 inch telescope on Mt. Palomar. When Berkner left Carnegie's DTM for AUI, it was apparently a setback to Tuve's radio astronomy ambitions, so with the support of his boss, Vannevar Bush, Tuve exchanged ideas with his Carnegie counterpart, MWPO Director Ira Bowen, about initiating some sort of cooperative radio program in conjunction with MWPO optical astronomers (Needell 1991, p. 63). But Ira Bowen was concerned that any support for radio astronomy might come at the expense of the more traditional MWPO programs in optical astronomy (Needell 1991, p. 65).

The Pasadena radio astronomy ambitions began at Caltech, two miles distant from the MWPO offices. While he was still a graduate student at Harvard, Jesse Greenstein had become fascinated with Karl Jansky's 1933 discovery of galactic radio emission. Although he went on to be recognized for his pioneering optical and theoretical research on interstellar dust, the chemical composition of stars, and the physical properties of white dwarfs (Gunn 2003; Kraft 2005), perhaps more than any other single individual, Jesse Greenstein (Fig. 3.5) later became a powerful force in raising the US to world leadership in radio astronomy, even though he himself never did any observational or experimental work in radio astronomy. Later Greenstein recalled that as a youth he had gazed at the giant radio antennas on the New Jersey shore being used by AT\&T for transatlantic telephone communications (Greenstein 1984a, b) and that he had illegally operated an amateur radio station without bothering to obtain the required FCC license. Together with Fred Whipple, while still a graduate student, Greenstein wrote the first theoretical paper in radio astron- 
Fig. 3.5 Caltech

Professor Jesse

L. Greenstein started the radio astronomy program at Caltech and was instrumental in gaining support for a national radio astronomy facility.

Credit:

Greenstein-10.12-12, Courtesy of the Archives, California Institute of Technology

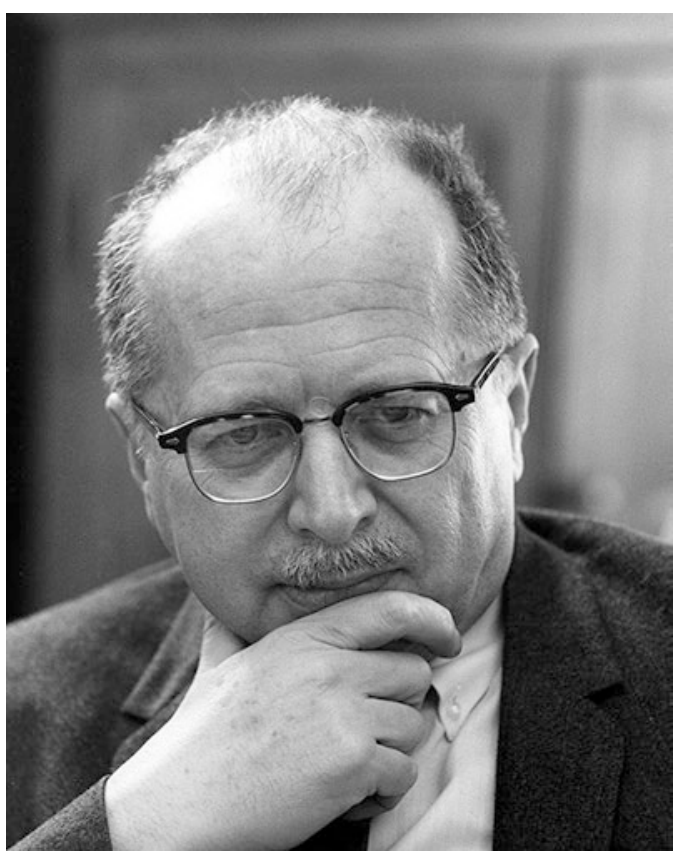

omy, trying to explain galactic radio emission as the result of thermal emission from interstellar grains, but their predictions were low by nearly a factor of 10,000 (Whipple and Greenstein 1937).

As discussed in Sect. 1.3 Greenstein had been part of the delegation that Otto Struve sent to Wheaton to evaluate Grote Reber's work. Following his several trips to Wheaton, Greenstein and Reber ultimately became good friends, and together with Reber, Greenstein wrote the first review paper in radio astronomy which served as an important trigger in bringing the work of radio astronomers to the attention of the broader astronomical community (Reber and Greenstein 1947). At Caltech, aware of the exciting discoveries in radio astronomy being made in the UK, in Australia, and elsewhere in the US, Greenstein argued that Caltech needed to get into this exciting new field (Gunn 2003; Greenstein 1994). ${ }^{21}$ Although Greenstein had strong support from the MWPO astronomers Walter Baade and Rudolph Minkowski, President DuBridge wanted "assurance that radio astronomy would uncover enough in the way of new, fundamental knowledge." 22 Ultimately, DuBridge would be convinced, but the persuasive arguments were to come not from Greenstein, but from DuBridge's old wartime friends, Taffy Bowen and Vannevar Bush.

Faced with the need to raise funds for his planned large radio telescope, Taffy Bowen suggested that Caltech needed to get into radio astronomy, and pointed out the unique opportunity that would be created by combining a large radio telescope with the unique facilities of the MWPO. Bowen suggested that he could come to Caltech along with some of "his boys" to take charge of 
running the radio telescope. To press his case, during a 1951 visit to the US, Bowen met not only with DuBridge, but also with his other former Radiation Lab friend, Robert Bacher, and with MWPO Director, Ira Bowen (no relation). DuBridge and Bacher were impressed by Taffy Bowen's enthusiasm for radio astronomy, although Ira Bowen, an atomic spectroscopist still unimpressed by the potential of radio astronomy, commented that radio astronomy was too hard and too complicated for his observatory. ${ }^{23}$ Earlier, Bowen had apparently discouraged Charles Townes $(1995$, p. 195) from working in radio astronomy with the remark, "I don't think radio waves are ever going to tell us anything about astronomy."

Following his Caltech visit, Taffy Bowen traveled to the East Coast where he met with Vannevar Bush, Alfred Loomis, a Trustee of both the Carnegie and Rockefeller Foundations, as well as other former Rad Lab colleagues Ed Purcell at Harvard, and Jerry Wiesner at MIT. Bowen was pursuing a two-pronged approach to support his ambitious radio telescope project. Either he would get American backing to finance the building of a radio telescope in Australia, or at least convince the Americans to build one in the US that he, along with "his boys" would come and help run.

The identification by Baade and Minkowski (1954) of the strong radio sources Cas A and Puppis A with Galactic nebulosities and of Cygnus A with a distant galaxy sparked interest among Caltech and MWPO astronomers including, finally, Ira Bowen. Encouraged by Vannevar Bush, Alfred Loomis, and Ira Bowen ${ }^{24}$ DuBridge wrote to [Taffy] Bowen asking him to "estimate where the subject stands at the present time and where it ought to go from here." 25 Although a large steerable dish of the order of 200 feet in diameter remained the centerpiece of Caltech's focus, DuBridge was already thinking more broadly of a "radio astronomy laboratory or radio astronomy observatory" and suggested to Bowen that they were "particularly enthusiastic about your being the director of such a laboratory." 26

Bowen responded with a thoughtful "Draft Programme for a Radio Observatory." 27 In his 11 page document, Bowen pointed out that radio astronomy "has tended to grow up in radio laboratories which are not closely associated with astronomical observatories," but that "the time appears ripe, therefore, to bring the radio and visual observations into closer contact." Bowen added that "the biggest single advance in the technique of radio astronomy is likely to come from the use of a very large radio telescope ... 200 to 250 feet in diameter." Following a brief summary of the outstanding observational areas of radio astronomy, including the Sun, the so-called "radio stars," and the recently discovered $21 \mathrm{~cm}$ hydrogen line, Bowen outlined the design concepts of a 200 to 250 foot diameter dish which he estimated could be built for about $\$ 1,000,000$ and operated by an initial staff of 13 scientists, engineers, and technicians, plus clerical and support staff, at an annual cost of about $\$ 100,000$. Bowen's report was well received by Bacher and DuBridge, although, around this time, DuBridge became aware of Lovell's plans to build a 250 foot radio telescope at the University of Manchester, and wrote to Bowen asking for his 
reaction to Lovell's telescope. ${ }^{28}$ Ever confident and enthusiastic, Bowen responded with more details of a possible antenna design, but noted that since "there is no point in making a telescope smaller than the one at Manchester, there may be some point in adopting a new unit of size namely 100 yards (or perhaps 100 meters)." 29

But Bowen had not given up hope of building his antenna in Australia, and he also asked Bush "if there is any possibility" of getting support from the Carnegie Foundation..$^{30}$ In spite of Bush's initial uncertainty about Carnegie funding, Bowen ultimately received grants from the Carnegie and Rockefeller Foundations and secured further funds from Australia to build his Giant Radio Telescope near the farming community of Parkes, several hundred miles west of Sydney (Sect. 6.6), and he dropped any further discussions with Caltech (Robertson 1992, p. 115). But he had planted the seeds of ambition in Pasadena, as well as in Cambridge and Washington, to bring the United States back into the field pioneered by Janksy and Reber. However, it remained unclear how Caltech might actually organize and operate a radio astronomy program.

Meanwhile, Greenstein and Bacher continued to pressure DuBridge to begin a radio astronomy program at Caltech. Greenstein recognized the potential power of combining a radio astronomy program with the optical facilities of the MWPO, and tried to convince DuBridge that Caltech needed to get more involved in this new window on the Universe. Greenstein was also the Chair of the new NSF Advisory Committee for Astronomy, and wrote to DuBridge that at their meeting on 5 and 6 February 1953, the committee discussed the need for a new observatory "in the southwest for use by scientists from other institutions and specifically devoted to photoelectric research" and the "need for a larger national effort in the field of radio astronomy." 31 Greenstein conveyed to DuBridge that his committee had pointed out that "we lag far behind Australia, Great Britain, and the Netherlands" and the need for "closer collaboration among the radio engineers and physicists who have thus far led this field, and astronomers who must interpret and use the results; the very great talents in applied electronics in the United States; and that important technical advances in electronics may arise in the course of this work." 32

Raymond Seeger was then the NSF Acting Assistant Director for Mathematical, Physical, and Engineering Sciences (MPE) and a close confident of Waterman. Looking for an entry into radio astronomy with its broad potential industrial and military implications, Seeger wrote to Greenstein, suggesting that Greenstein explore with DuBridge whether he "would sponsor a meeting of a group of active workers in the field, and of astronomers, to discuss our national situation in this field and to work out in outline a national program." 33 Seeger even suggested that the NSF would be willing to support such a meeting. Seeing the opportunity to establish Caltech's authority in the field, DuBridge responded favorably, and saying he felt it "desirable to have this conference in Pasadena." ${ }^{34}$ But DuBridge could not ignore the fact that the 
active radio astronomy programs in the US were at Cornell, Harvard, NRL, the Bureau of Standards, Ohio State, and DTM, and more broadly, that the power center for American science was on the east coast, particularly in Washington and Cambridge.

As Mt. Wilson and Palomar Observatories were jointly operated by Caltech and the CIW there was naturally close contact between the Caltech and Carnegie managements. With the encouragement and support of Greenstein, Bacher and Ira Bowen, DuBridge wrote on 20 March 1953 to Merle Tuve, DTM Director, as well as to Ed Purcell and Jerry Wiesner, offering to hold an international conference in Pasadena on radio astronomy in the autumn of 1953 and inviting them to be members of the organizing committee with himself as Chair and Greenstein as Executive Officer. In his letter, DuBridge explained that the purpose of the conference would be to

1) obtain a broad picture of the current status of the experimental work in radio astronomy in the United Sates,

2) to attempt to evaluate the probable major goals of radioastronomical [sic] work for the near future and the probable contributions to fundamental knowledge of the universe,

3) In light of the above, to reach conclusions relative to undertaking further research in radioastronomy $[\mathrm{sic}]$ in the United States..$^{35}$

Ed Purcell responded with enthusiastic support, but commented that he was aware "of one or two other projected US conferences in radio astronomy," including ones at the National Academy of Sciences and at URSI, both planned for April 1953 in Washington, DC, and he commented that "radio astronomy conferences are springing up all over the place." Purcell also noted that while the proposed Caltech conference appeared more comprehensive than the others, there might be a problem in that some of the potential international participants are unlikely to attend two meetings on radio astronomy held in the US around the same time period. Purcell also passed a copy of DuBridge's letter to Bart Bok (Fig. 3.6), head of the Harvard radio astronomy program. ${ }^{36}$ But Bok wrote to Greenstein that he had already organized a radio astronomy symposium at the American Association for the Advancement of Science (AAAS) to be held in Boston starting on 26 December 1953, and he invited Greenstein to be a speaker. ${ }^{37}$

Merle Tuve (Fig. 3.7) responded to DuBridge confirming that, indeed, he was already organizing a radio astronomy meeting at the National Academy of Science (NAS) on 29 April 1953 which would include talks by Martin Ryle, Walter Baade, Ed Purcell, H. C. van de Hulst, and John Hagen (Fig. 3.8), and also that John Hagan had scheduled three sessions on radio astronomy at the Spring URSI meeting in Washington on 27-29 April 1953..$^{38}$ DuBridge and Greenstein were surprised to learn that three other radio astronomy meetings had already been planned without their knowledge, especially considering that their MWPO colleague Walter Baade was an invited speaker at the NAS confer- 
Fig. 3.6 Harvard

Professor Bart Bok started the radio astronomy program at Harvard where many of the future NRAO leaders were trained, and also was a vocal supporter of AUI's plan to manage NRAO. Credit: NRAO/ AUI/NSF

Fig. 3.7 DTM Director Merle Tuve, 1946. Tuve, who chaired the NSF Radio Astronomy Advisory Committee, expressed reservations about the planned role of AUI as the manager of NRAO. Credit: Courtesy of Carnegie Institution, Department of Terrestrial Magnetism
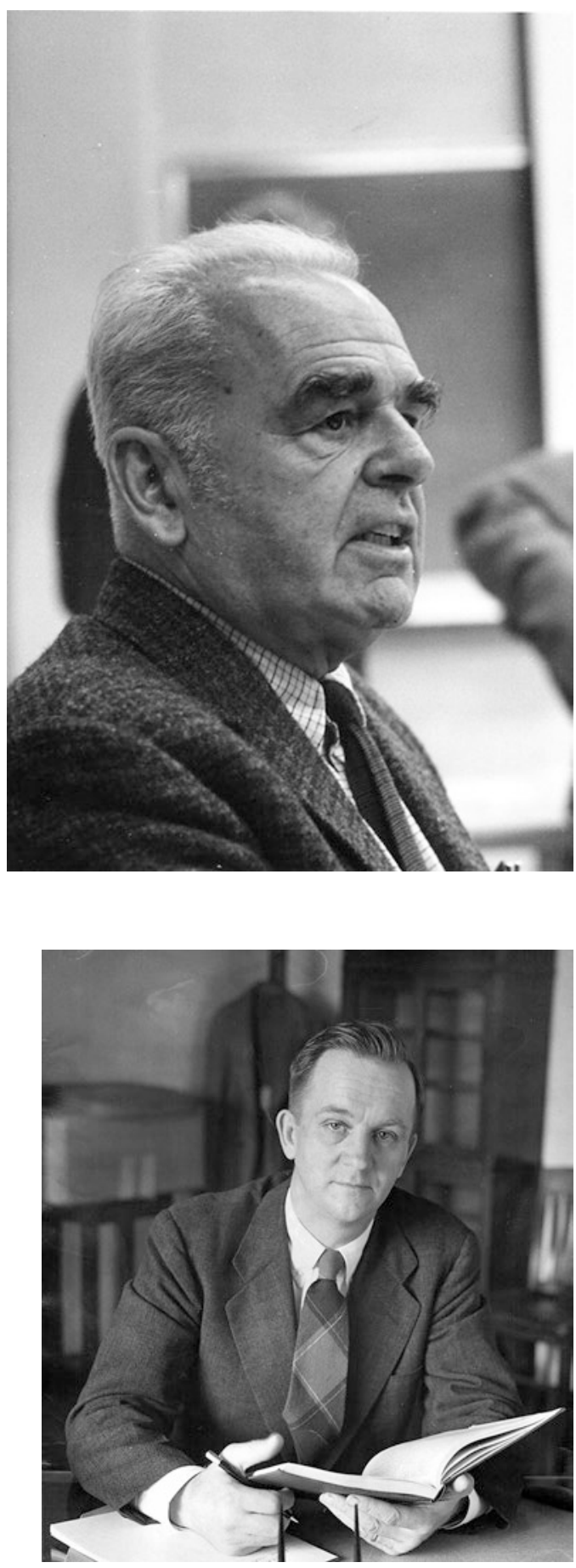
Fig. 3.8 John Hagen, Head of radio astronomy at the Naval Research Laboratory and Chair of the AUI Radio Astronomy Steering Committee. Credit: NRL

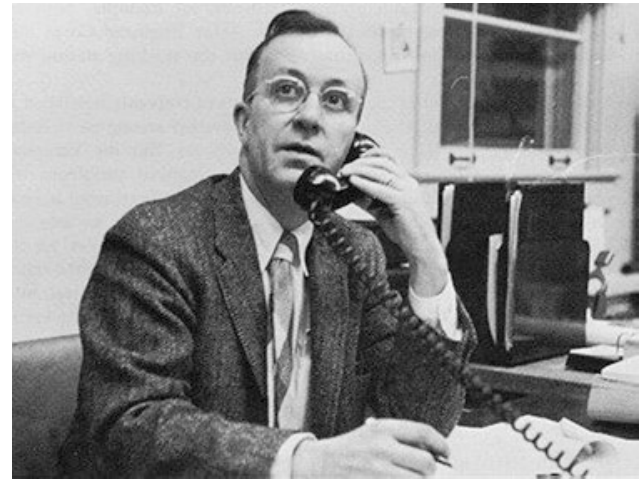

ence, that DuBridge was a member of the NAS, and that Greenstein and Bok were long-time friends. Trying to salvage some role for Caltech, Greenstein proposed that perhaps they could combine Bok's scheduled short meeting with the more comprehensive one that he and DuBridge had planned and suggested that perhaps they "could join forces, and apply to the NSF for travel funds." 39 Although Bok was supportive of Greenstein's suggestion, ${ }^{40}$ citing the Christmas holiday on one end and the AAS Nashville meeting on other end, DuBridge declined the opportunity for a joint meeting with Bok's AAAS conference. Instead, following discussions with Seeger at the NSF, DuBridge, at Vannevar Bush's invitation, reluctantly agreed to hold his proposed meeting during January 1954 at the Carnegie Institution in Washington and not in Pasadena as he had proposed. ${ }^{41}$

Greenstein and DuBridge discussed possible speakers and the need for travel funds, but, as Greenstein complained, they had their signals crossed with regard to publication. ${ }^{42}$ With the endorsement of the NSF, Greenstein and Bok had discussed the possibility of publishing some of papers from the January 1954 Washington meeting in the proceedings of the December 1953 Boston meeting. But DuBridge claimed he wanted to keep things informal and had declined the opportunity. ${ }^{43}$ An organizing committee for the Washington meeting was established, consisting of Greenstein as Chair, DuBridge, Bok, Hagen (NRL), Tuve, Wiesner (MIT), and Seeger (NSF).

The NSF agreed to provide financial support particularly for participant travel expenses. Although Merle Tuve volunteered to provide administrative support from the Carnegie Institution, including administering the NSF funds, he had very different views from Greenstein and DuBridge on the nature and purpose of the Washington meeting. As it was the last of four US meetings, Tuve echoed Graham Smith's comment that the Washington conference "can hardly be intended for their benefit; they surely feel no strong need for getting together to inform and stimulate each other." 44 While he agreed with the goal of bringing together "astronomers and electronic physicists into warm and stimulating contact with the current state of radio astronomy," Tuve, characteristically, was strongly opposed to "the idea that one of the purposes of the 
conferences might be to figure out what kind of a large-scale effort the United States might, or could, or should undertake in this field." Rather, he wrote Greenstein, "The only way to nurture a subject is by finding and encouraging young men who are interested in the subject." Tuve wrote that he was concerned that Greenstein and DuBridge "have not really moved away from the original idea of holding a conference in order to figure out what large-scale equipment and activity is appropriate for the United States, and presumably appropriate for NSF support," and he went on to say that "I do not wish to be a party of any such thing," and urged that "you and Lee should reexamine your own ideas before you write the invitation letters." In suggesting participants for the meeting, Tuve again stressed that, "the meeting is not for radio astronomy workers to inform each other of their latest activities, but rather to interest and stimulate toward active participation investigators from astronomy and research electronics, especially with the hope of inducing some young men to work in this interesting new area." 45 This was to be the start of Tuve's three year struggle against a major government-funded national facility for radio astronomy, first with Greenstein and DuBridge, and later, even more forcefully, with Lloyd Berkner and AUI.

The Washington Conference Sets the Ball Rolling Greenstein maintained that one of the objectives of the Washington conference was to explore opportunities for constructing a large antenna to allow American scientists to compete with those in England and Australia. However, in response to Tuve's concern about the goals of the meeting, Greenstein agreed that the invitations would state only that the meeting was intended to "encourage increased activity and participation of various American groups in this ... area of research." ${ }^{46}$ But Tuve's definition of increased activity was to "encourage young people who want to do something, rather than the deans and other officials who would like to start up a given activity, whether they have competent and enthusiastic personnel or not." Tuve went on to point out that "radio astronomy has been given quite a bit of financial help in this country." Indeed, as it would turn out, over the next half century, radio astronomers would receive a disproportional share of the NSF astronomy budget for new construction.

Bok's meeting was held in Boston on 26 and 27 December 1953, at the American Academy of Arts and Sciences, and was sponsored by the American Association for the Advancement of Science. Both organizations were known as the $A A A S$, contributing to some confusion. Bok, characteristically full of enthusiasm and undaunted by holidays, initially planned for an early morning start on 26 December, the day after Christmas. But facing objections from the participants, he moved the start to the afternoon so participants could travel overnight after celebrating Christmas with their families. Participants were also challenged by some of the coldest Boston temperatures ever recorded with overnight temperatures reaching $-26 \mathrm{~F}(-34 \mathrm{C})$. But the meeting went off without incident and included reviews by John Hagan, Harold (Doc) Ewen, John Kraus, Merle Tuve, Graham-Smith and Bernard Mills. Grote Reber, although invited, decline to come, characteristically citing his preference to 
remain in Hawaii to take data, but interestingly, a week later he did participate in the Washington meeting. Graham Smith and Bernard Mills, who were both on long term visits to DTM, inspired the group with their reports of the exciting work going on at Cambridge and Sydney. In spite of Bok's announced good intentions, there were no publications from the Boston meeting, nor was there any attempt made in Boston to influence any policy decisions regarding future US activities in radio astronomy.

The program of the Washington meeting was arranged primarily by Greenstein, following consultation with Tuve, with only minor input from the other members of the organizing committee. Greenstein convinced DuBridge to act as the titular Chairman of the meeting and, as such, to chair at least the opening and closing sessions. The conference, which was more elaborate than Bok's Boston meeting, ran from 4 to 6 January 1954 and was attended by about 75 people from universities, government, and industry. With the support of Vannevar Bush, Greenstein was able to secure funding from the new National Science Foundation to help support the participation of internationally prominent scientists such as Fred Hoyle, Graham Smith and Hanbury Brown from the UK, Hannes Alfvén from Sweden, Taffy Bowen and Bernard Mills from Australia, and Henk van der Hulst from the Netherlands. In addition to the organizers, other American participants included John Kraus from Ohio State, as well as representatives from NRL, DTM, Harvard, Princeton, MWPO, and the US Naval Observatory. The conference ignited the enthusiasm, not only of the astronomers present, but, perhaps more importantly, the influential east coast science power brokers. It would be this conference that provided the impetus toward establishing a US national radio astronomy facility, but the path would be a tortuous one, fraught with turf battles and long-standing personality conflicts.

The published reports of the conference in Volume 59 of Journal of Geophysical Research (pp. 149-198) only included short abstracts of the presentations (See also Hagan 1954). There were no formal discussions or recommendations from the conference about planning for the future, but after the close of the conference, a small group got together at the NSF "to consider some questions of national policy in this field." ${ }^{47}$ In a report authored by Greenstein, citing recent US work on discrete sources, the $21 \mathrm{~cm}$ hydrogen line, ionized gas regions, and the Sun, the group was unanimous in their belief that there were important new scientific results to be expected in the field of radio astronomy. Most, but notably not all, participants agreed that the existing US effort was inadequate, and argued that since existing radio astronomy programs at Harvard and Ohio State, as well as at several research centers would provide adequate training for young scientists, "consideration should be given to constructing at least one major research center with large equipment, such as a 250 -foot steerable paraboloid." Noting the limitations of private, industrial, and Department of Defense funding, they recommended that the NSF appoint a committee to "be responsible for a more detailed estimate of the budgetary needs, suggesting opportunities for immediate expansion and planning for the ultimate large scale capital expansion." 


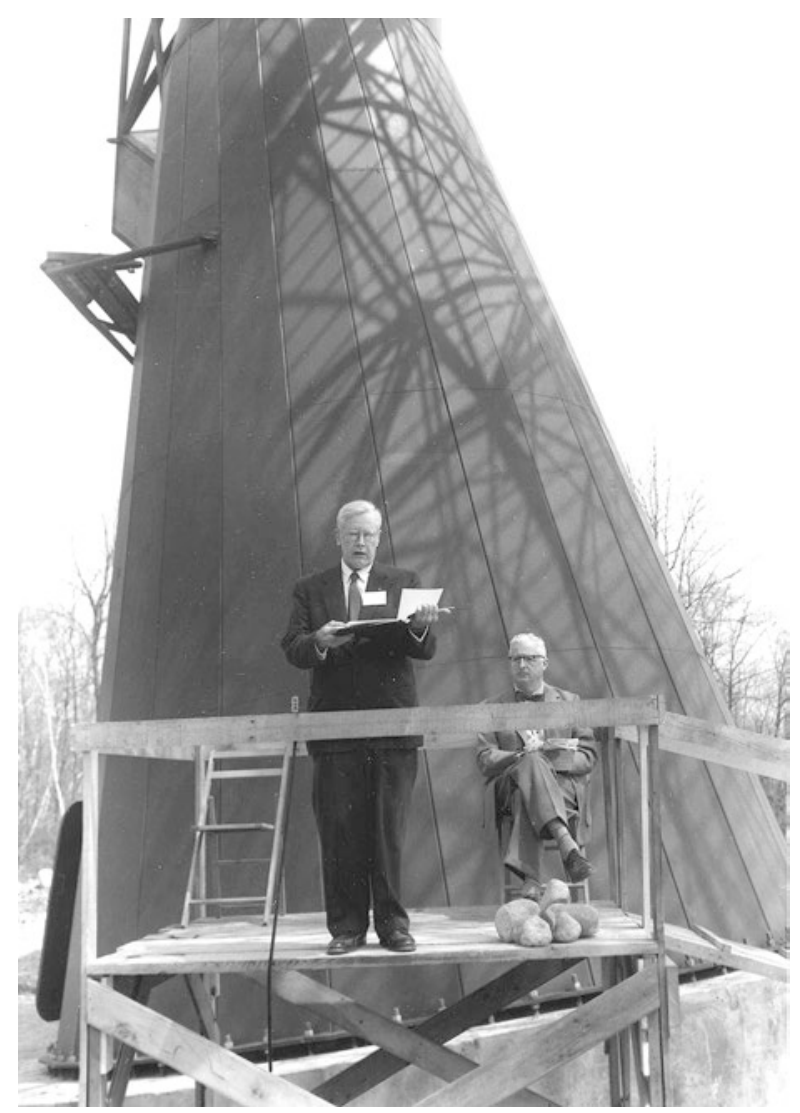

Fig. 3.9 NSF Director Alan T. Waterman speaking on 28 April 1956 at the dedication of the Harvard 60 foot antenna; Donald H. Menzel is seated behind him. Credit: NAADSH, Photographs

Alan Waterman (Fig. 3.9) had become the first director of the NSF just two weeks after Ewen and Purcell's detection of the $21 \mathrm{~cm}$ hydrogen line, and saw radio astronomy as an opportunity for the young NSF to make an impact. In February 1954, following a visit to Caltech and the MWPO, Waterman lost no time in responding to the January recommendation and created an NSF Advisory Panel for Radio Astronomy with Merle Tuve as Chair. ${ }^{48}$

The Menzel Report Inspired by the Washington meeting, Donald Menzel (Fig. 3.10), Director of the Harvard College Observatory, together with Ed Purcell, Doc Ewen, Fred Whipple, Cecilia Gaposchkin, and Bart Bok, met with MIT Vice President Julius Stratton and MIT Professor Jerome Wiesner, to discuss the possibility of a joint Harvard-MIT effort to acquire and operate a large research tool for radio astronomy." ${ }^{49}$ But they soon realized that their ambitious plans were probably too big, not only for a combined Harvard-MIT 
Fig. 3.10 Harvard College Observatory Director Donald Menzel, who authored the 1954 report that initiated Berkner's plans to develop a national facility for radio astronomy. Credit: Harvard-Smithsonian Center for Astrophysics

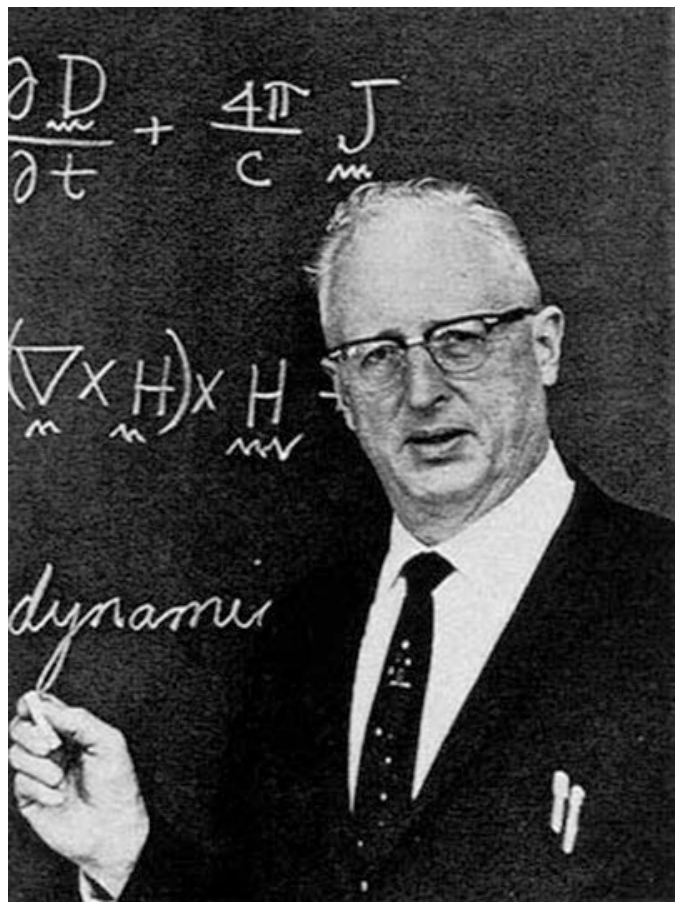

effort, but even if NRL were brought into the picture. Following Stratton's suggestion to establish "a radio observatory to be operated on behalf of all United States scientists" (Emberson 1959), Harvard Vice President for Research and Harvard member of the AUI Board, Edward Reynolds, suggested to Menzel that Associated Universities, Inc. might undertake the job of creating and operating a research facility.

Donald Menzel was trained as a physicist and was known primarily for his work in stellar spectroscopy, but he was not unknown to the radio community. In his youth, he held an amateur radio license (W1JEX), and as early as 1937, he had speculated on the possibility of communication with Martians by short wave radio. During WWII, working for the US Navy, Menzel studied the relation between radio propagation and solar activity. In this capacity he got to know Lloyd Berkner, who was in charge of naval aviation electronics. Menzel also remembered Grote Reber's 1936 letter to Harlow Shapley as well as Reber's 1946 proposal to build a 200 foot diameter radio telescope, and after the detection of the $21 \mathrm{~cm}$ hydrogen line by Ewen and Purcell, Menzel supported Bart Bok's efforts to start the first radio astronomy program at an American university.

Menzel traveled to Washington to meet with Berkner and Emberson to plan a May organizing meeting. In preparation for the May meeting, Menzel drafted a report for Berkner titled, "Survey of the Potentialities of Cooperative Research in Radio Astronomy." He ended his covering letter to Berkner with, "I hope this is the beginning of a new and important era in radio astronomy." 50 
In his introduction to the report, Menzel stated that the field of radio astronomy

encompasses most of astronomy, stars, cosmic evolution, geophysics of the atmosphere, aerodynamics, astroballistics, electronics, radio communication, electromagnetic and hydrodynamic properties of gases, statistical mechanics, thermodynamics, interaction of atoms and radiation, cosmic rays, properties of the atomic nucleus, and the speed of chemical reactions.

Menzel went on to discuss options for solar, planetary, and galactic studies, including prescient remarks on the prospects for radio astronomy investigations of the hydroxyl $(\mathrm{OH})$ molecule and deuterium as well the opportunities for further research based on the neutral hydrogen $21 \mathrm{~cm}$ line. Interestingly, $\mathrm{OH}$ would not be detected in the interstellar medium for nearly another decade (Weinreb et al. 1963) while deuterium remained elusive for more than half a century (Rogers et al. 2005). He also discussed the possibilities for research in the related areas of ionospheric physics, active lunar and planetary radar, as well as "allied laboratory and theoretical studies."

In his report, Menzel noted that "although several individual scientists in the United States were preeminent in the early development of radio astronomy, there has been no broad, coordinated attack in this country on the basic problems of this field," and he argued that "other nations (in particular Britain, Holland, and Australia) now lead in this important area." He speculated that part of the reason for "the lag" was the "enormous expense of the tools," and commented that the objective of his survey was to bring together "the various scientific groups who have an interest in the field, in order to pave the way for a coordinated attack on the problems, perhaps through the medium of a formal organization, similar to that of Associated Universities Incorporated."

As he had already discussed with Berkner and Emberson, Menzel's report suggested that "a small committee of interested scientists should be formed initially to discuss the details of the program, to formulate a working polity, and to make recommendations for future extension of the work." He added that the initial participants might include, "in addition to representatives from Harvard, MIT and other members of Associated Universities Incorporated, ... scientists from the Franklin Institute, Penn State, NRL, the Carnegie Institute [DTM] and possibly others." Caltech was noticeably absent from Menzel's list.

In a carefully laid out plan, Menzel thoughtfully emphasized the need to find a suitable site for the new radio facility. Although he commented on the need for "freedom from local radio interference," he considered that the "primary consideration be given to accessibility." Perhaps somewhat gratuitously, he added that "the council of the Harvard College Observatory wishes to express the opinion that its facilities at the Agassiz Station might be expanded to meet the needs of the proposal." He also suggested that the radio facility include several optical telescopes, and stated that Harvard might have some spare mirrors to donate. He laid out the requirements for recruiting staff and a 
director as well as the need to train students in this new field, pointing out that "only at Harvard is there at present an academic program in radio astronomy."

Menzel concluded his report to Berkner by noting that with the establishment and operation of Brookhaven, AUI had "effectively solved a similar problem" and "the suggestion that the Associated Universities Inc. should itself support the proposal merits most serious consideration." Menzel proposed that AUI set up a Steering Committee to develop plans to set up a radio observatory and suggested some 20 possible members of the Steering Committeeall from the Northeast. But as an apparent afterthought, he added DuBridge, Greenstein, and Otto Struve from UC Berkeley.

Contentious AUI and NSF Committees Berkner lost no time in reacting to Menzel's report. Two weeks later he and Menzel met with the NSF Director, Alan Waterman, and other NSF staff as well as Jerrold Zacharias from MIT and Emanuel (Manny) Piore from ONR. They convinced Waterman to sponsor a small meeting to "discuss the possibility of building a large dish in the near future," and to entertain a proposal from AUI to set up a group to further develop the planning. ${ }^{51}$ While the NSF anticipated that they or the Department of Defense might pay to construct such a facility, they expected that private funds would be sought "for the maintenance for the upkeep of the facility."

Following the 26 April 1954 meeting at the NSF, Berkner appointed an "Ad Hoc Group for Cooperative Research in Radio Astronomy" which he promptly convened on 20 May 1954 in AUI's New York Offices on the 69th floor of the Empire State Building. Berkner's meeting was attended by 37 scientists representing 28 different institutions, including Minkowski and DuBridge from Caltech, John Hagen from NRL, and Merle Tuve from DTM. ${ }^{52}$ Alan Waterman and Ray Seeger representing the NSF and Manny Piori from ONR came as observers. Jesse Greenstein chose not to give up his 200 inch observing time to participate in the meeting, but he later confided to John Hagan ${ }^{53}$ that while he supported anything that would bring new resources to radio astronomy, he was concerned about the role of AUI and particularly Harvard, and worried more about the lack of experienced people than the shortage of expensive telescopes.

Berkner conveyed AUI's interest in building a 250-300 foot dish, which he estimated might cost between $\$ 2,000,000$ and $\$ 5,000,000$, that AUI would make available for use by all universities, not just members of AUI. Although it was understood that construction funds would need to come from the federal government, probably the NSF, Berkner suggested that AUI might seek a $\$ 5,000,000$ endowment whose income of about $\$ 200,000$ per year could be used for operation of the observatory. Technical discussions were concentrated on the size of the dish and whether or not it should be on an equatorial or altaz mount. Princeton physicist Robert (Bob) Dicke made some insightful comments and suggestions. ${ }^{54}$ First he pointed out that to avoid unacceptably high sidelobes, it was necessary to taper the illumination and thus reduce the effective area that one had worked so hard to build. Second, he suggested that 
instead of trying to keep the feed support structure sufficiently rigid to avoid flexure, one might consider a servo system to stabilize the support structure. Finally, with great prescience, Dicke pointed out the advantages of using an interferometer system composed of a number of small dishes instead of a single large dish. Dicke specifically suggested an interferometer composed of three 87 foot dishes moving on a circular track which would have the equivalent collecting area as a single 150 foot antenna, but which, he argued, would only cost about $1 / 5$ as much, although he conceded that savings would be at least partially offset by the cost of the instrumentation. This seems to be the first ever suggestion to build a radio interferometer composed of multiple steerable parabolic antennas, and predates by several years the Caltech two-element interferometer or the Cambridge One-Mile Radio Telescope. However, Dicke's memo was ahead of its time, and appears to have had little serious impact to the subsequent discussions, which continued to focus on large fully steerable dishes.

Lee DuBridge surprised the participants by announcing that Caltech planned to create their own radio astronomy observatory with probable funding from the Office of Naval Research (ONR) (Sect. 6.6). The proclamation by DuBridge perhaps further motivated the Northeast science establishment and the NSF to try to establish their own facility, now needed to compete not only with Australia and the UK, but also with Caltech and ONR. It also obviated any argument to locate the proposed radio astronomy facility in the western part of the US. The group, which included the members of the NSF Advisory Panel for Radio Astronomy, supported the concept of establishing a national facility for radio astronomy and agreed that AUI should propose to the NSF to do a feasibility study for establishing a cooperative radio observatory. Emberson (1959) later wrote that the 20 May conference concluded that a three step process was needed, "(i) a feasibility study on objectives and organization, sites, and facilities, (ii) final design of facilities and equipment, and (iii) construction of the observatory."

The following day, the AUI Executive Committee authorized Berkner to apply to the NSF for a grant to study the selection of a site and to prepare a preliminary design for a radio astronomy facility, ${ }^{55}$ and at their next meeting on 18 June 1954, the Executive Committee approved Berkner's request to appoint Dick Emberson, as "Acting Director of a radio astronomy project," along with a supporting salaried staff. With his strong background in radiophysics, Emberson was a natural choice to guide the AUI radio astronomy program. The Executive Committee also approved the appointment of an ad hoc committee recommended by Menzel to "work in close liaison with the project staff" and with a committee of the AUI Board. Recognizing that their lack of expertise in radio astronomy might open them to criticism from Tuve and others, AUI considered the need to extend the composition of the Board of Trustees, but Berkner argued that the committee could keep the Board informed through a small committee of the Board. ${ }^{56}$

Berkner's choice of John Hagen to chair the AUI Committee was a logical move. Starting in 1935, Hagen had worked at the Naval Research Laboratory 
where, as described in Sect. 2.6, he had begun a program of research in radio astronomy. As the Chair of the US Radio Astronomy Commission V of URSI, Hagen was a natural choice to chair Berkner's study committee. The other 10 members of the AUI committee came primarily from the major East Coast universities and laboratories. ${ }^{57}$ At the suggestion of Bart Bok, David (Dave) Heeschen, who was soon to become one of the first Americans to receive a PhD degree in radio astronomy, was appointed as a consultant to the committee. Both Emberson and Heeschen worked with the Steering Committee and Berkner to plan the proposed feasibility study. Notably missing were Lee DuBridge and Jesse Greenstein, who had initiated the January 1954 meeting which had started the sequence of events leading to AUI's involvement in radio astronomy.

The Boston and Washington meetings had discussed "small science" programs typically carried out by small close-knit teams, but in just a few short months the discussion had grown to anticipate big science with a national facility, government funding, and management by committee. After years of neglect and following a series of high level meetings held over a period of four months, the United States suddenly had two national advisory committees for radio astronomy-one reporting to AUI and one reporting to the NSF. ${ }^{58}$ Sometime they worked together, but at other times they were in conflict. These were in addition to the two NSF committees for optical astronomy, the Advisory Panel for Astronomy and the Advisory Panel for a National Astronomical Observatory. Conflicts also arose between the East and West Coast establishments, between radio and traditional (optical) astronomers, between advocates for and opponents to big government spending for science, and even between long standing personal rivals. Four individuals, Bok, Hagen, Kraus, and Tuve, served on both the AUI and NSF radio astronomy committees, which led to further tensions and mistrusts. Leo Goldberg, a member of the NSF radio astronomy panel who also served on the Advisory Panel for a National Astronomical Observatory as well as the NSF Division Committee for Mathematical, Physical, and Engineering, expressed concern about radio astronomers taking funds from "real" astronomers. ${ }^{59}$ Much of the deliberations of the two committees and interaction between them were by written letters, sometimes private between only two committee members, other times with multiple carbon copies sent to all members of one or both committees. Little formal documentation remains from these committee/panel deliberations, although the sense of the deliberation can be reconstructed from the private papers of the participants, particularly those of Greenstein and Tuve. The situation was confused by the loose and changing definition of the committee names. At various times each committee was referred to as a "panel" or "committee" and as "advisory committee/ panel" or "steering committee/panel," often leading to confusion over who was speaking for which committee or panel and what hat they were wearing.

The NSF and AUI committees each addressed similar questions: what instruments to build at the national radio facility, where to build the facility, who would manage the facility, and how to recruit staff, particularly a director. But over the next two years the discussion invariably returned to the size and cost of the proposed radio telescope, how it would be managed, and by whom. 
To discuss the draft proposal that had been prepared by Berkner and Emberson, the AUI Steering Committee met together with the members of the NSF Advisory Panel on 26 July 1954 at the AUI offices in New York. Merle Tuve, Chair of the NSF Panel was unable, or perhaps, unwilling to attend. After reviewing the broad range of potential scientific research programs, the participants dismissed the need for co-locating the proposed radio facility with optical facilities, but in order to meet all of the scientific objectives, they suggested that a range of equipment, including a high gain antenna as well as a number of smaller antennas, a standing fan-beam antenna for surveying, and an interferometer, would be needed. They also discussed the criteria for siting the facility, recognizing the need to balance observing conditions (weather and freedom from RFI) with practical accessibility. ${ }^{60}$

The next day, Berkner hand-carried 15 copies of an AUI proposal, along with minutes of the January and 20 May meetings, to Waterman at the NSF. The proposal requested $\$ 105,000$ for a one-year study to investigate the feasibility of establishing and operating a national radio astronomy facility. AUI intended that the Phase I proposal would produce (a) a consensus of research objectives, (b) a list of the instrumentation needed, (c) an examination of possible sites, (d) an examination of other costs that might be required, e.g., roads, power, buildings, etc., (e) a determination of the cost of a Phase II study for the detailed design and construction, and (f) consideration of operating costs. ${ }^{61}$ Dick Emberson was specified as the Principal Investigator. Berkner and Emberson referred to the January and 20 May 1954 meetings as justification for the study, but interestingly, they did not mention the December 1953 meeting in Boston.

Waterman apparently quickly recognized the opportunities for the NSF and called Berkner back the next day to explain that if funds for Phase II, which Berkner estimated to be between $\$ 1$ and $\$ 1.5$ million, would be needed starting in 1956, Waterman would need that information now, with "as much justification as feasible," and that he needed to know by the spring of 1955 what funds Berkner would need for fiscal 1957. Over the following week, after discussions within the Foundation, it was agreed that "plans for radio astronomy should be worked out as a specific NSF program," and that the NSB and Bureau of the Budget be kept informed. Waterman was keen that "this schedule can move forward rapidly," and hoped that the NSB would give him the "authority to carry on with the Bureau of the Budget." ${ }^{62}$ But first Waterman had to deal with Tuve and his NSF Advisory Panel for Radio Astronomy.

Berkner's proposal was sent to more than 12 referees, including members of Tuve's committee, as well as to the Chairs of other related NSF advisory committees. Although many of the reviewers noted that they had no experience in radio astronomy, there was a general consensus that the United States had fallen behind in this important new field of astronomy and that to compete with the new and planned international facilities such as the Jodrell Bank 250 foot antenna, there was an urgent need for a cooperative large facility for radio astronomy. But some members questioned the need for the proposed study, asking whether it was an appropriate use of NSF research funds, or say- 
ing that it was too expensive. Several respondents asked whether AUI, which had no experience in radio astronomy, was the appropriate organization to carry out the study, while others noted AUI's success in managing Brookhaven. A few reviewers recognized the likelihood that AUI's study would lead to requests for millions of dollars, much more than the NSF could likely afford. ${ }^{63}$ As Rudolph Minkowski later commented, "The most severe criticism came from those referees who are least familiar with radio astronomy." ${ }^{64}$

Before consulting with his Panel, Tuve paid a quiet visit to the NSF to express his concerns to Waterman, Seeger, and Peter van de Kamp, the new program manager for astronomy, that the AUI proposal was overly ambitious, claiming that, with the exception of Harvard, there was little interest even among the AUI universities. He also noted that AUI's first responsibility was to Brookhaven, and he did not see how the proposal for radio astronomy was related to Brookhaven. Finally, Tuve claimed that since his Panel "had informed itself rather thoroughly as to the potentials of radio astronomy and the plans that might be undertaken," that "much of the feasibility study proposed by AUI was unnecessary." 65 Waterman explained to Tuve that he "was looking entirely to the Tuve Committee [i.e. Panel] on Radio Astronomy" for guidance on "how the general program of the country in radio astronomy might be developed." Seeger added that they urgently needed some guidance about the 1956 radio astronomy program if funds were to be needed in the next fiscal year. Somewhat contradictorily, Tuve responded that his committee could not "make such a recommendation without having had a meeting on the subject," but that "they would probably not recommend as a major program as indicated." 66

In summarizing the reports of the reviewers to his Panel, Tuve argued that no one at AUI was active in radio astronomy, that the "proposal is being made by administrators not researchers," and that "there is no visible basis for continuity of any activity on radio astronomy in the AUI." Tuve also called attention to the construction problems with the Manchester 250 foot project, saying it would be prudent to await the outcome of that effort "before another project of the same kind is initiated." ${ }^{67}$ Once again, having been alerted by Tuve, Taffy Bowen stepped forward with an offer to volunteer his services to lead a jointly financed feasibility study for a large steerable radio telescope, and Tuve suggested that Bowen, rather than AUI could be "in full charge of the design project." ${ }^{68}$ Tuve, who opposed big government support of science, and was reacting to his long standing suspicion of Berkner's motives, argued that since the reviews were negative they should give AUI only $\$ 15,000$. But Greenstein came to AUI's rescue, pointing out that the average rating of the proposal was between good and excellent and that Tuve's report reflected only his own views. ${ }^{69}$

Following his meetings with Waterman, Berkner spent the next $2 \frac{1}{2}$ months in Europe, primarily to attend scientific meetings in Belgium, the Netherlands, and in the UK. Although he was able to take advantage of the opportunity to talk with Ryle, Lovell, and Oort and to learn about their progress and plans, his lengthy absence delayed meeting with the NSF to respond to questions from 
the reviewers and the NSF Advisory Panel. However, during Berkner's absence, Emberson did meet with the NSF and provided an estimate of the funds that would be needed for construction, for land acquisition and the rate at which funds would need to be made available. This information was subsequently forwarded by the NSF to the Bureau of the Budget to aid in their planning for the FY56 and FY57 budget cycles. But Emberson noted that Tuve's Panel was a "real block to early action on the AUI proposal." 70 Emberson also shared these details with the members of the ad hoc AUI committee, who interestingly pointed out the additional costs that would be needed to acquire a suitably large parcel of land to minimize any local sources of interference as well as the cost of providing advanced electronic instrumentation.

Aside from Berkner's absence from the US, although the NSF had established a Radio Astronomy Panel, no funds had been allocated for the Panel to meet until Tuve proposed that the Carnegie Foundation should administer a grant to provide for it to hold three meetings over the next year. ${ }^{71}$ It was not until mid-November 1954 that the NSF Panel was able to meet to discuss the AUI proposal. In preparation for their 18 November 1954 meeting, a subset of the group, together with Berkner and Emberson, met on the evening of 4 November at the Cosmos Club in Washington to discuss revisions to the AUI proposal. As described by Bok, "it was a long and difficult evening." ${ }^{72}$ In response to the issues raised by the reviewers and the Advisory Committee, Berkner addressed the criticism that AUI had no active radio astronomers by pointing out that the AUI proposal was based on a "a number of meetings, conferences, and discussions in which every U.S. leader in radio astronomy has participated to some extent," and that as a collaborative effort he anticipated extensive participation from the university community as well as from Ryle, Lovell, Bowen, and Oort, all of whom, he said, had offered to supply their construction plans. ${ }^{73}$

Prior to the 18-19 November meeting of the NSF Advisory Panel, Tuve informed its members that he felt that the AUI proposal should be for "a" facility and "not necessary for 'the' national facility of the USA" and went on to emphasize the importance of the existing facilities and that the subject is "astronomy and astrophysics," and not "automatic gadget engineering." " Tuve's Panel was hardly unbiased or disinterested. Greenstein, who was involved in planning Caltech's own major radio astronomy project, responded in favor of the cooperative facility but expressed reservations about starting with a large antenna. ${ }^{75}$ Six members of the Panel were also members of the AUI ad hoc committee that had met at AUI to help to develop the AUI proposal, while Bok and Kraus themselves had large grant proposals before the Foundation. At their 18-19 November meeting, which was held at the Carnegie Institution, the Advisory Committee (a) reviewed the previous relevant meetings including the evening "rump meeting" on 4 November, (b) reviewed the AUI proposal as modified on 8 November in response to the 4 November meeting, (c) considered proposals from Harvard for their 60 foot radio telescope along with informal proposals from Kraus at Ohio State, and 
possible needs for other radio astronomy projects at Cornell, NRL, DTM, Caltech, the National Bureau of Standards, Michigan, Princeton, Stanford, Penn State and the University of Alaska. ${ }^{76}$ Rather surprisingly, just before the meeting, Greenstein stated that he was resigning from the NSF Panel citing both internal and external responsibilities, but Tuve asked him to reconsider. ${ }^{77}$

The Panel struggled with the realization that the AUI proposal could not be treated in the same way as a typical research grant, so there was considerable debate about to what extent the proposed AUI study should be "supervised" by the Panel, by the NSF itself, or whether AUI should be free to act independently. ${ }^{78}$ While Tuve wanted AUI to concentrate on antenna design, Berkner responded that "If all the panel wants is a cost estimate, .... I could get Hughes Aircraft to submit one." But Tuve argued that "We can't turn this whole job over to AUI," to which Berkner replied, "You must have confidence in what we are trying to do," and appealed to the success of Brookhaven, and that "nothing should be done by the Panel to question AUI's judgment." It was becoming clear at this meeting that radio astronomy might be in a very privileged position for rapid growth. Although the NSF 1954 total budget for astronomy was less than $\$ 200,000$, Peter van de Kamp pointed out that "radio astronomy was considered at present to be in a special class of subjects, and that it might not be impossible for the Foundation to give a hearing to recommendations which total more than $\$ 200,000$ during the present fiscal year." 79

Apparently encouraged by van de Kamp's remarks and not wanting to miss an opportunity, the NSF Panel agreed that the AUI study should concentrate on a steerable antenna and not a Mills Cross type of radio telescope, and that the cost of the antenna might be in the vicinity of $\$ 3$ million, but that they should also consider antennas that might be built for $\$ 1$ and $\$ 6$ million, as well as consider the "the largest steerable antenna that might be built without special regard to cost, its limits being based on the strength of materials and similar considerations." $"$ They also specified that the antenna should work to at least $21 \mathrm{~cm}$ over the whole surface and down to 3 or $10 \mathrm{~cm}$ over a limited area and be able to see the entire northern sky "at least as far south as 10 degrees below the Galactic Center." Moreover, the committee suggested that the "search area for the site be confined to an area within 300 miles of Washington, D.C." The reason given for the geographical restriction was to minimize travel time by scientists and students from northeast universities, although by this time jet travel was already making single day transcontinental travel feasible. But the panel members were also likely seeking balance between the national radio facility and big west coast optical astronomy facilities as well as the planned new radio astronomy program beginning at Caltech which they felt would give west coast radio astronomers adequate access. Also, with a possible location near Washington, the NSF could watch with a closer eye and exert some control over the radio facility.

The Panel then quibbled over the size of the grant. Following Tuve's suggestion that the AUI member organizations should demonstrate their interest by contributing to the study, they recommended that AUI be given only 
$\$ 85,000$ and not the requested $\$ 105,000$, but only as an initial grant which could be supplemented by another $\$ 15,000$ "if AUI found it difficult to obtain this portion from their participating members." However, this recommendation was subject to AUI more specifically defining the scope of their study to evaluating only the feasibility of a national radio facility and the criteria by which the site should be chosen. The Panel then went on to recommend that the NSF award grants to Bok for a total of $\$ 128,000$ for the operation of the Harvard 24 foot radio telescope and toward the construction of a 60 foot radio telescope, to Kraus at Ohio State for \$23,000 for further studies of standing parabolic antennas, and to Tuve to administer a grant to host visiting radio astronomers to the United States and to send US students to other countries. Following a request from van de Kamp, the committee assigned the following ranking to the proposals "in order of their estimated importance: 1) Harvard, 2) Ohio State, 3) AUI, 4) grants for visitors.”

That same day, Berkner sent to the NSF a three page letter essentially identical to the draft that that he shared with the Tuve's group at the Cosmos Club meeting, repeating the justification for the feasibility study, the endorsement of the radio astronomy community, and saying that, if successful, he expected this Phase I study to "generate the basic plans for the construction, management, and operation of the required facility," to be followed by a more detailed Phase 2 for the actual antenna design and choice of a contractor. ${ }^{81}$ While he was careful to reassure Tuve and the NSF that funding of this Phase 1 proposal was not a foot-in-the door toward AUI operation of the radio astronomy facility, Berkner went on to add, "I would be less than frank in saying that in undertaking Phase 1 under the present proposal, AUI would expect to make a further proposal under Phase 2 if Phase 1 proves that such a further proposal is feasible." Of course, as had already been discussed earlier in the day at the Advisory Panel meeting, the fact that Lovell was currently building a 250 foot radio telescope, that a slightly smaller one was being planned by Bowen in Australia, and that Caltech was developing plans, already demonstrated clearly that it would be feasible to construct a national radio facility in the United States with a "large" antenna as the centerpiece. And Lloyd Berkner was determined that AUI would have a major role in building and operating the national facility.

Without waiting to receive formal notification of the NSF grant, Berkner lost no time in planning for a national radio astronomy facility and organized a small meeting at AUI on 10 December 1954 with Charles Husband, who had designed the Jodrell Bank 250 foot antenna and was supervising its construction, and Michael Karelitz from Brookhaven as a consultant to AUI. The assumption was that the basic instrument would be a "big dish" as the most versatile way "to solve certain problems," but that "the need for interferometers ... must not be ignored." ${ }^{82}$ Berkner pointed out that the AUI task would be to determine "what should be built and at what cost." Husband optimistically advised "not to be scared by engineering problems in the structural steel phase," and that the "big engineering difficulties are in the control gears and the instrumentation." Based on his design and experience with the Jodrell Bank 
alt-az antenna, Husband outlined design concepts and cost estimates for steerable antennas up to 500 feet in diameter. Karelitz argued that "Serious consideration, has to be given to advantages of an equatorial mount," but at the time, an equatorial option seems not to have been seriously discussed. At this stage both the NSF and AUI were thinking of only a "collaborative" observatory, where the construction funds would somehow be provided by the government (NSF or ONR), but ongoing operations would be the responsibility of the universities interested in radio astronomy who would provide people and resources.

\subsection{Creating the National Observatory}

Sensitive to the accusations that AUI had no expertise in radio astronomy or, for that matter in antenna design, Berkner sought advice from Bell Laboratories, and in particular from Janksy's old boss at Bell Labs, Harald Friis, who advised that " 425 to 450 feet is about the limit for a reflector or dish of conventional design which would probably cost close to ten million dollars." ${ }^{83}$

In January 1955, Berkner learned from Waterman that the NSF would grant $\$ 85,000$ to AUI for their proposed feasibility study ${ }^{84}$ Assuming that this planning and feasibility study did not require National Science Board approval, the NSF had not consulted the NSB, apparently ruffling some feathers of those NSB members from southern universities who looked at AUI as an elite private institution (England 1982, p. 282). Upon learning of the grant award, Berkner relieved Emberson of his other tasks as Assistant to the President so that he could assume full time responsibility as the Project Director for radio astronomy. In February 1955, following approval of the NSF funding, the AUI ad hoc committee was formally reconstituted as the AUI Steering Committee for Radio Astronomy. With the support of the Steering Committee, following a meeting with the NSF staff on 9 April 1955, AUI put the project on a fast track with the intention of presenting to the Foundation, "a proposal looking to the immediate establishment of a radio astronomy facility to be operated by AUI," and with a goal of presenting it to the 20 May 1955 meeting of the National Science Board ${ }^{85}$ But the NSB presented hurdles that would first need to be overcome: "whether the Foundation, as a matter of policy, should embark on a program involving continuing support of a large scale project, and if this question is answered in the affirmative, the Board will need to ... chose from a selection of several proposals which will then be before it for consideration." $" 86$

From the beginning, AUI's goal was to construct a facility that "should provide research opportunities not available elsewhere." ${ }^{87}$ This may be contrasted with AURA, which was organized to create a national optical observatory to provide observing opportunities for astronomers who did not otherwise have access to their own facilities. AUI also recognized that some research groups might be interested in bringing their own instruments to the new observatory at their own expense, providing that the site was sufficiently radio 
quiet. However, the emphasis was on building a large antenna whose cost was beyond the means of an individual university and would be at least competitive with the large dishes being built in Manchester and Sydney. One of the first questions asked was "Are there any real technical limitations to the maximum size of steerable radio telescopes?" Following consultation with structural experts, AUI optimistically, even if not realistically, concluded that diameters up to several thousand feet would be feasible.

Knowing that Lovell was already building a 250 foot telescope at Jodrell Bank set an unspoken lower limit on Berkner's ambition. When the AUI Steering Committee met on 26 March 1955, they agreed that size needed to be balanced against cost. But, perhaps seduced by the prospects of generous federal funding, the Steering Committee initially focused on a 500 or 600 foot diameter radio telescope which they felt was justified, especially by the opportunities for both galactic and extragalactic $21 \mathrm{~cm}$ hydrogen line research. The Committee also noted the need for high resolution and sensitivity for continuum studies at $21 \mathrm{~cm}$ and shorter wavelengths that would be afforded by a very large steerable paraboloid.

Jacob Feld, an independent contractor, outlined the factors to be considered in the design of large radio telescopes and proposed to undertake a design study for a 600 foot antenna with full sky coverage, a surface tolerance of 1 inch, ${ }^{88}$ and a pointing accuracy of $7 \operatorname{arcsec}(5 \%$ of the $10 \mathrm{~cm}$ half power beam width). Some concession was made by limiting the sky coverage to 8 hours about the polar axis if an equatorial mount was adopted, although the declination range was rather unrealistically and unnecessarily specified to reach from 5 degrees below the North Pole to 5 degrees below the horizon.

But the Steering Committee also recognized that that it would be challenging to construct a 600 foot antenna and that to establish its viability, the new national radio astronomy facility needed to have observing facilities sooner than a 600 foot instrument could be erected. It is not clear to what extent the discussions about a 600 foot diameter radio telescope were based on knowledge of the NRL 600 foot antenna planned for Sugar Grove (Sect. 9.3). At least some members of the AUI Steering Committee, in particular John Hagen from NRL, were surely aware of this then-classified project, as apparently were Emberson and senior NSF staff (McClain 1960, 2007; Needell 2000, p. 284).

Since modest size antennas in the range of 50 to 85 feet in diameter were being built at Harvard, DTM, and NRL as well as for the military, both Merle Tuve $^{89}$ and AUI confidently assumed that their "design might be extrapolated to 100 to 150 feet and be essentially off-the-shelf." 90 They agreed to take immediate steps to procure a radio telescope with an aperture of about 150 feet and to simultaneously conduct feasibility studies for apertures in the range of 300 to 500 feet and greater. ${ }^{91}$ The Steering Committee reviewed a detailed design submitted by Grote Reber for a 220 foot dish, as well as Reber's thoughts about 500 feet and larger dishes. 
For both the 600 foot and 150 foot designs, the Steering Committee considered the pros and cons of placing the antenna in a radome to protect a much simpler and less expensive antenna structure from the weather. Two novel radome designs were discussed, one an air supported fiber-glass or nylon fabric, another based on a geodesic dome proposed by Buckminster Fuller. But they soon concluded that the cost of a radome would more than offset the decreased cost of the antenna structure. Moreover, they recognized that it would be difficult to build a radome that would not attenuate incoming signals over the broad frequency range of interest to radio astronomy. ${ }^{92}$

Both Berkner and Emberson were nervous about confining design considerations to extrapolations of antennas that had already been built and agreed that they needed to receive independent outside advice. Nevertheless, Emberson proposed an ambitious schedule which called for requesting an additional grant of $\$ 300,000$ to continue the feasibility study in 1956 , with a goal of starting a five-year construction and operating plan on l July 1957 "involving an expenditure of about twenty million dollars," although it was recognized by the AUI Board of Trustees that " 20 million dollars is considerably in excess of the entire annual budget of the National Science Foundation," and that "the Corporation has never formally decided that it should undertake the management of an enterprise of this character." The Board also noted that the AUI charter would prevent its operating outside the state of New York, so they voted to amend the charter to allow AUI to operate in a state other than New York. At the same time they authorized Berkner to "enter into contractual arrangement for the construction and operation of a facility for research in radio astronomy," for which they anticipated AUI would receive a management fee "of between $\$ 35,000$ and $\$ 50,000$ a year." $" 3$

To support their ambitious plans, the Steering Committee asked Bart Bok to convene a sub-committee to "promptly" prepare "a report on a scientific justification for a variety of large steerable parabolic reflectors, with aperture of 150 feet, 300 feet, and 500 feet." "94 Bok's Panel noted that high gain might be more important than narrow beam width, but stressed the need to maintain sufficient precision to operate at least to $21 \mathrm{~cm}$ if not shorter wavelength. Not surprisingly, they emphasized the impact that $21 \mathrm{~cm}$ observations with a large radio telescope could make to the understanding of galactic structure, and commented on "the potentialities for research into the structure and dynamics of neighbor galaxies and the fainter galaxies," as well as speculating on the possibility of other spectral lines such as deuterium at $327 \mathrm{MHz}$ and $\mathrm{OH}$ at $1668 \mathrm{MHz}$. They also pointed out the importance of measuring precise positions, flux density, and spectra of the discrete radio sources, but there was no consensus about the relative merits of interferometers and Mills Cross instruments for this type of work. Although they considered that "the primary justification for a paraboloid antenna with an aperture of 150 feet or more rests on the research potential of the instrument for galactic and extra-galactic studies," they also called attention to the "great possibilities for solar work," and especially the importance of a large paraboloid for planetary radar. The panel report 
concluded that "there are few problems to be expected in the construction of [a 150 foot paraboloid]" and that "the acquisition of new and superior equipment, designed to round out or fill in the picture obtained with present equipment, has led to new discoveries."

Emberson and Berkner met again on 8 April 1955 with Waterman and other NSF staff to discuss their planned proposal, but Berkner rejected the NSF suggestion that Tuve participate in the meeting. ${ }^{95}$ Emberson explained that their proposed mode of operation would closely parallel the academic, corporate, and government partnership that had been so successful at Brookhaven, and that "all qualified scientists without regard to institutional affiliation would have access to the facility," thus "insuring maximum scientific progress." To review the effectiveness of both staff and visitor research, Emberson and Berkner proposed to institute a Visiting Committee patterned after the successful Brookhaven Visiting Committees. ${ }^{96}$ Following their 8 April meeting, based on a preliminary draft of the Planning Document, Emberson submitted a seven page detailed statement of AUI's thoughts on "The Establishment and Operation of a National Radio Astronomy Facility." $" 97$

Tuve's skepticism became apparent to Bok at Tuve's 24 April 1955 presentation at the NSF, which was also attended by Bok and Hagen. Bok became concerned about how Merle Tuve and his NSF Advisory Panel would treat the AUI proposal. Without strong support from Tuve's Panel, it was not going to get very far with the NSB at their 19-20 May 1955 meeting. Bok wrote to Tuve urging that the NSF Panel report should, (a) urge continuing support for the existing university facilities (Ohio State, Harvard, and Cornell) as well as extending support to others such as Michigan, Illinois, Caltech, and Berkeley in order to "insure a steady research productivity," and a "steady flow of PhD's;" (b) support "the prompt establishment in the Eastern United States of a National Radio Observatory," to be operated by AUI, (c) that "a 120 to 150 foot paraboloid reflector be promptly built for the Observatory, $\ldots$ and at a later date .... a very large at least partially steerable paraboloid." More specifically, Bok urged that AUI be given a grant in 1956 to design and construct "a 120 to 150 foot instrument" ... operating to $10 \mathrm{~cm}$, "to purchase the land for a National Radio Observatory," and to "continue the inquiry into the construction of a large dish." 98 But aside from completing the design of the 120-150 foot antenna, Tuve wrote a bold "No!!!” beside most of Bok's ambitious proposals..$^{99}$

In anticipation of the 19-20 May NSB meeting, Tuve summarized his understanding that the NSF Panel ${ }^{100}$

a) was enthusiastic about the prospects for radio astronomy including the need for "special budget support,"

b) agreed that "very high priority, probably ahead of anything else, must be given to the support of existing activities in radio astronomy at universities and research institutions, along with the encouragement of one or two new additional groups," 
c) agreed to endorse "the construction of a reflector of intermediate dimensions, in the range 120 to 150 feet in diameter (probably 140 feet [ 43 meters])," and said that

d) "the proposal for a very large dish (250 to $600 \mathrm{ft}$. in diameter) is a project of uncertain value."

As an afterthought, Tuve added, "We regard radio astronomy as part of astronomy, and do not believe that it should compete with the proposed National [optical] Observatory. ... Radio astronomy is a study of the heavens, not just glorified electronics." Tuve acknowledged that there was no firm agreement on whether AUI was the appropriate organization to develop and operate the intermediate size dish, and suggested that operation by two state universities "might be a better arrangement." He went on to suggest that funds be made available to purchase at least options on a suitable site "preferably within reasonable distance of Charlottesville, Virginia," and that planning for the very large dish should not impact the construction of the intermediate size antenna. But he added, "I refuse to be pressured into any detailed approval or disapproval of AUI proposals on such a schedule," to which Greenstein noted on his copy of Tuve's letter, "I absolutely agree."

Tuve's letter triggered responses from Hagen, Greenstein, and Minkowski. Hagen took strong issue with Tuve's opposition to a large antenna. ${ }^{101}$ Elaborating on Bok's scientific justification, Hagen listed 11 research areas, ranging from the Sun and other solar system objects to galactic and extragalactic problems, that required a large dish. As he acknowledged, Hagen had initially opposed the intermediate size dish on the grounds that it "might prejudice our chances of arriving at our real goal, which is to obtain an antenna of at least $300 \mathrm{ft}$. aperture." But he did not oppose the majority decision to start with the 150 foot antenna, provided that it had sufficient precision. Minkowski's response $^{102}$ primarily addressed the Kraus antenna which he felt unjustified, since he argued there were enough surveys, and that the need was to identify optical counterparts and have frequency flexibility to enable measurements of radio spectra. Minkowski also contended that the AUI budget proposal was unrealistic and included too large a staff, particularly for administrative personnel. In a separate letter, Greenstein and Minkowski pointed out the "prime purpose" for the AUI initiative was to consider the feasibility and cost of large antennas, and urged that "AUI concentrate cost studies on the 300 and 600 foot dishes," but they recognized that "experience with the Manchester 250 foot and the proposed U.S. National 140 foot" might be needed before the costs were known. Acknowledging the equal demands of optical and radio astronomy, they claimed that the AUI plan to spend " $\$ 25$ million for several large reflectors," was "inspiring in scope but is not realistically justified by the capabilities in the United States." 103 Moreover, they argued, because of the small number of radio astronomers in the United States, there was no justification for a Brookhaven-type facility. Rather, they claimed, the "intermediate size dish" could be "administered by one or two state universities, for example 
Virginia and Michigan, with the site probably near Virginia." Like Tuve, they felt "it dangerous to leave the direction of the activities of a new cooperative institution to a group familiar with the problems of large physics laboratories." Of particular concern was the staffing needs of a large national facility, which they speculated would "destroy all going institutions in the field," and that it was "improbable that student training could be carried on away from the universities with the very large equipments proposed." Many of their concerns would be echoed over the following decades as NRAO indeed grew to dominate US radio astronomy.

Tuve's Panel finally suggested a total of $\$ 3.93$ million for what they referred to as the "Eastern Radio Astronomy Facility." 104 Of this nearly four million dollars, they suggested that $\$ 1.7$ million would be needed for the 140 foot "intermediate" sized reflector and its auxiliary equipment and $\$ 300,000$ for continued engineering studies of a "super" reflector. Another \$1.25 million was suggested for the construction, operation, and maintenance of the university facilities. Peter van de Kamp, then head of NSF Astronomy, was charged with preparing a written report for the NSB. Van de Kamp's report ${ }^{105}$ closely followed Tuve's recommendations, but gave a somewhat more positive twist to the idea of a very large dish by saying that "the feasibility of a large dish (250 to $600 \mathrm{ft}$. in diameter) deserves careful study," rather than Tuve's "is a project of uncertain value." Based on Tuve's recommendations, van de Kamp went on to suggest a budget of $\$ 3.5$ million over four years starting in FY 1957 for the construction and operation of an intermediate sized radio telescope, $\$ 200,000$ for a $70 \times 700$ foot standing parabolic reflector at Ohio State, $\$ 700,000$ for construction, maintenance and operation of a number of smaller facilities, and $\$ 300,000$ for engineering studies for a large dish type radio telescope. However, van de Kamp added that the ultimate cost of the proposed AUI Radio Astronomy Observatory, including the construction and operation for 5 years of a large steerable dish, was estimated to be \$24 million, and that Kraus envisioned building a 4,000 $\times 400$ foot standing paraboloid at an estimated cost of $\$ 8$ million.

Following the recommendations of the AUI Steering Committee, on 6 May 1955, on behalf of AUI, Emberson submitted to the NSF a detailed five-year plan centered about "at least one very large and very precise radio reflector," but which also included, "a precision surface 20-50 foot" dish, a " $100-150$ foot reflector," a "250-foot reflector that would be a scale model of the fourth reflector, which would be perhaps 600 feet." ${ }^{106}$ Emberson included Bok's summary of the "research objectives," arguments supporting the "need for a radio astronomy program in the United States," and a detailed discussion of the proposed "organization of a national facility for radio astronomy research." $\mathrm{He}$ reiterated the importance of radio astronomy to understanding the Universe, as well as to electronic communication and military security, and that the United States was being challenged by new radio astronomy facilities under construction in Australia, England, and the Netherlands. He did not miss the opportunity to point out that "the British 250 -foot antenna, built by a nation 
with a fraction of our resources is scheduled for operation in 1955." With great prescience, Emberson noted that because "among the radio sources already discovered there appear some that appear not to follow the classical laws of radiation by hot bodies, and further that radio frequencies have been identified through molecular beam experiments in the physics laboratory, one can sense that these two branches of science may join in solving some of the riddles of nature." Perhaps more important, and prophetic, he went on to state, "It would be a serious error to suppose that all possible discoveries have been made in this new and expanding field of science."

Although Emberson presented eloquent arguments for establishing a large radio facility patterned after the successful Brookhaven operation, he also recognized the need to maintain the smaller university facilities to train students, to conduct research appropriate to the smaller facilities, and to provide "a breeding ground" for "great researchers" to use the "great facilities." The AUI plan projected an "ultimate" staff of 106 individuals with an annual operating budget of about $\$ 700,000$. Emberson suggested that they would need another $\$ 300,000$ in 1956 for Phase 2 of the feasibility study, followed by $\$ 6,899,000$ in 1957 which included site acquisition, buildings, roads, etc. as well as $\$ 800,000$ for construction of a 150 foot reflector. Perhaps to mitigate "sticker shock," he offered, "It is our hope that non-government sources of support may be found, both for part of the initial construction of the facility and for its operation, [and] that the NSF be asked to underwrite the operations for a five-year period, with the implicit understanding that if and as other sources of support materialize during that period the Foundation's obligation would be proportionatly [sic] reduced." The AUI plan called for a scientific staff "a nucleus of permanent employees whose efforts would be supplemented by qualified visiting scientists." Finally, as a major policy directive, the plan proposed that, "All qualified scientists without regard to institutional affiliation would have access to the facility, thus permitting its efficient use and insuring maximum scientific progress." This "Open Skies" policy, as it became known, would characterize NRAO for the next half century, and to an extent would be adopted by other radio and later optical observatories, although often only after "encouragement" by the NSF in return for funding. To counter criticism about the lack of radio astronomy experience, the proposed AUI plan called for a periodic review by a Visiting Committee appointed by the AUI Board.

The 19 May 1955 meeting of the NSB Committee for MPE Sciences began with a closed session where the NSF MPE Acting Assistant Director Raymond Seeger summarized the recommendations for the proposed large scale radio and optical facilities. He was followed in an open session by separate presentations from R.R. McMath, Chairman of the NSF Advisory Panel for the National Optical Astronomy Observatory, and by Tuve, supported by Bok, Greenstein, Hagen, and Minkowski, for the radio astronomy Panel. Tuve's Panel recommended that the AUI concentrate on the 140 foot telescope and only do feasibility studies for the larger instrument. One issue faced by the NSB was not only the large dollar amounts involved in these proposed national facilities, but 
that, unlike research grants which may typically provide support for limited periods, the national facilities appeared to require a continuing commitment by the NSF for a large operating budget. This tension between national facilities and research grants would continue in the astronomical community over the next half century. The university scientists wanted access to the unique facilities provided by the national observatories, but not if it came at the expense of their research grants. However, the research grants were of limited value if there were no telescopes to use.

The AUI Steering Committee met on Saturday, 28 May 1955 to review the specifications for the intermediate size telescope, whose size seemed to oscillate from 140 feet to 150 feet depending on the committee, the audience, and the day. The AUI Committee also discussed a plan for the operation of the facility, the choice of a site, and how to reconcile the planned budgets with those recommended by the NSF Committee. Bok noted that the NSF Advisory Panel was concerned that AUI was putting too much emphasis on the very large radio telescope, apparently at the expense of the 140 foot dish, but he was reassured by Berkner and Hagen that they were serious about an early construction of the 140 foot radio telescope.

In reviewing the draft specifications for what was now considered the "small" 140 foot telescope, Bok reported that the NSF Panel did not consider the specifications for construction to be sufficiently precise. But the AUI Committee was concerned that if "detailed materials and construction specifications were prepared, a manufacturer would strive to give only what might conform to the specifications without regard as to whether the completed instrument would perform as desired." Wisely, the AUI Committee agreed that they would continue with the use of performance specifications, ${ }^{107}$ but questions of this nature would continue to plague NRAO when faced with contracting for future radio telescopes. Charles Husband, who designed and was building the Jodrell Bank 250 foot radio telescope, had been contracted to advise AUI, and wrote, ${ }^{108}$ "We have tended to carry out improvements to the design as actual construction work proceeded. For many reasons this is not a good thing to do." Perhaps, less obviously, he also commented, "I think you would save a great deal of money by preparing a design in considerable detail before inviting bids," and went on, "The client being responsible for producing the design is practically always the more economical in the long run." This latter philosophy was fundamental to all of NRAO's future antenna Requests for Proposals, except in the case of the Green Bank Telescope. The extenuating circumstances surrounding the GBT funding and the perceived need to begin construction before the design was finalized led to a huge cost increase (Chap. 9). The AUI Committee also struggled with the question of equatorial vs. alt-azimuth design. Based on his experience with the NRL 50 foot dish, Hagen expressed concerns that ${ }^{109}$ "the alt-azimuth mounts require more complex computers and servo-mechanisms and that maintenance would therefore be more costly and time consuming." But Goldberg and Haddock argued that ${ }^{110}$ "low altitudes would be highly desirable for some solar work, lunar occultations, and 
eclipses," that would be more difficult with an equatorial mount, and Bill Gordon"11 "stressed that atmospheric and ionospheric problems required access to very low altitudes, particularly to the north." Unable to decide between the two options, the Committee agreed to seek two bids, one for each type of mount.

Although the budget recommended by the NSF Advisory Panel did not differ significantly from the AUI plan, Emberson defended the slightly larger AUI figures by pointing out that AUI had included essentially 112 "everything that might be considered for the Facility." Nevertheless, there was concern that the AUI was planning for a much larger staff and more extensive operation than recommended by the NSF Panel. Following discussions among Seeger, van de Kamp, and Tuve, and in recognition of an expected increase in the FY1957 NSF budget, Seeger agreed to an increase in the budget for salaries and maintenance, but Tuve expressed concern that the proposed budgets for radio astronomy would 113 "equal or exceed the figure currently planned for astronomy," and that the proposed budget for radio astronomy "should not be allowed to reduce the sum being apportioned to optical astronomy, but should be added to it, thus serving to greatly increase the grand total for astronomy. Our panel still considers radio astronomy as a branch of astronomy and not a substitute or competitor.”

By the time of the 17 June 1955 meeting of the AUI Executive Committee, AUI had not received any formal notification of the results of the 19-20 May meeting of the NSB, but, through the joint membership of the AUI and NSF committees, Emberson reported that he had learned that the NSB"14 "had a lively interest in radio astronomy and that the Foundation's radio astronomy panel had proposed that $\$ 3,300,000$ be allocated for a national radio astronomy facility." Emberson also informed the Executive Committee that he had initiated a contract with Jacob Feld for design studies of a 600 foot reflector and had engaged two consultants from the University of Pennsylvania to evaluate Reber's design.

To continue the feasibility studies started under the first NSF grant, AUI applied for another grant for $\$ 234,500$, which included funds for two independent designs for the 140 foot telescope along with a preliminary design for the 600 foot telescope, and for site evaluations including options to purchase land. In discussions with Waterman and other NSF staff, Emberson stressed that since the feasibility study for the 600 foot antenna had been successfully completed under Phase 1, omission from the Phase 2 grant would "constitute a time delay somewhat greater than six months." 115 The NSF was already beginning to appreciate that the cost of the new radio astronomy facility would be significantly more than Tuve's panel had indicated. ${ }^{116}$ At the same time, the NSF was considering comparable levels of funding for the proposed American Astronomical Observatory to be located somewhere in the Southwest to provide clear skies and suitable facilities for photoelectric observing, and this would surely add to the NSF budget burden. ${ }^{117}$ Nevertheless, at its August 1955 meeting, the NSB approved the AUI budget proposal for $\$ 3.5$ million to be 
spent over a four year period starting 1 July 1956 and asked the Bureau of the Budget that this be included in the NSF's FY1957 budget.

Bart Bok, with his usual enthusiasm, wrote in support of full funding for the AUI Phase 2 proposal, citing the successful progress of the Phase 1 study and the urgency of moving ahead so that the United States did not lose momentum at what he called "this critical stage." 118 Jesse Greenstein indicated that since funds were limited he could not "go along with the wholehearted endorsement of a $\$ 234,000$ grant," 119 and that it was premature to invest too much money in the design of the 140 Foot Telescope until it was clear that construction funds would be approved by Congress. John Kraus's strongest statement in support of the AUI proposal was that "continued support for studies and planning on a multi-million dollar national facility is unavoidable," but he spent most of his two-page report arguing for the smaller university facilities, especially his standing parabolic reflector at Ohio State. ${ }^{120}$ Minkowski pointed out that there was serious concern that " 300 feet is the maximum possible size of a sufficiently rigid dish," and that no "further funds be diverted from the core of the study." ${ }^{121}$ Merle Tuve, reporting on a series of telephone conversations with his Panel, expressed concern about the impact of the AUI grant on astronomy research grants and suggested that funds be specifically earmarked for Kraus's antenna at Ohio State. He reported that the Panel recommended that the NSF grant to AUI be cut to only $\$ 140,500$ since some of proposed activities could be deferred, but that AUI should add "one or two high level members to their professional staff, preferably appointing the director who is to take charge of the evolution of this project." The challenge to find a director turned out to be more difficult than anticipated, and would end up taking another five years. However, Tuve's panel went on record "to use AUI as the vehicle for bringing the Eastern National Radio Astronomy Facility into being, but that the actual title to the property and decisions as to the future ownership and control be held in abeyance, probably for several years." Unwilling to give AUI a free hand, Tuve added, "It is understood, however, that this ownership and control would be in the hands of universities, whether through the AUI mechanism or directly with one or two selected institutions." ${ }^{122,123}$

At a meeting with Waterman on 6 December 1955, Berkner outlined the proposed scientific and administrative structure of the facility, the nature of the expected contract between the NSF and AUI, and said he hoped to have a director appointed by 1 July 1956. ${ }^{124}$ They also began a discussion on how the land for new facility would be acquired, whether it should be public or private land, and who would hold title to the property. Although no decision had been reached, or even formally discussed about who would manage the radio astronomy facility, both Berkner and Waterman tacitly assumed that it would be AUI.

Meanwhile, Waterman was juggling inquires and pressures from both Berkner and Tuve, each promoting their own agendas. Even the name of the new facility was contentious. Tuve had started to use the name "Eastern Radio Astronomy Facility" to make it clear that it wasn't a government operated "national" facility, but Waterman didn't want it to appear as a facility only for 
the East Coast. "Green Bank Observatory" was suggested, but Tuve argued that would be inappropriate if the facilities were dispersed. They both agreed that it was "difficult to pick a proper name until the site was selected, property purchased etc." Waterman agreed not to call it a "National Observatory," and suggested to just call it the "Radio Astronomy Facility." 125 In his phone conversation with Waterman, Tuve also complained about "Berkner's attitude toward the whole thing," arguing that "Berkner is trying to run everything his way and that Hagen and Bok are going along for political reasons." Waterman cautioned Seeger, "that we should watch AUI carefully as they have a technique for pushing things through and it is hard to do anything about it. Berkner lines up a few members of Tuve's committee beforehand and then calls committee meeting and everyone usually agrees with him, but major points should be considered by the Foundation before giving him a 'yes." He advised Seeger, "In any conversation with Berkner in which he wants a quick OK, to tell him that he must check with me first." Waterman explained that he saw a need "to encourage something else than AUI," as "this will keep AUI in bounds." Tuve and Seeger also did not miss an opportunity to exchange a few criticisms, with Tuve expressing concern about "Seeger's willingness to agree to all of Berkner's suggestions," and Seeger's criticism of the way Tuve was running his Panel. ${ }^{126}$

The AUI Steering Committee met again on 11-13 December 1955, together with NSF and AUI staff as well as invited consultants from the US Geological Survey and elsewhere. Much of the meeting was devoted to reviewing the site studies and a planned 12 December trip to a candidate site at Massanutten, Virginia (see following section "Choosing the Site"). ${ }^{127}$ But the Committee also discussed the design of the 140 foot telescope and the difficult problem of guidance and control. Tuve argued for an equatorial mount since he contended "that precision positioning could be more easily achieved ... on an equatorial mount than on an alt-az mount." Unfortunately, neither Tuve nor the rest of the participants appreciated that while the drive system might be simpler and more accurate, structural distortions on an equatorially mounted telescope could lead to much larger positioning errors than those introduced by the control system on an alt-az mount. The Committee did recognize, however, that an equatorial mount would lead to "something less than full hemispheric coverage," a reasonable constraint that somehow was to be forgotten when it came to defining the final design.

Emberson described the progress on the three ongoing commercial 140 foot design projects, all of which were for an alt-az mount. Numerous arguments were presented against an equatorial design, including the limited sky coverage, the need for counterweights, and most importantly that "problems of stiffness and rigidity would be more difficult." It was also "pointed out that since there was little prospect for a 600 foot equatorial mounted dish, ... an equatorial 140 foot would teach little of the problems that would be met with larger instruments." Although it would "delay the 140 foot project by at least two months, ... the Committee unanimously recommended the above equatorial program be initiated," although this would mean diverting funds from the large telescope design. Unable to agree on the size of the planned "smaller" 
telescope to be mounted on the Laboratory building, the "the Committee concluded that two small instruments were desirable, one in the 25 foot range, and the other 60 foot." The announced schedule optimistically called for completion of the 140 foot design and call for bids in March 1956 followed by the award of a construction contract in May or June. Emberson reported that he expected construction to start in September 1956 after review of the detailed design, and had set a target date of December 1957 for the completion of the 140 foot radio telescope. Sadly, it would be almost ten years before the 140 foot radio telescope would be completed and available for research. Perhaps recognizing that the Steering Committee had outlived its purpose of consolidating community support for Berkner's ambitions, a few days later, at their 14 December 1955 meeting, the AUI Executive Committee approved Berkner and Emberson's request to disband the informal Steering Committee and replace it with an "Advisory Committee to the Board of Trustees." 128 This step, perhaps, was facilitated by John Hagen's announcement that he would be resigning from the Committee, as he was about to assume charge of the illfated Project Vanguard. ${ }^{129}$ Nevertheless, Tuve was "dumbfounded" when he learned from Seeger that the AUI Steering Committee would be dissolved. ${ }^{130}$

In reporting to his NSF Panel about the Steering Committee meeting, Tuve expressed his frustration about the decision to "build an extensive community in the deep woods," rather than have "at least an auxiliary laboratory and administration building adjacent to some nearby university, probably in Charlottesville, or in Northwest Washington." Tuve complained, "I was consistently and vigorously opposed in this by a variety of arguments," and went on to quote verbatim the two resolutions passed by the Steering Committee, but he neglected to mention that he had proposed the motions. ${ }^{131}$

The NSF Advisory Committee met again on 16-17 January 1956 to address the delicate question of the management and location of the radio astronomy facility. They asked if the facility should be managed by a single university, a group of universities, or other non-profit institutions, with or without experience in radio astronomy; to what extent was it necessary to choose a site that required building an extensive and expensive nonscientific infrastructure; and to what extent should the country's radio astronomy facilities be concentrated at one site. ${ }^{132}$ The Panel and Waterman expressed concern that AUI, with its membership confined to the Northeast, did not properly represent all of the major institutions in the country with interests in radio astronomy, ${ }^{133}$ and the Panel concluded that "there are serious problems with AUI as the corporate organization." 134 Waterman considered the possibility of letting AUI construct the facility and some other group or university handle the "detailed administration," but Berkner again argued that an appropriately chosen Visiting Committee would satisfy the need for national representation. ${ }^{135}$ Following assurances of cooperation in securing the land from the Governor of West Virginia, Berkner was anxious "to proceed with plans for a contract for construction, operation, and maintenance of the observatory." But he was informed by the NSF that although they would consider the AUI plans, the NSF could not proceed with contracts until they received the House report on the 
Foundation's budget request. ${ }^{136}$ Meanwhile, Tuve's concerns about AUI were supported by the NSB, which unanimously recommended that "to the extent possible and practicable, the governing body for any major facility receiving substantial assistance from the Foundation should be as representative as possible of interested universities and institutions throughout the country with experience in the field." ${ }^{37}$ Waterman also explained the Board's policy.

In supporting large-scale facilities, the Federal Government should aim to limit its support to established construction costs, but might recognize that in individual instances continuing support may be required, preferably on a diminishing scale. Once a sound venture is started, the Government should stand behind it, but not necessarily be its sole support. ${ }^{138}$

Although AUI and the NSF agreed that while the discussions about a national radio astronomy facility were not secret or classified, "there should be no public announcement covering the construction of facilities"139 until Congress appropriated the funds. However, someone leaked the news, and a long story appeared in the 26 January 1956 issue of The New York Times under the headline, "President Recommends Radio Telescope Funds for New Astronomy Research." 140 The Times article reported that, if approved, the 140 foot telescope would cost about $\$ 7$ million, but that the total cost of the facility might cost up to $\$ 30$ million. The article turned out to be somewhat of an embarrassment, as the House Appropriations Committee had approved only $\$ 4.5$ million for the total cost of the radio astronomy facility. ${ }^{141}$

Meanwhile, no steps were taken toward disbanding or renaming the AUI Steering Committee, although Bart Bok replaced Hagen as the Committee Chair. The Steering Committee unanimously agreed with Berkner's suggestion that that the new facility be called "The Karl G. Jansky Radio Astronomy Observatory." ${ }^{142}$ A week later, the NSF agreed to Berkner's suggestion to name the observatory after Jansky, but there is no evidence that name was ever considered further. ${ }^{143}$

On 10 January 1956, at the request of Waterman, AUI submitted their draft Planning Document for the National Radio Astronomy Facility. ${ }^{144}$ With unsuppressed optimism and enthusiasm, Berkner suggested a five-year budget for the construction and operation of four radio telescopes with diameters of 25-50 feet, 140 feet, 250 feet, and 600 feet. Berkner's plan was reviewed by an equally enthusiastic small subcommittee of the Advisory Committee composed of Bok, Leo Goldberg, and Ed McClain. The final Plan for a Radio Astronomy Observatory submitted to the NSF in August 1956 included: ${ }^{145}$

1. A "standard size" 28 -ft dish to develop and test electronic equipment as well as making "worthwhile observations."

2. A 60 foot dish which had now also reached the status of "standard size" by virtue of the 60 foot Kennedy dish recently completed at Harvard.

3. A 140 foot dish. 
4. A 250 to 300 foot diameter antenna, possibly a scale model of the 600 $\mathrm{ft}$ antenna.

5. A $600-\mathrm{ft}$ radio telescope following the specifications given for the Feld study.

AUI's "Plan" was apparently the first use of the word "Observatory" in any AUI or NSF document. While the NSF was openly discussing the establishment of a National [Optical] Astronomy Observatory, all reference to the parallel radio program had previously referred only to a "facility." In addition to specifying the planned radio telescopes, the AUI "Plan" carefully laid out a management plan which was received with some alarm by the NSF. Basically, the AUI plan called for government (e.g., NSF) funding and ownership of the facility, but all aspects of the operation would be controlled by AUI. Under the AUI plan the NSF would have no control over the selection of the director or advisory committees, operating policies, expenditure of funds or auditing. While the NSF recognized that "good administration requires a single line of authority," and that the AUI plan "does this with remarkable thoroughness. It also succeeds in divorcing the National Science Foundation from any practical measure of control over responsibility for use of the funds provided." 146 Also, of continuing concern to the Foundation, was AUI's repeated reference to itself as "scientists and institutions in the eastern part of the United States" and their repeated insistence against expanding the AUI Board which appeared to stand in contrast to the NSF goal of a "national" radio astronomy facility. Berkner reacted "very strongly" to these NSF criticisms, alluding to "interference of government with research in general and with the proposed facility in particular." 147

At their 27-28 March 1956 meeting, the NSF Advisory Committee, led by Merle Tuve, was not enthusiastic about AUI's ambitious plan, and rejected the two larger radio telescopes proposed. They suggested instead that the initial construction include only four more modest sized instruments: one 28 foot antenna, two 60 foot antennas, and one 140 foot antenna. The two 60 foot antennas were included because the committee projected a heavy demand for observing time from university staff and students, and also anticipated their possible use as an interferometer. The NSF Advisory Committee also had their own ideas about how to build a radio telescope. Specifically, some members of the Committee had concerns that the coordinate conversion for an alt-azimuth mounted antenna would not meet the stringent pointing requirements, so AUI was instructed to develop at least one design based on an equatorial mount. ${ }^{148}$ Berkner anticipated that AUI would first issue an RFP for an altazimuth mounted 140 foot dish, but defer a construction contract until an equatorial design was available. Following a later review of the Feld, Husband, and Kennedy designs, as well as the separate designs for the drive and control systems by a team of consultants, it was realized that none of the designs could meet all the requirements, so the proposal to the NSF acknowledged that the design "is still open for study." 149 
In addition to debating the number and size of the major instruments, the AUI proposal gave careful consideration to how the observatory would be run, what staff was needed, and of course how big an annual budget would be required. The AUI proposal delegated considerable authority to a Director who "must bear the overall responsibility for the Observatory," and went on to specify that "he must be not only be a research scientist of recognized ability; he must also have proved his ability to administer scientific projects; and that he possess special aptitude in selecting and supervising scientific personnel." Characteristic of the time, only the pronoun "he" was used; there was no recognition of the possibility that the Director, or any of the scientists, might be a woman, and indeed, none were considered in the subsequent lengthy Director search.

The proposal included a Chief Scientist who would also act as the Deputy Director, a Chief Engineer, and a Business Manager to round out the senior staff. AUI anticipated that the scientific staff would be approximately equally divided between resident and visiting scientists. Responding to repeated reminders from the NSF as well as from Merle Tuve and his Panel that neither the AUI staff nor any of the Trustees had any expertise in radio astronomy, AUI finally agreed to add two at-large Trustees with experience in radio astronomy, but Berkner refused to consider any changes in the Board's basic organization. Tuve expressed concern about AUI appointing the Visiting Committee, since, as he argued, "this mechanism can be self-biasing." Tuve also expressed concern about AUI's offer to "contribute recreational facilities costing hundreds of thousands of dollars," since he correctly appreciated that this "would be quite a hurdle if a new contractor had to buy out the facilities which belonged to AUI." Somewhat surprisingly, Tuve also suggested that some two to three million dollars be invested in placing a 24 inch Schmidt along with a larger 72 inch reflector in Green Bank to facilitate related optical studies. ${ }^{150}$ While such a scheme had obvious scientific merit, the very different environmental requirements of radio and optical observatories rendered this impractical.

Not dissuaded by the concerns of their Advisory Committee, the NSF Deputy Director, Charles Sunderlin, leaked to Berkner and Emberson that Waterman intended to recommend to the Foundation's Committee on Physical Science and to the National Science Board that AUI be selected "as the operating agency for the National Radio Astronomy Facility," 151 although this was not fully supported by all of the NSF staff, some of who preferred a "rather loose type of organization that would permit a greater degree of control by the Foundation." 152 In response to a question from Sunderlin, Berkner emphasized "the great importance of having the operating institution in full control during the construction phase," and that, "AUI would not be prepared to act simply as a construction contractor," although he was prepared to accept a contract for "three to five years with provision for extension." 153 Sunderlin also informed Berkner that because the House of Representatives had voted to reduce the NSF budget by a factor of two from $\$ 7$ million to $\$ 3.5$ million, and because it was uncertain whether or not the Senate would try to restore some 
or of all of the deleted funds, it was unclear how much money would be available for the radio facility in 1957. Berkner was therefore told to consider three 1957 budgets levels of $\$ 2.095$ million, $\$ 3.895$ million, and $\$ 5.170$ million, respectively, as an absolute minimum cost for a facility that would compare with others, the minimum cost for a facility including the 140 foot telescope, and the cost of fully carrying out AUI's plans for the development of the facility. ${ }^{154}$ Emberson encouragingly commented that in his opinion "the Foundation does not wish to omit thel40 foot radio telescope."155

Recognizing the magnitude of the effort on which they were about to embark and noting that AUI was constituted to manage the Brookhaven National Laboratory, not to do radio astronomy, Berkner asked the AUI Board if it was necessary to consult the founding universities, although he speculated that "in his opinion, the language of the agreement is sufficiently broad to cover almost any contractual obligation." The Board agreed, and told him only that "the universities should be kept advised." 156 Signals from the NSF were encouraging. In his address at the 28 April 1956 dedication of the new Harvard 60 foot radio telescope, (Sect. 2.5) the NSF Director, Alan Waterman, publically acknowledged the NSF plans to build a 140 foot diameter radio telescope to be operated by a "group of universities," and said that "substantial funds for this purpose have been included in our 1957 budget." ${ }^{157}$ Waterman went on to refer to radio astronomy as "A new window on the universe," and acknowledged the responsibility of the Federal Government to support basic research "when such support is necessary and in the interest of science." 158

Very shortly after the dedication of the Harvard radio telescope, Berkner gave a talk at the 94th meeting of the American Astronomical Society describing the need and plans for a national radio astronomy facility. In his short twopage published paper, Berkner (1956) referred to the 600 foot reflector as an "ultimate compromise between cost and operating characteristics," and expressed his believe that "it would be entirely feasible to construct a radio telescope of this size with adequate precision."

\subsection{Choosing the Site}

Discussions on the important question of site selection for the national radio astronomy facility began very early. Already, in November 1954, the NSF Advisory Panel on Radio Astronomy dictated that the site should be within 300 miles of Washington. Following discussions with Harold Alden, Director of the University of Virginia's McCormick Observatory, Carl Seyfert from Vanderbilt, John Hagen from NRL, and Peter van de Kamp from the NSF, Emberson and the AUI Steering Committee defined an additional set of criteria deemed important for the successful operation of a radio observatory. These included $^{159}$ :

(a) Radio Noise: To minimize the impact of radio frequency interference (RFI), AUI specified that the telescopes should be located in an area 
with a small local population, should not be in view of any high voltage lines, should be in a valley surrounded by mountains, be at least 50 miles distant from any city, and not be near any commercial air route. Furthermore, AUI noted that "the quietness of the site must be assured for the future; for example, by appropriate zoning regulations.”

(b) Weather: Low humidity to minimize erosion of steel structures and impact to electrical insulation, low winds, and low occurrence of hurricanes and tornadoes along with little ice and snowfall to minimize loads on the telescopes were specified. "Reasonably mild" weather was desirable to facilitate maintenance. At the time, little was understood about the impact of tropospheric water vapor ${ }^{160}$ on centimeter wavelength radio astronomy measurement, and so was not considered in evaluating the quality of each of the sites considered.

(c) Latitude: Lower latitudes were preferred to maximize the amount of available sky and in particular facilitate access to the important region near the center of the Milky Way Galaxy. However, AUI noted that northern latitudes would facilitate research on "aurorae, ionospheric scintillation, and polar blackouts."

(d) Social and Professional Amenities: To the extent possible, AUI sought "as many as possible of the attributes of a university campus, including laboratories, shops, libraries, conference rooms," and proximity to scientists working in broadly defined related areas. Easy access to "housing ... stores, theaters, and recreational facilities" was also considered to be "desirable."

(e) Access: The chosen site should be "easy to reach by plane, rail, or automobile" and as previously specified by the NSF, the site was to be within 300 miles of Washington.

(f) Availability and Size: A total area of five to ten thousand acres was desired to allow for adequate separation of future telescopes and arrays. Such a parcel of land would need to be available either as existing government property or by purchase from private owners.

AUI recognized that it would not be possible to meet all of these criteria, and that indeed, some were "mutually contradictory and incompatible," some compromises would be necessary. Consideration of known weather patterns, and population distributions along with the other geographical constraints suggested a valley somewhere in the Appalachian Mountains located within an area approximately 300 miles by 100-150 miles in extent oriented in roughly a northeast-southwest direction and west of Washington, DC (Fig. 3.11).

After receiving his second NSF grant in the spring of 1955, Berkner appointed an ad-hoc panel to evaluate potential sites for how well they met the criteria set out by the Steering Committee. Panel members included the state geologists from Virginia, West Virginia, and Tennessee, representatives of the University of Virginia and the NSF as well as radio astronomers from NRL and 

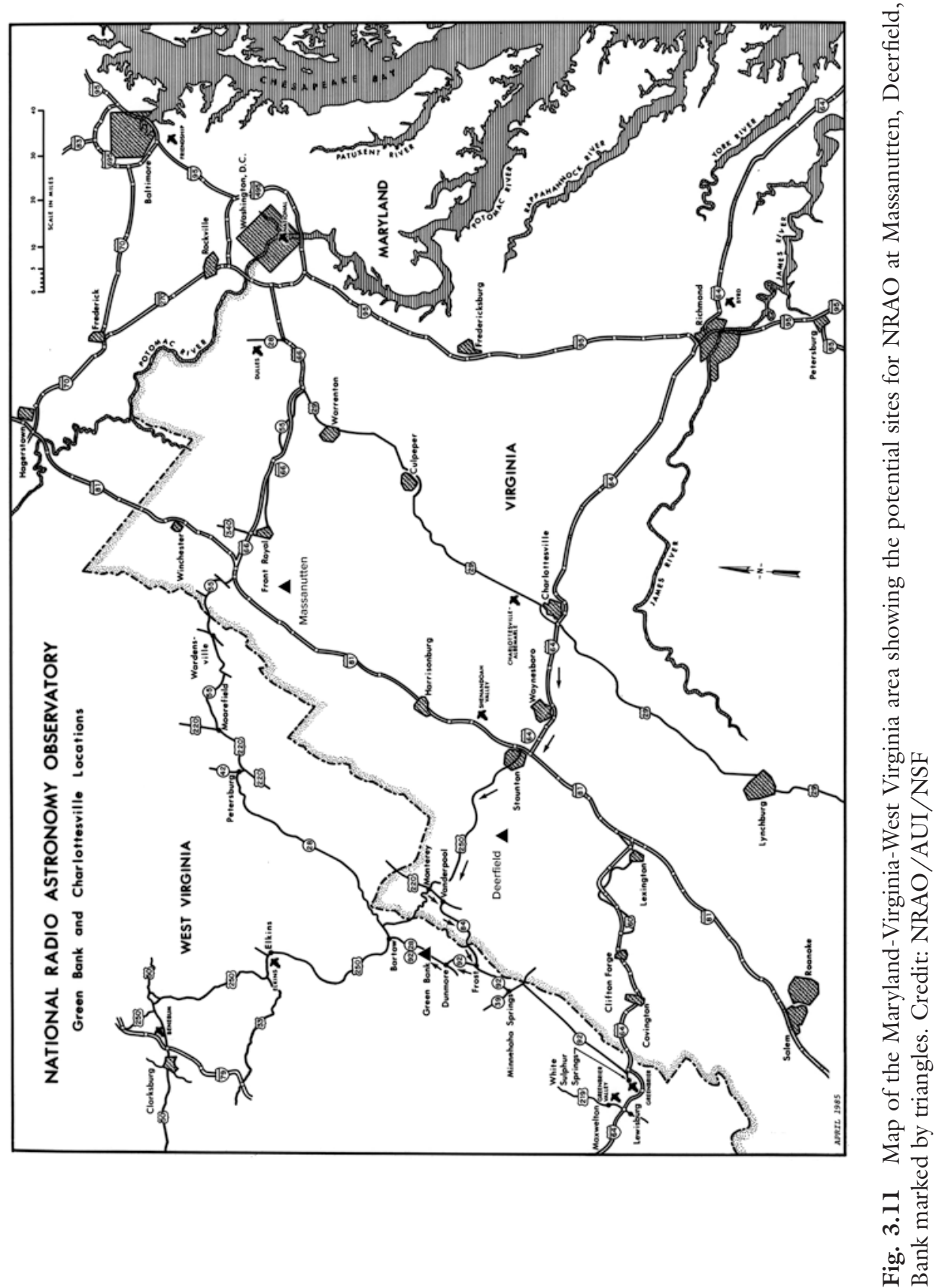
Harvard, along with two optical astronomers with experience in astronomical site testing. Richard Emberson represented AUI. ${ }^{162}$ The panel evaluated 20 different potential sites in Georgia, Tennessee, Virginia, and West Virginia. Much of the groundwork was done by Hagen and Emberson who spent a couple of weeks in what Hagen later referred to as the "wilds of West Virginia, Tennessee and Virginia looking at the potential sites, many of which were easily rejected due to their proximity to urban or industrial centers, power lines, radio or radar transmitters." 163 One site was considered unacceptable due to a high southern horizon which would have restricted observations of the southern sky. The US Forest Service, the Park Service, the Geological Survey, the General Services Administration, and the Tennessee Valley Authority all provided valuable support, but the Army Map Service was less helpful. ${ }^{164}$

For the most part, the study proceeded objectively, with little political interference, except from a few Congressmen who gratuitously offered what they each claimed were ideal choices for the planned radio facility. West Virginia Congressman C. M. Bailey requested consideration of the marshy area known as Cranberry Glades which had previously been rejected due to inadequate shielding from mountains and inadequate terrain to support large radio telescopes, but Bailey insisted on meeting with the NSF along with "a small committee of business men," to present the advantages of their proposed site. ${ }^{165}$ One of the attendees at their NSF meeting on 14 March 1956 was the warden of the local prison, who noted the availability of prisoner labor. ${ }^{166}$ Following a site visit urged by the NSF to keep the Congressman happy, Emberson reported that "if one jumps up and down ... with water oozing up ankle deep, persons standing twenty feet away can feel the waves passing by." ${ }^{67}$ Long time Congressman Harley Staggers, also from West Virginia, called Waterman to point out the desirable features of Spruce Knob, the highest point in West Virginia which looks out over three counties. Rather than try to explain to Staggers that the technical requirements for a radio telescope were not the same as for an optical telescope, Waterman merely told him that "the determination of the site was in the hands of a committee which is highly qualified scientifically," and that he "would be glad to bring his invitation to their attention." 168 Once Green Bank was chosen as the future site for the radio facility, Staggers helped to dispel the local fears about the impact of a big federally supported program in their quiet valley, and emphasized the new opportunities for employment (Kenwolf 2010).

Based on their initial review, the panel narrowed their consideration first to five sites, four in Virginia and one in West Virginia, some of which were also being considered by the Naval Research Laboratory as potential locations for their planned facility which ultimately went to Sugar Grove, WV. ${ }^{169}$ The consulting firm of Jansky \& Bailey ${ }^{170}$ was hired to evaluate the levels of RFI at each site, using equipment borrowed from NRL. During the latter half of 1955, Jansky \& Bailey made measurements between $50 \mathrm{MHz}$ and $10 \mathrm{GHz}$, but due to changing propagation effects, they found significant differences in RFI between measurements made in daytime or nighttime and between measure- 
ments made in the summer or winter months. Differing amounts of commercial activity in the areas surrounding each site also contributed to the day-night differences. Only one site, at Massanutten, VA was studied in both the summer and winter, and this was used to try to normalize the other studies to determine the differences in RFI among the five sites. The Green Bank, WV site was judged to be superior "to all others in regard to radio noise" and also had by far the smallest surrounding population, and compared with Deerfield, VA, less likely to have population or industrial growth. ${ }^{171}$ As described by Bart Bok, "the rather remote valley near Greenbank [sic] and Arbovale in West Virginia (at an altitude of 2600 and 2700 feet) seems to be the answer to the radio astronomers' prayers." ${ }^{172}$ As it turned out, the region chosen has one of the highest percentages of cloud cover in the United States, and this has greatly limited the effectiveness of the Green Bank radio astronomy program at centimeter wavelengths.

The isolation of Green Bank from population centers was recognized as both an advantage and disadvantage. The isolated site offered better observing conditions in terms of lower radio noise, but clearly more difficult access and less attractive living conditions. Tuve, claiming that "Berkner would like a large community in the woods, $" 173$ perhaps more than others appreciated the practical difficulties that would be faced by an isolated staff and urged that at least some of the facilities be placed in Charlottesville, Virginia. In fact, the NSF had some informal discussions with Professor Jesse Beams from the University of Virginia who conveyed the interest of both the physics and astronomy communities in seeing UVA as a possible manager of the proposed facility. To strengthen their position Beams offered that within a few years the University was likely to appoint a radio astronomer to the faculty. ${ }^{174}$ Berkner, on the other hand, noted that placing some of the administrative facilities in Charlottesville would keep the Green Bank staff even more isolated, and instead envisioned what Tuve called a Los Alamos type of operation. But the Bureau of the Budget reportedly did not like the idea of providing housing at government expense, ${ }^{175}$ so Berkner began to discuss seeking private funding for housing and other non-operational infrastructure. Concerns about the social impact of living in rural Appalachia would continue to plague the Observatory for the next decade, finally leading to migration of most of the scientific staff to Charlottesville, and effectively creating Tuve's model (Sect. 4.7).

In preparation for the planned AUI Steering Committee meeting scheduled for 13 December 1955, on 2 December six groups set out in different cars to personally inspect the five most promising sites. Due to recent rain and snow they were unable to reach the Massanutten site, which probably should have been a message about the suitability of the site for building a radio telescope. A lengthy debriefing session was held in Washington on Sunday evening 11 December, which included some other AUI Steering Committee members, some AUI Trustees, along with C. E. Curtis and Helen Sawyer Hogg from the NSF. The following morning a group of 15 people left by bus for one final inspection of the Green Bank site. During the trip they again reviewed all 
aspects of the site question, including radio quietness, geographic requirements, and the nature of the operation of the facility. In view of the problems encountered in reaching the Massanutten site, the representatives from the US Geological Survey surprisingly reported that the five sites appeared to be about the same regarding geology and the effect of inclement weather on access.

The Steering Committee met the next day at the NSF for further discussion, after which Merle Tuve moved and Bart Bok seconded a motion which read ${ }^{176}$ :

(1) It is the recommendation of the Committee that the site near Green Bank, West Virginia, subject to verification down to very low field intensities of the expected low radio interference level, be selected specifically for the proposed 140 -foot parabolic reflector, and possibly for two or three antennae rays [sic] or other equipment of modest cost; and

(2) This recommendation is made without prejudice to the possible location or locations which may in the future be recommended if this National Radio Astronomy Facility grows to include other specialized equipment or laboratory facilities.

The resolution was unanimously passed by the Committee, although it was later realized that the existing noise measurements were the best that could be made with existing equipment, so the requirement for additional noise measurements was rescinded. The second part of the resolution showed great prescience in recognizing the need for the future extension of NRAO to Arizona for the 36 foot millimeter wave antenna (Chap. 10) and later to New Mexico for the VLA (Chap. 7). To ensure against protection from locally generated interference, the Steering Committee also unanimously agreed to another motion, again proposed and seconded by Tuve and Bok respectively, which read

It is the recommendation of the Committee that all or nearly all of the land in the Green Bank, West Virginia valley shown in the attached map be acquired by direct purchase or as an alternative, suitable controls e.g., by some agency of the State of West Virginia, be arranged to insure [ sic] the future continued suitability of this valley for the National Radio Astronomy Facility; and the Committee is confident that the U.S. Forest Service will assist in maintaining radio quietness in the surrounding forest and overlooking mountain heights. ${ }^{177}$

Recognizing that it would be useful to consider contingency sites in case the Green Bank proved unsuitable, and, as Berkner pointed out, consideration of alternate sites would strengthen the bargaining position in acquiring the land, the Committee unanimously agreed to include Deerfield and Massanutten, in that order, as alternates. In parallel with the site search, AUI commissioned the New York City-based architectural firm of Eggers and Higgins to prepare a site development plan based on four radio telescopes of 25-50 feet, 140 foot, 250 foot, and 600 foot diameter, a staff of about 100, a central laboratory and administrative building, site maintenance and telescope maintenance buildings, telescope control buildings, along with a dormitory and apartment building in 
combination with a cafeteria, as well as several on site residences for key staff and visiting scientists. Based on a generic site taken from a selection of 14 potential sites being considered by AUI, Eggers and Higgins determined that the total cost of site development for the antenna foundations, roads, buildings, power, and water would be close to $\$ 10$ million. ${ }^{178}$

A more intensive site inspection took place in January 1956 with a two-day visit by Emberson, Heeschen, Bok, and A. Doolittle from the consulting firm of Eggers \& Higgins. ${ }^{179}$ As a measure of the "human activity in the area" and potential sources of interference, they counted somewhat over one hundred houses in the valley, and laid out potential locations for the planned 25 foot, 60 foot, 140 foot, 200-300 foot, and 600 foot radio telescopes, along with laboratory, maintenance, housing, and cafeteria buildings. Characteristic of the area, the nearest hotel the group could find was in Elkins, WV, 50 miles distant over Cheat Mountain.

Earlier, Emberson had reported that the "Foundation fully recognizes the desirability of moving rapidly, and would not object to the acquisition of a site with private funds." 180 Still facing competition over who the NSF would chose as the managing organization, in March 1956 AUI acquired options to purchase 6,200 acres of land at a cost of $\$ 502,000$, thus apparently squeezing out any potential competitors including those representing gas and oil interests. Three months later, Congress appropriated $\$ 3.5$ million to acquire the land, erect buildings, and design and construct a 140 foot radio telescope. However, not willing to accept Berkner's preemptive strike in obtaining the land options, the NSF invoked the right of eminent domain, and authorized the Army Corps of Engineers to seize the land, and the AUI options became irrelevant. This not only had the effect of neutralizing Berkner's tactical maneuver, but also removed the prospects of having to deal with landowner holdouts for higher prices. But the seemingly government land grab also had negative consequences. The Corps of Engineers was instructed to start their acquisition at the center and work outward until the authorized sum of $\$ 550,000$ was committed (Emberson 1959). Most of the privately owned land was bought at market value, but there were a few holdouts who only relinquished their land under pressure or perceived pressure. Although the affected land owners were all compensated, the non-negotiable seizure of private farms and homes that had been owned by generations of the same families would impact relations between NRAO and the local population for decades to come. Some years later, a small portion of land was returned to the local cemetery, accepting the local argument that the occupants of the cemetery "won't bother you none" (Lomask 1976, p. 142).

Even before being formally selected to manage NRAO, Berkner was lobbying with his long-time friend, William Marland, then the Governor of West Virginia, for the protection of the Green Bank site from RFI. Following the urging of a number of influential Harvard alumni in the state government, on 9 August 1956 Governor Marland convened a special session of the West Virginia state legislature to enact the "West Virginia Radio Astronomy Zoning 
Act (WVRAZA)" which prohibited the use of any electrical equipment within two miles of a radio observatory "if such operation causes interference with reception by said radio astronomy facility, of radio waves emanating from any non-terrestrial source." 181 In addition, the Zoning Act set limits on the field strength of any electrical equipment operated within ten miles of the radio observatory. Although a fine of $\$ 50$ a day was specified for any knowing violation, there is no evidence that anyone was ever prosecuted for violating the West Virginia Zoning Act. Nor is it clear that the Zoning Act was legal, since the 1934 Federal Communications Act placed the regulation of radio transmissions only in the hands of the federal government and the Federal Communications Commission. Nevertheless, the WVRAZA has remained valuable in restricting the use near NRAO of a growing list of potentially harmful devices, such as TV antenna mounted preamps, microwave ovens, and most recently cell phones. The initiative of the West Virginia legislature was the first legislation in the world specifically intended to protect basic research, and it set a precedent for the National Radio Quiet Zone (NRQZ) established in 1958 by the Federal Communications Commission to protect both NRAO and the Sugar Grove Naval Information Operations Center (Fig. 3.12). Within the NRQZ, all applications for licensed radio transmitters are referred to NRAO for comment. NRAO does not have veto power over radio transmissions within the NRQZ, but can provide comments to the FCC on applications for radio licenses, and often successfully negotiates with the applicant to modify their frequency or antenna beams to reduce the impact of their transmissions.

\subsection{Confrontation And Decision}

Continued friction between the AUI and NSF Radio Astronomy Committees, between Berkner and Tuve, and between the NSF radio and optical astronomy committees, led the NSF to call for another meeting to iron out the differences among the various individuals and the different advisory bodies. As later described by Heeschen (1996), "It really boiled down to a disagreement between Berkner and Tuve over just what the observatory should be. Berkner was the archetypal 'big science' scientist," and "wanted the observatory to be an institution like Brookhaven, which would provide extensive facilities and services for visiting scientists, and have its own scientific and technical staffs engaged in research and development." By contrast, "Tuve was the classical 'string and sealing wax' scientist, and had established a very successful and productive research group at DTM along these lines. Tuve wanted the observatory to consist of just a telescope, with minimal staff, facilities and services." According to Heeschen, Berkner and Tuve had "developed a mutual dislike and distrust" dating back to the time they had worked together before and during WWII. ${ }^{182}$ But Tuve also resented the way that Berkner grabbed the momentum which he, DuBridge, and Greenstein had started when they organized the January 1954 Washington meeting, and the possible impact that this might have to the major radio astronomy initiative now being pursued by 


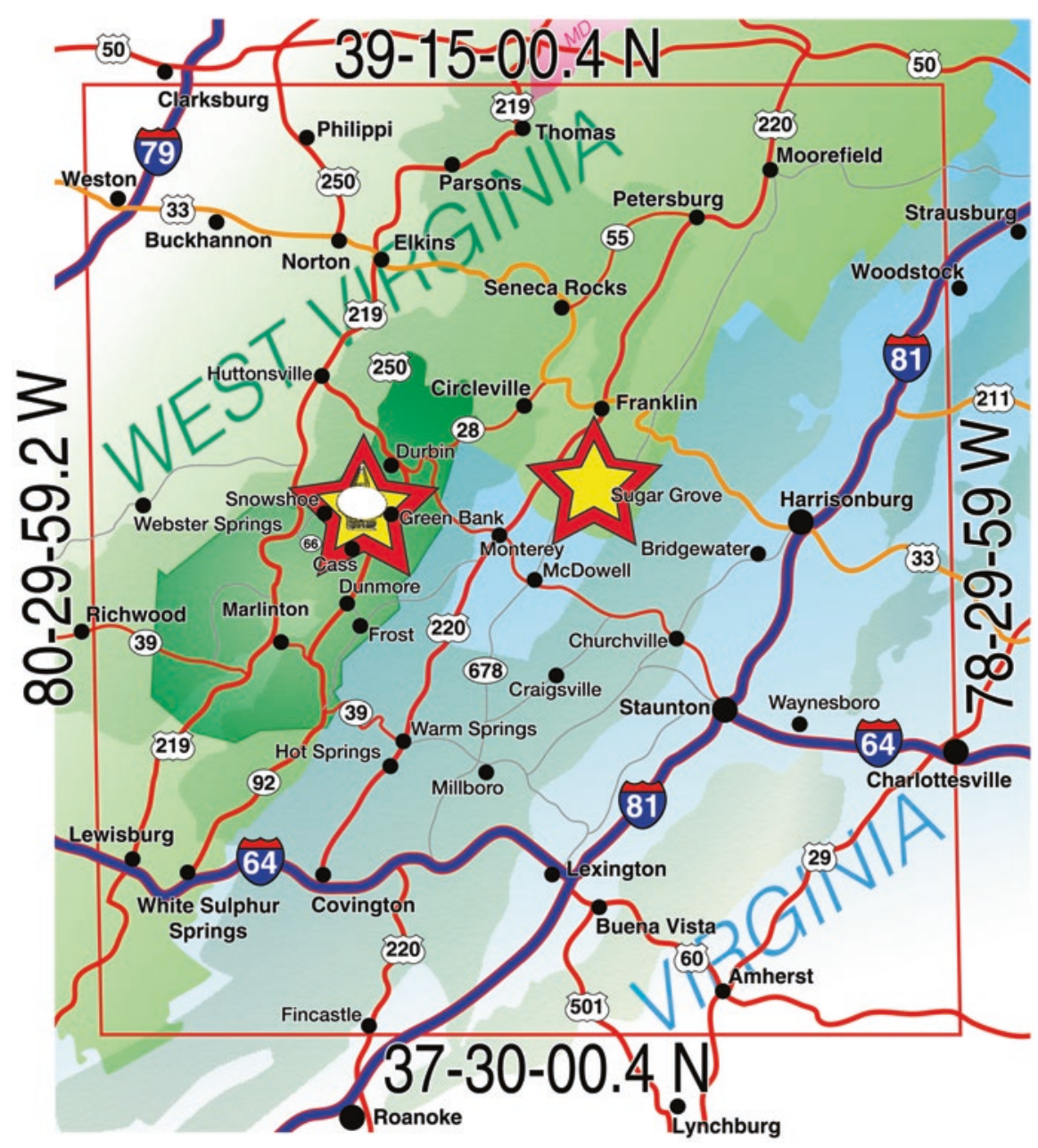

Fig. 3.12 Map showing the boundaries of the 13,000 sq. mile $(34,000$ sq. $\mathrm{km})$ National Radio Quiet Zone. The NRAO Green Bank, West Virginia and the Sugar Grove, Virginia Naval Station are shown as stars. Credit: NRAO/AUI/NSF

DuBridge and Greenstein at Caltech together with DTM's sister institution, the MWPO. Ed McClain (2007) later speculated that Berkner put Tuve on the AUI Steering Committee fully expecting that he would get criticism from Tuve, but that the criticism would come from a member of an AUI committee, and not from an outsider.

Although the AUI "Plan for a Radio Astronomy Observatory" was not formally submitted to the NSF until August 1956, early drafts were circulated to the NSF and others, so the 11 July 1956 meeting participants, especially members of Tuve's Panel, all had access to the ambitious AUI plan. On the table 
were AUI vs. an alternative contractor; equatorial vs. alt-az mount for the 140 foot antenna; the viability of a 600 foot class antenna; national facilities vs. support for small university facilities; radio vs. optical astronomy; Green Bank vs. co-location with the national optical observatory; and not least of all the prestige of Merle Tuve and Lloyd Berkner.

In the weeks leading up to the 11 July meeting, the confrontations further expanded through vigorous lobbying. ${ }^{183}$ Tuve, apparently unaware that Waterman was already committed to AUI, started a letter campaign to undercut the AUI initiative. Again, Tuve told his Panel that AUI was a northeastern, not a national organization, and as "a large-scale atomic energy activity ... their Trustees cannot be expected to give major attention to the needs of astronomy and radio astronomy." 184 Tuve also wrote to Irvin Stewart, President of West Virginia University ${ }^{185}$ and to Jesse Beams at the University of Virginia ${ }^{186}$ claiming that "our Advisory Panel for Radio Astronomy has taken the position that the trustees of AUI are too fully occupied with the large-scale operations at Brookhaven for us to feel confident that the radio astronomy activities will have full and unbiased attention," and that the NSF was looking for an alternative to AUI. In his letter to Stewart, Tuve remarked that the "Oak Ridge Institute for Nuclear Studies [ORINS] has expressed some interest in becoming a possible sponsor for this activity." To Beams, he ended with, "I trust that you will take appropriate initiative in this matter." Beams, Stewart and Tuve had all worked together in wartime Washington and knew each other well.

On 28 June 1956 Tuve also wrote Leo Goldberg and Ira Bowen, "as the principal able bodied members of the Optical Observatories Panel," expressing his concern with the growing separation of radio and optical astronomers, and suggesting that they consider a "single trusteeship for the optical and radio astronomy ventures." 187 Bowen was sympathetic to the idea of a jointly administered radio and optical facility, but noted that in view of the different observing requirements (RFI vs. sky transparency) any common headquarters might be far removed from at least one of the actual observatories themselves, although he noted that with the expected introduction of commercial jet transport that "it will require little if any more time than the ground transportation from a nearby city to the point of operation regardless of whether the installation is in the East or West." 188 Bowen, however, underestimated the need not to separate the engineers and technicians who, of necessity must be located close to the facility, from the observers who may prefer a more academic environment. It was this issue which a decade later restricted the relocation of the NRAO headquarters to a location "close" to Green Bank (Sect. 4.7).

Bok responded to Tuve on 20 June 1956, with copies to the Panel and to the NSF staff stating that "I do not share these misgivings" and that "At least half dozen of AUI's Trustees ... have in the past year shown a profound personal interest in the problems of the National Radio Observatory, and I have nowhere found any indication that anyone at AUI is inclined to favor the northeastern part of the United States over other sections." 189 The next day, Bok wrote again, this time in response to Tuve's and Stewart's letters, and 
somewhat more forcefully he stated, "I must say frankly that I do not remember our Panel actually taking this stand, and I for one feel that this is not a fair statement." 190 Bok was careful not to appear to offend Tuve, since he was also lobbying Tuve's committee for increased support for his Agassiz project. ${ }^{191}$ On 25 June 1956 John Hagen responded more forcefully to Tuve's assertion about the Panel's position on AUI, by saying that he was "greatly disturbed by your two recent letters," and that "This is just not a fact, the Advisory Panel has never taken such a position. It is my feeling that the majority of the members of the Advisory Panel feel that AUI has done an excellent job to date in planning this activity and would look with favor upon continuation of the NSF relations with AUI." "Moreover," wrote Hagen, "I feel that when as radical a move as an attempt to generate a combination of two universities and the Oak Ridge Institute for Nuclear Studies with the implied support of the National Science Foundation is taken by the Chairman of the NSF Panel, he should first call a meeting of the Panel, discuss the matter and have agreements within the Panel." 192

Jesse Greenstein was not able to attend the July meeting, but wrote expressing great concern over the performance and reliability of a computercontrolled telescope and strongly favoring an equatorial mount for the 140 foot telescope, even if it cost more. Greenstein did not express any great concerns about AUI management of the radio astronomy facility, but more broadly he worried about the impact to the funding of the university facilities, both radio and optical. Moreover, he remarked "I am absolutely aghast at the enormous expenditure for buildings," which he noted had more sleeping rooms (32) than the number of radio astronomers working in the United States."193 Both Greenstein and Bok challenged Tuve's suggestion to build optical telescopes or to locate optical astronomers in Green Bank, pointing out the very poor sky condition in that part of the country. But, they both concurred with Tuve in the need to bring optical and radio astronomers together. Ed Purcell ${ }^{194}$ and Bill Houston ${ }^{195}$ had more tempered responses. Purcell conveyed confidence in having AUI act as the manager of the radio facility, but expressed concern about what he felt were the inappropriately tight AUI specifications for the 140 foot pointing accuracy and the need for a very large fully steerable antenna, suggesting that a very large antenna with limited sky coverage would be cheaper and more useful than a somewhat smaller fully steerable instrument, and that, if needed, a separate instrument could be built for solar astronomy. Houston expressed confidence in AUI, but recognized the possible advantages in having a broader group of 30-40 universities involved, and perhaps combining the management of both the national radio and optical facilities.

In a second letter on 29 June 1956, addressed to Bok but apparently as an afterthought also sent to his Radio Astronomy Panel and NSF staff, Tuve indicated that when two years earlier, the Panel "removed the onus from Berkner and the AUI of a political decision as to regional location by stating that the search for sites should be within 300 miles of Washington, D.C.," they had not realized that they were "going to set up something comparable to Palomar in 
cost and complexity." Now, he argued, "since we have moved into the range of 4.5 to 5.0 millions of dollars," he wanted to explore the possibility of a "joint installation with the national optical observatory, evidently in Arizona." 196 Tuve went on to point out the "relatively sad state of the 140 foot dish," and that neither Berkner nor Emberson had made the necessary "crucial engineering decisions," and accused Berkner of knowingly setting the specifications too high. He accused AUI of "using clerical procedures and a checkbook," to purchase "some exceedingly expensive studies ... so warped by the aim for a 600 foot dish that they have produced only a series of contradictory suggestions instead of a design." Moreover, Tuve again argued that there was no one at AUI who would use the new facility, and that the other radio qualified astronomers at Harvard, DTM, Ohio State, Caltech, and Stanford were all building their own facilities with funds from ONR, NSF, and the Air Force. "Where," he asked, "are the sound research men who will need this new five million dollar facility? ... Shall we now decide we must import them from Manchester or Sydney.... Can we name even one first-rate man who is prepared to accept personal responsibility to make this added 'National Facility' a wise and fruitful venture for the NSF." Tuve, of course, did not miss the opportunity to remind Bok that the two strongest advocates for the national radio facility and the two most qualified people to assume the position of director were Bok and Hagen, and that Bok was leaving the US to go to Australia and Hagen was about to leave radio astronomy for a "satellite adventure."

Three days later, claiming that "radio astronomy activities have largely been 'captured' during the past two years by Berkner, Hagen, and Bok" and their plans for a $\$ 25$ to $\$ 30$ million facility, Tuve laid out a more detailed plan for how the "NSF and its advisors in astronomy should firmly and flatly dissociate themselves from this kind of thinking," arguing that "the AUI proposal can wreck the entire NSF if it is adopted." 197 Instead, Tuve proposed forming a "University Corporation for Astronomy," and suggested the possible names of a number of "men with some immediate active connection with Radio Astronomy." But he specifically added, "Do not include, Bok, Hagen, or Berkner."

Meanwhile, Bok, feeling offended, did not delay, and responded on 3 July 1956 to Tuve's letter of 29 June $1956 .{ }^{198}$ Reacting to the perceived allegation that he "was running away from the project," Bok felt obliged to point out that in January he had informed everyone of "his decision to leave Harvard" and that he had "in mind either going to Australia or joining the staff of the National Radio Observatory." When Bok received a formal offer for the Directorship of the Mt. Stromlo Observatory in Canberra, he let it be known that he would accept the Australian position after two weeks, "unless good reason could be given why I should not do so." John Hagan apparently wrote to Waterman that it was important to keep Bok in the United States, but as Bok described, "nothing developed, ... [and] I decided that I was free to accept the [Australian] Directorship." 199 More to the point, Bok laid out a seven- 
point plan of action that he wished might come out of the scheduled July meeting.

1. NSF should purchase the land in Green Bank,

2. Settle the administrative issues with preference given to AUI as the contractor,

3. Decide on the needed precision for the 140 foot telescope,

4. Obtain an engineering study for an equatorial mount making use of the experience with the Harvard 60 foot and Caltech 90 foot antennas,

5. Appoint a Director,

6. Build up a staff and instrumentation,

7. Increase NSF support for university facilities.

Bok also challenged Tuve's accusation that the radio astronomers were isolated from optical astronomers by pointing out that the projects at Harvard, Caltech, Ohio State, and Michigan were led or co-led by an optical astronomer, but that "the contact [between radio and optical astronomers] may not be a close one for the radio astronomers working in and near Washington, D.C." Bok also expressed that, in view of the heavy concentration of optical facilities in the west, he was "strongly opposed" to Tuve's suggestion of co-locating the national radio observatory together with the optical observatory near Phoenix, Arizona, and with a final dig, he pointed out that "some of you people in Washington, fairly remote from university contacts, do not apparently realize the terrific boon to the development of student interest in the Eastern United States in radio astronomy as a result of the [planned] Greenbank [sic] operation."

Greenstein took a more intermediate approach. ${ }^{200}$ While not opposed to having AUI as the contractor for the construction and operation of the radio observatory, he agreed with Tuve that the NSF should establish a single Board for both observatories to apportion resources between the two fields, and that consideration be given to locating the 140 foot dish in the same area as the optical facility although travel from the East would be more expensive, "but hardly more time-consuming than road travel to Greenbank [sic]." Like Bok, Greenstein felt that there were a sufficient number of young men in the United States who would use the radio observatory, and that "if we lack the ideal leader for the group, I would, personally, not be embarrassed at importing one."

The "shootout" to decide on the management for the national facility was held on 11 July 1956 in Washington and was organized by the NSF Acting MPE Director, Raymond Seeger along with Frank Edmondson, at that time the NSF Program Director for Astronomy. ${ }^{201}$ Prior to the meeting, AUI decided to take a "passive role," and not do any advance lobbying in response to Tuve's letters. ${ }^{202}$ More than 40 people attended, including not only members of Tuve's Advisory Panel and the AUI Steering Committee, but also John Bolton from Caltech and many of the major players in optical astronomy, including Seyfert, Lyman Spitzer, and Albert Whitford. Institutional leaders 
attended as well, perhaps looking to grab a piece of the action: the Presidents of Rice and Ohio State Universities, and the Universities of Pennsylvania, Virginia, and West Virginia, along with the Directors of DTM (Tuve) and the Oak Ridge Institute for Nuclear Studies (Pollard), and a number of University Vice Presidents. AUI was represented by President Lloyd Berkner, Frank Emberson, and Charles Dunbar, the AUI Corporate Secretary. Jerry Wiesner and Julius Stratton, two future MIT presidents, represented MIT, while Harvard was represented by Menzel and Ed Reynolds, the Harvard Vice President for Administration and member of the AUI Board of Trustees. Alan Waterman and eight other staff attended from the National Science Foundation. NRL and ONR sent representatives. Detlev Bronk, President of the National Academy of Sciences and Chairman of the National Science Board, presided. Greenstein and Purcell were unable to attend.

The morning session opened with a brief review from Waterman explaining that with the approval of the Administration, the Foundation now accepted responsibility for the construction of new scientific facilities, although that was not part of its original charter to support research. He then added that, based on the recommendation of Tuve's Advisory Panel for Radio Astronomy, the NSF had financed a feasibility study for a radio astronomy facility, but since the Foundation was not allowed by law to operate research laboratories itself, ${ }^{203}$ the NSB would consider the AUI study, and would make a final decision about how to operate the new facility at its August meeting.

Tuve, perhaps not to anyone's surprise, claimed that there already was good support for new radio astronomy facilities at universities around the country, that the need was to integrate radio and optical astronomy, and to keep control within the universities and away from "the hands of a professional management group." Tuve contrasted management by "a true university operation ... in the hands of university research men" and a "special laboratory operation, nominally in university hands, but actually controlled and guided by small selfapproving groups of experts." He went on to argue that "very high priority, probably ahead of anything else, must be given to the support of existing activities in radio astronomy at universities," and that NSF money should go to active research astronomers, not to physicists, engineers, or administrators. Departing from his prepared remarks, Tuve contended that "the AUI plan is a poisonous whitewash," adding that, "a very large dish $(250-600-\mathrm{ft})$ is a project of uncertain value," and that "the AUI plan for a $600-\mathrm{ft}$ radio telescope is a power bid by people who love to manage things." (England p. 284). Tuve concluded his speech by stating, "My frank advice against accepting AUI as the contracting agency for radio astronomy is not based on their list of trustees, but on their very large plans and on the pattern of self-generated approval and on their automatic initiative for larger and larger projects of the same technical type."

Bart Bok followed with brief history of the development of radio astronomy, both in the US and abroad, including a detailed description of the status of solar, planetary, $21 \mathrm{~cm}$, continuum research, and various radio astronomy 
activities underway at each of ten different US facilities. Contrary to Tuve, Bok claimed that, "the majority of radio-astronomical centers in the Eastern and Central United States are not contemplating the construction in the near future of new large scale equipment, because they expect to make use of the Greenbank [sic] facilities."

Berkner again reviewed the history leading to the current meeting, reminding everyone that AUI was approached by Harvard, MIT, and NRL to undertake a study on how a radio observatory might be organized to provide large scale facilities that seemed beyond the capacity of any one university to undertake. Naturally, he described the success of AUI in operating Brookhaven, and noted the addition of Dave Heeschen ${ }^{204}$ to the full time staff at AUI to supplement the radio astronomy expertise of the Steering Committee. But he added that the AUI Planning Document was a general report with respect to the character of the management, and it did not recommend that AUI operate the facility.

Emberson summarized the content of the Planning Document, including the process which led to the choice of the Green Bank site and the status of the 140 foot design. Following Rudolph Minkowski's brief outline of the interdependence of radio and optical astronomy, Leo Goldberg spoke of the need for balance between national and university facilities, for both radio as well as for optical astronomy.

Although the morning session went off without much acrimony, the seeds of discontent had clearly been sown. Detlev Bronk led off the afternoon deliberations with the premonition, "I have the unsatisfactory feeling that after the end of the afternoon conference you may have an unsatisfactory feeling of nothing have been accomplished or decided." More to the point, while acknowledging that neither he nor the NSB had expertise in radio astronomy, Bronk reminded those present that it would be the NSB that made the final decision on the development of radio astronomy through the national facility, so the NSB would of necessity depend on the advice received. Moreover, he pointed out that as the first large NSF research facility, the decisions made on how to operate the radio astronomy facility would have broader impact "than merely for radio astronomy itself." Noting that because the NSF is funded on a year to year basis, the construction of a research facility can provide no legal responsibility for its future operation, but Bronk nevertheless warned that "I can conceive a time when the National Science Foundation would be using all the money it could get from the National Treasury in the support of the activities which it had created in the past." Waterman added that "astronomy being pure research is in the position of requiring probably more support on the part of the Government than most facilities would have." Berkner spoke at great length about his interpretation of a national facility as one that responds to broad interests and pressures from individual scientists and not from universities, but is not an independent laboratory with its own agenda or programs. M.V. Houston, President of Rice University and NSB member, cynically commented that "Washington is a long way off from most of the country," and 
since you can't have more than one national facility for radio astronomy, "one has to make it clear that the facilities are available to all who wish to use them, ... not as a favor, but available ... as a matter or right.”

Menzel and Wiesner reminded the group that AUI involvement came about only because the instrumental needs were too great even for the combined resources of MIT and Harvard, and that Edward Reynolds, Harvard's Financial Vice President, had suggested that they approach AUI, not the other way around as Tuve had contended. Wiesner recalled that their small MIT-Harvard group had discussed forming a new corporation, but realized that the management cost would be much less working with AUI, and that it would take much longer to set up a new organization. Menzel acknowledged that the 600 foot dish was a long range vision, but that the immediate need was for a 150 foot class antenna, and argued that the design of the intermediate size antenna should not be affected by any consideration that it be a prototype for the 600 foot telescope.

William Pollard, Director of the ORINS, suggested instead that they form "a new corporation of national scope" to manage the new radio astronomy facility. Pollard acknowledged that he was "not a radio astronomer or for that matter an astronomer of any kind," nor was he even aware of the proposed radio astronomy initiative until learning about it from Merle Tuve just a month earlier. Pollard and Tuve had worked together at Los Alamos during the war, and Tuve, who expressed concern about his "Christian responsibility" had contacted Pollard, a recently ordained Episcopal priest, as Tuve later reported, "to help me orient my thoughts constructively" (Wang 2012). Apparently the previous NSB Vice Chair, Paul Gross, had lobbied with Seeger in support of Pollard's initiative (Needell 1987, p. 279) and he received further support at the 11 July meeting from Houston and Morris, the other southern members of the NSB present at the meeting. At the meeting, Pollard passed around a descriptive brochure of his proposed new organization that included an "Agreement for Incorporation," along with draft by-laws, and suggested a procedure for the organization to be chartered under West Virginia law. Pollard argued that his new organization would be more open to new membership than AUI and suggested that since the new organization could be established in "three to five weeks," it would not introduce any significant delay in establishing the national radio astronomy facility. Irvin Stewart, President of West Virginia University, added that "if you are going to locate in our backyard," the University has "an interest in this," and spoke in support of the Pollard proposal. Tuve claimed that since the technical specifications for the 140 foot antenna were not yet decided and that "if it is built according to the present internal contradictions ... it will be a white elephant. ... Therefore, you need not think you are holding things up if it takes a while to get a sponsoring agency."

Tuve returned to his concerns that creating a national radio facility separate from the planned national optical facility would further split astronomy, but 
was challenged by Bok, who claimed that "many of us do not agree that there is even a limited divorce between optical and radio astronomy at the present time," and suggested a joint meeting of the two panels to discuss this question. Bok was supported by Hagen, who argued that "the connection between radio astronomy and astronomy is much, much better today than it has ever been and it is steadily improving." Tuve read from Greenstein's letter expressing concern about the competition between the universities and the national facility for funds, but under pressure from Wiesner, he also read from the very strong letter from Purcell, who wrote, "I don't know of any organization in the country that has had experience and success comparable to that of AUI in this special sort of enterprise." Bok added that the real issue was the concern about management by committee, and the solution was to find a good director, give him the power and responsibility to make the decisions and "fire him if you don't like him."

Asked about the position of the optical community, Leo Goldberg agreed that because of the obvious different technical requirements, it would be inappropriate to co-locate the two national facilities, but he could conceive of a single management structure possibly including a national solar facility as well.

Finally, following up on their agreed strategy, Theodore Wright, Vice President for Research at Cornell and long-time AUI Trustee, spoke passionately saying,

The Trustees of AUI would not want to undertake the management of this new facility if they were not to be enthusiastically supported by the NSF, by its Advisory Committee and by the scientists and universities in the country who will do the research work in the laboratory itself. AUI is not out to get the job. It feels however, it can make a real contribution and if it is backed, it will go ahead enthusiastically.

\section{"Furthermore," added Wright,}

I do not think that AUI would wish to undertake the construction phase and then bow out. So, in the interest of time saving and after all I have heard here, I am convinced that the National Science Foundation will not go astray if it looks favorably upon contracting with AUI to manage the contemplated National Radio Astronomy Facility.

Wright was supported by Harvard's Ed Reynolds, who, pointing his arm at Tuve, added (England 1982, p. 285)

The atmosphere here has disturbed me very, very much indeed. ... My disturbance goes so far that I am going to enlarge on what Dr. Wright has just said. ... We don't want this contract under this atmosphere. You are going to have to want us enthusiastically if we are to take it on. Then we can do a good job for you. 
In reflecting over the afternoon's tumultuous session, MIT's Julius Stratton was said to have remarked, "Never have so many thought so differently on so few matters" (England 1982, p. 284). Bronk summarized the meeting with the important conclusion that there was agreement that the managing organization would be responsible to both the NSF and to the astronomical community. But considering the lack of agreement about if or how the NSF-sponsored radio and optical astronomy initiatives should be coordinated, Bronk concluded the meeting with a call for the NSF Panel for Radio Astronomy and for the two Optical Astronomy panels to meet jointly and consider what they would like to recommend to the National Science Board as to the relationship between the three panels "and the desirability or undesirability of having some sort of more formal common association in this general undertaking."

Returning from the 11 July meeting, Menzel wrote a scathing letter to Tuve pointing out the many contradictions between his testimony and his prior written statements. ${ }^{205}$ Menzel complained that "many of us are greatly disturbed that you chose to inject regional competition into the situation by writing Dr. Stewart and Dr. Beams in your letters of June 19 inviting opposition to the AUI plan." Menzel specifically chastised Tuve for his claim, "Our Advisory Panel for Radio Astronomy has taken the position that the trustees of AUI are too fully occupied with the large-scale operations at Brookhaven for us to feel confident that the radio astronomy activities will have the full and unbiased attention," whereas in fact wrote Menzel, "You did not even consult your panel, before taking this unilateral action." Later, Berkner shared his frustrations with Menzel, expressing his concerns about Tuve's attempts to undercut AUI's plans to construct and manage the national radio astronomy facility. ${ }^{206}$

Meanwhile, Pollard and Stewart, apparently undiscouraged by the lack of reaction to their bold suggestion, circulated a formal proposal to form a new corporation to be known as the Association of Universities for Radio Astronomy, or AURA, with its headquarters to be located in Green Bank. Pollard's invitation went to 12 prominent scientists and science administrators, including Menzel, Goldberg, Hagen, Struve, and Greenstein, as well as Colgate Darden, President of the University of Virginia, and Howard Bevis, President of Ohio State University, inviting them to become an "incorporator" of AURA. Pollard and Stewart included a proposed "Agreement for Incorporation" along with seven pages of proposed "By-Laws." But aside from his co-conspirators Irvin Stewart and Merle Tuve, there was no support from within the astronomy community for this initiative. Donald Menzel was particularly incensed, and accused the conspirators of "southern pork barrel interest" and "selfish motives on the part of the Carnegie-Cal Tech [sic] axis" for the attempt to discredit AUI (England 1982, p. 286).

Interestingly, the acronym AURA was to be soon reconstituted as the Association of Universities for Research in Astronomy, which would manage the Kitt Peak National [optical] Observatory, the sister organization of NRAO. However, Pollard's initiative was supported by the influential National Science Board Vice Chair, Paul Gross, who also happened to be a member of 
the ORINS Board. Earlier, encouraged by Tuve, Gross had told Waterman that he supported what he (incorrectly) claimed was the view of the NSF Radio Astronomy Advisory Committee that the national radio astronomy facility should be managed by a group with broader representation than AUI (Needell 1987, p. 227).

Sensitive to the anti-AUI sentiment, Waterman spoke with both West Virginia University President Stewart and University of Virginia President Darden to explore their interest in having a role in managing the radio facility. Both expressed possible interest in some joint management scheme, but neither Stewart nor Darden seemed interested in assuming responsibility for sole management of the facility (England 1982, p. 287).

Following the 11 July meeting, Berkner wrote to Waterman stating AUI "will make a proposal to construct and manage a National Radio Astronomy Facility," but only "if desired and requested to do so by the National Science Foundation." ${ }^{207}$ However, Berkner emphasized, "it would not be appropriate to undertake the management of the Facility through an initial phase only, ... after which some other agency would manage the operation itself." In response to the criticism raised by Tuve and others that AUI did not have sufficient expertise in radio astronomy, Berkner repeated that AUI "would appoint an Advisory or Visiting Committee for the Radio Astronomy Facility, similar in composition and function to the visiting committees for the various departments at Brookhaven," and that "appropriate representation will be given to astronomy" on the AUI Board of Trustees.

Meanwhile, Leo Goldberg and others were still concerned about the developing divide between the radio and optical factions of the astronomy community, as well as the deepening rift emerging over who would manage the new national radio observatory. Goldberg, perhaps more than anyone else, appreciated that unless the two communities could come together, chances of funding for either the national radio or optical facilities would be dubious. Following the 11 July closing directive from Detlev Bronk, the NSF Radio Astronomy Panel, the NSF Advisory Panel for Astronomy, and the NSF Astronomical Observatory Panel agreed to meet in a joint session. The combined meeting of the three NSF astronomy panels was held on 23 July at the University of Michigan in Ann Arbor and was attended by Waterman along with other members of the NSF staff. Waterman opened with the announcement that unless there were objections, "the NSF was ready to proceed with acquisition of the Green Bank site," and made it clear to the assembled panel members that the advisory panels were purely advisory to the NSF. ${ }^{208}$ Ever the optimistic statesman, Goldberg argued, "I think our positions should be that we need them all, and that the country is rich enough to afford them. I have been rather impressed by the timid attitude on the part of astronomers which seems to take it for granted that funds must always be limited." According to Greenstein, ${ }^{209}$ the Ann Arbor meeting "went off very well in a mood of friendliness and compromise. There was no debate of any kind about the details of management, and this is now definitely in the hands of the National Science Foundation and 
its board for final decisions." Greenstein reported a consensus agreement on the choice of Green Bank for the radio astronomy facility, but that "beginning with the next fiscal year, applications for operating funds for university installations in radio astronomy will be handled by the regular advisory panel for astronomy." Two days later the NSF issued a press release announcing that Green Bank had been selected as the site for a new radio astronomy facility. ${ }^{210}$

After the 11 July meeting, and again after the joint meeting in Ann Arbor, Tuve's Panel met to recommend operating funds for various university radio astronomy programs as well as funds to help support international radio astronomers planning to attend the 1957 URSI General Assembly, to be held in Boulder Colorado, and for Greenstein to visit Australia. In accord with the discussions toward integrating all of the astronomy advisory functions, the Radio Panel agreed that future yearly research grants in radio astronomy should be handled by the reconstituted NSF Advisory Panel for Astronomy. However, Tuve made it clear that the Radio Panel would retain the responsibility for facility grants. The Panel also made special mention of "the great importance" that they attached to "the fact that Dr. David Heeschen has now joined this activity," and urged that he "retain his connection with the NSF activity whether or not the management sponsor is AUI or some other agency." 211

However, the issue of the relationship between radio and optical facilities, the level of NSF control over these facilities, and the constitution of AUI continued to fester. With a combined management of the radio and optical facilities, the NSF might maintain a higher level of influence and control, which Berkner opposed. Greenstein, concerned that since Berkner would never give up control over the radio facility, worried that this would lead to AUI management of both the radio and optical facilities, and also opposed any joint operation of the two national facilities. ${ }^{212}$

After making revisions resulting from the 11 July meeting and the subsequent informal exchanges between AUI and NSF staff, AUI delivered 50 copies of the Planning Document to the NSF in time for consideration by the NSB at its August meeting. Among the modifications to the earlier version, AUI, realizing that the restricted nature of AUI could be a deal killer, finally broke down and agreed to add three "at-large members" to the AUI Board. Initially, these would be Otto Struve from the University of California, Leo Goldberg from the University of Michigan, and Carl Seyfert from Vanderbilt University.

On 24 August 1956 the NSF National Science Board met to discuss three options for the new radio astronomy facility ${ }^{213}$ :

(a) Management by a university. (The NSF Director, Alan Waterman had already held discussions with both West Virginia University President Stewart and the University of Virginia President Colgate Darden and Physics Department Chair, Jesse Beams.)

(b) Management by a new organization such as the Oak Ridge Institute for Nuclear Studies [ORINS].

(c) Management by AUI. 
Also on the table were the long debated issues of the nature and performance specifications for the first radio telescopes, and to what extent the management of the national radio and national optical facilities should be combined. Waterman presented the AUI plan, reported that AUI had obtained options on the land, and that the West Virginia Zoning Act had been passed (England 1982, p. 288). Merle Tuve testified on behalf of the NSF Advisory Panel claiming that there is "no value in a telescope capable of operation at less than $10 \mathrm{~cm}$," that AUI was "too busy and has no experience," and went on to ask, "where will the staff come from? UK? Australia?" There is "no need to rush," he argued, but Hagen responded that Tuve "had misrepresented the committee and was speaking only for himself." 214 The NSB realized that there was no really viable option to AUI. This was the first big NSF project. Both Waterman and the NSB needed a success, but they weren't going to give AUI a blank check.

On 4 September 1956 Waterman notified Berkner that the NSB had decided that it would take too long to form a new organization and authorized the NSF Director to enter into negotiations with AUI for the establishment and operation of the Radio Astronomy Observatory. ${ }^{215}$ But there were strings attached. Concerned about the lack of any AUI experience or involvement in astronomy, and that AUI only represented a limited number of universities, all in the Northeast, the NSB stipulated that AUI would need to agree to appoint three at-large members to the Board of Trustees and that AUI would operate the facility for the "use of the nation's scientists," independent of their institutional affiliation. Waterman also conveyed that the NSB decision to contract with AUI for the construction and initial management of the radio facility was

subject to a clear understanding with AUI that the Foundation will give serious consideration to the possibility of establishing at the end of that time a common management for the Radio Astronomy Observatory and for the Optical Astronomy Observatory; it is to be further understood that the selection of the Director and of the AUI Advisory Committee for the Observatory will be made in consultation with the Director of the National Science Foundation. ${ }^{216}$

Berkner responded firmly, informing Waterman that "the detailed planning, construction, and management of the Observatory will be handled ... by AUI," although he added that "AUI will, of course welcome basic policy recommendations by the NSF concerning the general direction of the program." ${ }^{217}$ Berkner went on to remind Waterman that while the proposed $\$ 4$ million initial budget "will cover the creation of an effective radio astronomy facility," \$6.7 million "represents a realistic estimate of what is needed to provide the facilities that radio astronomers in the United States really need." Not to be intimidated, Waterman stated that "authority for major decisions with respect to the radio astronomy observatory are lodged at the National Science Board and the Director," and that "the Foundation is not in any position at this time to comment on the magnitude of future commitments."218 
At its meeting on 21 September 1956, the AUI Executive Committee authorized Berkner to "negotiate and execute ... a contract for the construction and operation of a Radio Astronomy Observatory." 219 On 17 November 1956, AUI and the NSF signed a contract for the "Construction and Operation of the Radio Astronomy Observatory (Fig. 3.13)."220 The five-year contract initially committed the amount of $\$ 5.13$ million, but noted that "The Foundation may increase or decrease this obligation at its discretion from time to time." Indeed, the signed contract obligated only $\$ 4$ million, although a month before signing, the NSF Director had authorized an additional amount of $\$ 1.13$ million. No indication was made in the contract that this was to be a "national observatory," although it was specified that the observatory would be made available to qualified personnel to the extent possible. The contract was written in very general terms and did not include any details of the instrumentation to be built other than, "The observatory shall contain facilities and equipment appropriate for the conduct of research in radio astronomy (including one or more radio telescopes, at least one of which shall have a diameter of at least 140 feet) and appropriate ancillary buildings and facilities as mutually agreed upon from time to time." There was no mention in the contract of any possible larger instrument such as a 600 foot telescope. The NSF also specified that AUI "consult with the Director of the Foundation" before appointing the

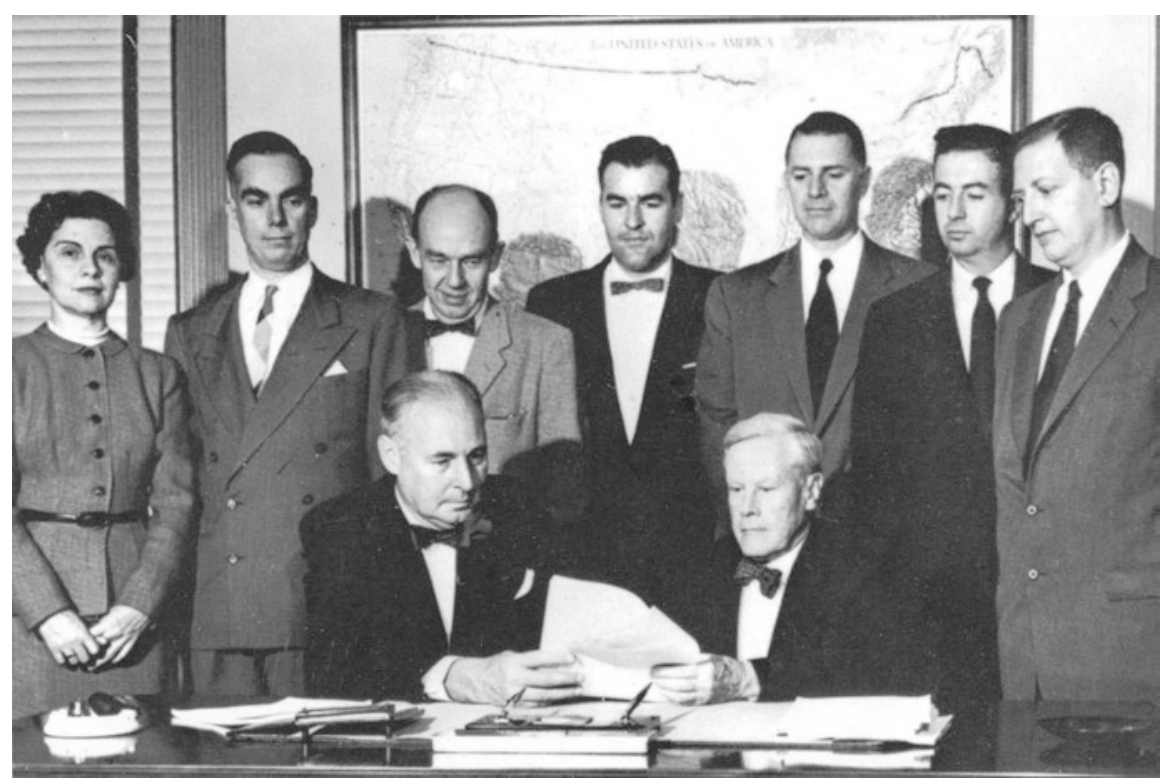

Fig. 3.13 17 November 1956 signing of the first AUI 5-year contract to operate NRAO. Seated on the left is AUI President Lloyd Berkner and on the right is the NSF Director, Alan Waterman. Watching are members of the NSF staff. Credit: NRAO/ AUI/NSF 
Director of the Observatory. After this initial five-year period, the NSF stipulated that the choice of the management would be reconsidered, possibly for a joint operation with a national optical observatory.

For more than half a century, until 2015, the NSF would renew the AUI contract or Cooperative Agreement every five years based on a non-competitive proposal from AUI. There was never any further serious discussion of combining the management of the national radio and optical astronomy observatories, although for a period of years in the mid-1960s, the NRAO and KPNO staffs met annually for exchange visits. However, due to budget pressures and increased emphasis on visitor use at both observatories, and less attention given to in-house research programs, these exchange visits ended after a few years. The national radio and optical observatories continued as they had begun, with independent management by AUI and AURA respectively, reflecting the differing technology and different scientific emphasis at the two national observatories.

\section{Notes}

1. This section is based in part on The Science Foundation: A Brief History, NSF88-16 by George T. Mazuzan (1994). https://www.nsf.gov/about/history/nsf50/nsf8816.jsp. Maruzan was a former NSF Historian at the Office of Legislative and Public Affairs. More detailed background on the NSF can be found in the books by J. Merton England (1982) and by Milton Lomask (1976).

2. Minutes of the NSB 34th meeting, 20 May 1955.

3. Public Law 507-81st Congress, Chapter 171-2D Session, S. 247.

4. Ibid.

5. Waterman to Gabriel Hauge, Administrative Assistant to the President, 26 August 1955, LoC-ATW, Box 26.

6. Events leading to the establishment of the Kitt Peak Astronomical Observatory (KPNO) operated by the Association of Universities for Research in Astronomy (AURA) are discussed in more detail by England (1982), Goldberg (1983), Edmondson (1991, 1997) and Leverington (2017).

7. Other panel members were Lawrence Aller (Michigan), Dirk Brower (Yale), Martin Schwarzschild (Princeton), Gerard Kuiper (Arizona), Fred Whipple (Harvard), and Gerald Kron (Lick). Leo Goldberg, a member of the NSF Mathematical, Physical, and Engineering Sciences (MPE) Divisional Committee, was effectively an ex officio member.

8. Other members of the Panel were Ira Bowen (MWPO), Bengt Stromgren (Yerkes), Otto Struve (UC Berkley Leuschner Observatory), and Albert Whitford (University of Wisconsin).

9. Waterman notes to diary, February 1954, LoC-ATW, Box 26.

10. Tensions between the well-equipped Caltech/MWPO and KPNO continued for many years, although Caltech later became a member of AURA in 1972. By 2017, there were 44 member institutions of AURA. 
11. This section is adopted from The Early History of Associated Universities and Brookhaven National Laboratory, BNL 992 (T-421), which is based on a talk given by Norman Ramsey at Brookhaven on 30 March 1966.

12. Columbia, Cornell, Harvard, Johns Hopkins, MIT, Pennsylvania, Princeton, Rochester, and Yale.

13. Ramsey op cit.

14. Ramsey op. cit.

15. AUI-BOT, 18 July 1952.

16. This section is based in part on Hales (1992) and Needell (2000).

17. See Needell (1987) p. 264.

18. Berkner to James Webb, 31 March 1961, The Space Studies Board, Compilation of Reports, National Academies of Science, Engineering, Medicine, Washington, DC.

19. President John F. Kennedy, speech to a Joint Session of Congress, 25 May 1961.

20. The circumstances leading up to the creation of NRAO are discussed by DeVorkin (2000), England (1982), Kenwolf (2010), Lockman et al. (2007), Lomask (1976), Malphrus (1996), Munns (2003, 2013) and Needell (1987, 1991, 2000). Numerous factual errors in the Malphrus book have been noted by Baars (NAA-KIK, Open Skies) and by Findlay (NAA-JWF, Miscellany, Theses).

21. See also Greenstein oral history at Caltech. CITA.

22. Greenstein, unpublished manuscript, "I Was There in the Early Years of Radio Astronomy”, NAA-KIK, Open Skies.

23. Robert F. Bacher oral history, CITA. http://oralhistories.library.caltech. edu/93/

24. According to Needell (2000, p. 265), during an early 1952 visit to Pasadena, Bush met with DuBridge and Ira Bowen to discuss the possibility of building a large radio telescope close to the Caltech/Carnegie MWPO. Apparently similar discussions had taken place earlier between Merle Tuve and Ira Bowen.

25. Bush to DuBridge, 14 February 1952, CITA-LAD, Box 35, Folder 1.

26. DuBridge to Bowen, 21 February 1952, CITA-LAD, Box 35, Folder 1.

27. E. Bowen, Draft Programme for a Radio Observatory, 22 May 1952, CITALAD, Box 35, Folder 2.

28. DuBridge to Bowen, 11 June 1952, CITA-LAD, Box 35, Folder 2.

29. Bowen to DuBridge, 30 August 1952, CITA-LAD, Box 35, Folder 2.

30. Bowen to Bush, 22 August 1952, CITA-LAD, Box 35, Folder 2.

31. Greenstein to DuBridge, 19 February 1953, CITA-JLG, Box 113, Folder 1.

32. Ibid.

33. Ibid.

34. DuBridge to Greenstein, CITA-JLG, Box 113, Folder 1.

35. DuBridge to Tuve, Purcell and Wiesner, 19 and 20 March 1953, CITA-LAD, Box 34, Folder 15.

36. Purcell to DuBridge, 26 March 1953, CITA-LAD, Box 34, Folder 15.

37. Bok to Greenstein, 30 March 1953, CITA-JLG, Box 3, Folder 26.

38. Tuve to DuBridge, 2 April 1953, DTMA, Series 1, Box 4, Folder 3.

39. Greenstein to Bok, 9 April 1953, CITA-LAD, Box 34, Folder 15.

40. Bok to Greenstein, 13 April 1953, CITA-LAD, Box 34, Folder 15.

41. DuBridge to Bok, 5 May 1953, CITA-LAD, Box 34, Folder 15. 
42. Greenstein to DuBridge, 10 June 1953, CITA-LAD, Box 34, Folder 15.

43. Ultimately, papers from the December 1953 Boston meeting were never published. The January 1954 Washington meeting papers were published in the Journal of Geophysical Research, Vol. 59, p. 149 (1954).

44. Tuve to Greenstein, 23 September 1953, DTMA, Series 1, Box 4, Folder 8.

45. Ibid.

46. Tuve to Greenstein, 14 October 1953, DTMA, Series 1, Box 4, Folder 8.

47. Participants included: P. E. Klopsteg, J. H. McMillan, and R. J. Seeger from the NSF, R. Minkowski from the MWPO, Merle Tuve from DTM, Greenstein and DuBridge from Caltech, Bart Bok from Harvard, John Kraus from Ohio State, and Taffy Bowen from Australia. The group's report to the NSF was written by Greenstein (CITA-LAD, Box 34, Folder 15).

48. Other members of the NSF Advisory Panel were Bart Bok (Harvard), Jesse Greenstein (Caltech), John Hagan (NRL), John Kraus (Ohio State), Rudolph Minkowski (MWPO), and Ed Purcell (Harvard). Peter van de Kamp represented the NSF on the Panel.

49. Historical account presented by Richard Emberson at the 28 May 1955 meeting of the AUI Steering Committee, NAA-NRAO, Founding and Organization, Planning Documents, and by Menzel at the 11 July 1956 NSF meeting, NAANRAO, Founding and Organization, Meeting Minutes. Also see Emberson (1959).

50. Menzel to Berkner, 13 April 1954, "Survey of the Potentialities of Cooperative Research in Radio Astronomy," NAA-DSH, Radio Astronomy History, NRAO. https://science.nrao.edu/about/publications/open-skies\#section-3

51. Diary notes of Raymond Seeger, 26 April 1954, LOC-ATW, Box 26.

52. The discussion of the 20 May 1954 meeting is based on diary notes of Raymond Seeger, LOC-ATW, Box 26.

53. Greenstein to Hagan, 1 June 1954, CITA-JLG, Box 14, Folder 1.

54. Dicke to AUI Committee on Radio Astronomy, 7 June 1954, CITA-JLG, Box 111 , Folder 7.

55. AUI BOTXC, 21 May 1954.

56. AUI BOTXC, 18 June 1954.

57. Other members of the AUI Steering Committee were Bart Bok (Harvard), Armin Deutsch (MWPO), Harold (Doc) Ewen (Harvard), Leo Goldberg (Michigan), William Gordon (Cornell), Fred Haddock (NRL), John Kraus (Ohio State), Aden Meinel (Yerkes Observatory), Merle Tuve (DTM), Jerry Weisner (MIT), and H.E. Wells (DTM).

58. The NSF Advisory Panel was at times referred to as "Committee" rather than "Panel," but we have consistently used "Panel" to avoid confusion with the AUI Steering Committee appointed by Berkner.

59. Goldberg to van de Kamp, 4 August 1954.

60. Summary Notes AUI Steering Committee, 26 July 1954, DTMA, Series 1, Box 4, Folder 2.

61. Research Proposal to the National Science Foundation for a Grant in Support of a Feasibility Study for a National Radio Astronomy Facility, 26 July 1954, NAA-NRAO Founding and Organization, Planning Documents. https://science.nrao.edu/about/publications/open-skies\#section-3

62. Waterman to diary, 3 August 1954, LOC-ATW, Box 26.

63. The total NSF 1954 budget was $\$ 8$ million. 
64. Minkowski to Tuve, 19 October 1954, DTMA Series 1, Box 4, Folder 1.

65. Waterman to diary, 7 September 1954, LOC-ATW, Box 26.

66. Ibid.

67. Tuve to NSF Radio Astronomy Panel, (Purcell, Bok, Greenstein, Minkowski, Hagen, and Kraus), 5 October 1954, DTMA, Series 1, Box 4, Folder 1.

68. Ibid.

69. Greenstein to Tuve, 14 October 1954, DTMA, Series 1, Box 4, Folder 1; CITA-JLG, Box 39, Folder 12.

70. AUI-BOTXC, 11 September 1954; AUI-BOT, 28 October 1954.

71. Tuve to van de Kamp, 29 October 1954, DTMA, Series 1, Box 4, Folder 1.

72. Bok to Greenstein, 8 November 1954, CITA-JLG, Box 3, Folder 26. Other participants included Bok, Purcell, Seeger, Hagen, and Tuve.

73. Berkner to Seeger, 18 November 1954, Appended to AUI-BOTXC minutes, 19 November 1954.

74. Tuve to NSF Radio Astronomy Committee [i.e. Panel], 17 November 1954, DTMA, Series 1, Box 4, Folder 2.

75. Greenstein to Tuve, 16 November 1954, DTMA, Series 1, Box 4, Folder 1.

76. Tuve to NSF Radio Astronomy Committee [i.e. Panel], 11 November 1954, DTMA, Series 1, Box 4, Folder 1; LOC-ATW, Box 26. Participants were Bok (Harvard), Hagen (NRL), Kraus (Ohio State), Minkowski (MWPO), Tuve (DTM), and van de Kamp (NSF).

77. Greenstein to Tuve, 11 November 1955 telegram, DTMA, Series 1, Box 4. Starting with his friendship and collaboration with Grote Reber, two early publications on radio astronomy, his organization of the Washington Conference, his role in starting radio astronomy at Caltech and in the discovery of quasars (Chap. 6), his early support of the AUI radio astronomy initiatives, and his influence at the 1970 NAS Decade Review of astronomy (Chap. 7) that recommended the VLA as its top priority, Greenstein, perhaps more than anyone else in the United States, was a central figure in the development of the American radio astronomy program.

78. Notes on NSF Advisory Committee [i.e. Panel] meeting dated 19 November 1954 and minutes of the meeting dated 20 November 1954, DTMA, Series 1, Box 4 , Folder 1.

79. Seeger in fact had estimated that between $\$ 200,000$ and $\$ 300,000$ would be available from the NSF out of Fiscal Year 1955 funds. Seeger to diary, 16 November 1954, LOC-ATW, Box 26.

80. NSF Advisory committee minutes, 19 November 1954, op. cit.

81. Berkner to Seeger, 18 November 1954, op. cit.

82. Dunbar to Berkner, 28 December 1954, DTMA, Series 1, Box 4, Folder 1. Summary of meeting 28 December 1954. Also in attendance were Peter van de Kamp from the NSF, John Hagen from NRL, and other AUI officers.

83. AUI-BOT, 20 January 1955.

84. Ibid.

85. AUI-BOT, 14 April 1955.

86. Ibid.

87. Plan for a Radio Astronomy Observatory, p. 31, NAA-NRAO, Founding and Organization, Planning Documents. https://science.nrao.edu/about/publications/open-skies\#section-3 
88. It was not specified, but presumably this referred to the maximum, not rms, deviation. One inch maximum deviation would have meant approximately an $8 \mathrm{~mm}$ rms surface accuracy roughly consistent with a minimum operating wavelength of about $10 \mathrm{~cm}$.

89. Tuve to DuBridge, 10 March 1955, CITA-LAD, Box 35, Folder 2.

90. Plan for a Radio Astronomy Observatory, op. cit., p. 32.

91. Research Objectives for Large Steerable Paraboloid Radio Reflectors (prepared by Bok and his Panel for the AUI Steering Committee), 22 April 1955, NAANRAO, Founding and Organization, Planning Documents. https://science. nrao.edu/about/publications/open-skies\#section-3; AUI-BOT, 14 April 1955.

92. AUI-BOT, 14 April 1955.

93. Ibid.

94. Research Objectives for Large Steerable Paraboloid Radio Reflectors, op. cit.

95. Seeger to diary, 1 April 1955, LOC-ATW, Box 26.

96. Emberson to Seeger, 21 April 1955, CITA-JLG, Box 111, Folder 7.

97. Ibid.

98. Bok to Tuve, 28 April 1955, with copies to Hagen, Greenstein, Minkowski, Purcell, Kraus, Ewen, CITA-JLG, Box 111, Folder 6.

99. Bok to Tuve, 28 April 1955, DTMA, Series 1, Box 4, Folder 1.

100. Tuve to NSF Panel, 2 May 1955, CITA-JLG, Box 111, Folder 6; DTMA, Series 1, Box 4, Folder 1.

101. Hagen to NSF Panel, 10 May 1955, CITA-JLG, Box 111, Folder 6; DTMA, Series 1, Box 4, Folder 1.

102. Minkowski to Tuve, 4 May 1955, CITA-JLG, Box 111, Folder 6. Both Minkowski and Hagen incorrectly argued against interferometers on the grounds that, unlike a parabolic dish, interferometers were narrow band.

103. Greenstein and Minkowski to NSF Committee, 18 May 1955, CITA-JLG, Box 111, Folder 6; DTMA, Series 1, Box 4, Folder 1.

104. An initial report to the NSF Divisional Committee was presented by Tuve, Bok, and Hagen on Sunday 24 April (Tuve to NSF Advisory Committee, 2 May 1955, CIT-JLG, Box 111, Folder 6). On 21 June 1955, Tuve sent a more detailed report to the Committee, CITA-JLG, Box 111, Folder 7.

105. van de Kamp, "Inter-University Radio Astronomy Observatory," May 1955, CITA-JLG, Box 111, Folder 6.

106. Emberson to Seeger, 6 May 1955, LOC-ATW, Box 26.

107. Minutes of the AUI Steering Committee for 28 May 1955, NAA-NRAO, Founding and Organization, Meeting Minutes.

108. Ibid.

109. Ibid.

110. Ibid.

111. Ibid.

112. Ibid.

113. Tuve to van de Kamp, 23 June 1955, CITA-JLG, Box 111, Folder 6.

114. AUI-BOTXC, 17 June 1955.

115. Waterman to diary, 16 August 1955, LOC-ATW, Box 26.

116. van de Kamp to Waterman, 14 July 1955, LOC-ATW, Box 26. 
117. Paul H. Kratz to diary, 24 August 1955, LOC-ATW, Box 26.

118. Bok to Charles Cutts, NSF Engineer, 23 September 1955, CITA-JLG, Box 3, Folder 26.

119. Greenstein to Bok, 29 September 1955, CITA-JLG, Box 111, Folder 6.

120. Kraus to Tuve, 24 September 1955, NAA-JDK, Notes and Papers, US Radio Astronomy; DTMA, Series 1, Box 4, Folder 1; CITA-JLG, Box 111, Folder 6.

121. Minkowski to Tuve, 8 October 1955, CITA-JLG, Box 111, Folder 7.

122. Seeger to diary, 27 September 1955, LOC-ATW, Box 26.

123. Tuve to Seeger, 29 September 1955, CITA-JLG, Box 111, Folder 6; DTMA, LOC-ATW, Box 26.

124. Sunderlin to diary, 9 December 1955, LOC-ATW, Box 26. Also in attendance were Bok, Tuve, Emberson, and from the NSF Seeger, Cutte, Hogg, and Sunderlin.

125. Waterman to diary, 21 and 22 December 1955, LOC-ATW, Box 26.

126. Ibid.

127. Minutes of the AUI Steering Committee, 30 December 1955, CIT-JLG, Box 113 , Folder 2.

128. AUI-BOTXC, 14 December 1955. Members named to the New AUI Advisory Committee were: Bart Bok (Harvard), W. E. Gordon (Cornell), Merle Tuve (DTM), E. F. McClain (NRL), Leo Goldberg, (Michigan), John Kraus (Ohio State), A.B. Meinel (National Optical Observatory), A.J. Deutsch (Caltech, MWPO), J.B. Wiesner (MIT).

129. Under Hagen's leadership, Project Vanguard was an NRL program, designed as part of the International Geophysical Year, which intended to launch the first artificial satellite into Earth orbit. After the naval rocket collapsed in flames during a nationally televised launch failure, Explorer 1 was launched by Army Ballistic Missile Agency under Werner von Braun's leadership a few months after the successful launch of Sputnik land 2 by the USSR, and became the first US orbiting satellite.

130. Seeger to diary, 25 January 1956, LOC-ATW, Box 26.

131. Tuve to NSF Advisory Panel, 20 December 1955, CITA-JLG, Box 111, Folder 6. Tuve's reference to Green Bank as the "deep woods" was perhaps a sarcastic reference to the mythical home of the Phantom, a popular comic strip character of the 1950s.

132. Advisory Panel for Radio Astronomy, Agenda, 16-17 January 1956, CITAJLG, Box 111, Folder 6; LOC-ATW, Box 26.

133. Waterman to diary, 18 January 1956, LOC-ATW, Box 26.

134. Hogg, 4 May 1956 Summary Notes on the Radio Astronomy Observatory, LOC-ATW, Box 26.

135. Waterman to diary, 19 January 1956, LOC-ATW, Box 26.

136. Sunderlin to diary, 23 January 1956, LOC-ATW, Box 26.

137. Hogg, op. cit.

138. Hogg, op. cit.

139. Minutes of the December 11-13 1955 AUI Steering Committee, CITA-JLG, Box 111 , Folder 2.

140. New York Times, 22 January 1956, p. B15.

141. Seeger to diary, 30 March 1956, LOC-ATW, Box 26. 
142. Minutes of AUI Steering Committee, 25-27 March 1956, NAA-NRAO, Founding and Organization, Meeting Minutes.

143. NSF-AUI meeting, 2 April 1956, NAA-NRAO, Founding and Organization, Meeting Minutes. https://science.nrao.edu/about/publications/ open-skies\#section-3

144. Planning Document for the National Radio Astronomy Facility, NAA-NRAO, Founding and Organization, Planning Documents. A second draft was submitted on 21 May 1956.

145. Plan for a Radio Astronomy Observatory, p. 39. https://science.nrao.edu/ about/publications/open-skies\#section-3

146. G.H. Hickox to diary, 15 February, 1956, LOC-ATW, Box 26.

147. Seeger to diary, 23 March 1956, LOC-ATW, Box 26.

148. Seeger to Berkner, 22 March 1956, NAA-NRAO, Founding and Organization, Meeting Minutes; LOC-ATW, Box 26.

149. Plan for a Radio Astronomy Observatory, op. cit. p. 39.

150. Tuve to Seeger, 14 June 1956, CITA-JLG, Box 111, Folder 6.

151. AUI-BOT, 19 April 1956.

152. AUI-BOTXC, 18 May 1956; Dunbar to Berkner, 14 May 1956, NAA-NRAO, Founding and Organization, Meeting Minutes.

153. Ibid.

154. AUI-BOTXC, 19 April 1956.

155. Ibid.

156. Ibid.

157. Waterman, Remarks at the Dedication of the George R. Agassiz Telescope, NAA-NRAO, Founding and Organization, Planning Documents. https://science.nrao.edu/about/publications/open-skies\#section-3

158. Ibid.

159. The criteria for selecting the site were outlined in the Plan for a Radio Astronomy Observatory submitted to the NSF in August 1956.

160. Precipitable water vapor is a measure of the total water vapor content in path through the atmosphere and differs from the relative humidity (often just called "humidity") which is a measure of the fraction of water vapor in the local atmosphere compared with the maximum amount possible.

161. Plan for a Radio Astronomy Observatory, op. cit., p. 18.

162. Those who actively participated in the search included H.L. Alden, E.R. Dyer, and W. Nelson (University of Virginia), J.E. Campbell (Tennessee Valley Authority), C. Cutts and P. van de Kamp (NSF), R.M. Emberson (AUI), H.I. Ewen (Harvard), F.T. Hadock and J.P. Hagen (NRL), W. Hardiman (Tenn. State Geologist), R.A. Laurence (Knoxville Geological Survey), W. McGill (Virginia State Geologist), P.H. Price (West Virginia State Geologist), and C.K. Seyfert (Vanderbilt). August 1956, Plan for a Radio Astronomy Observatory, Section III B.

163. NAA-WTS, Sullivan interview with John Hagen, 27 August 1976. https:// science.nrao.edu/about/publications/open-skies\#section-3

164. Plan for a Radio Astronomy Observatory, op. cit., p. 16.

165. James Mitchell, Diary Note, 20 February 1956, LOC-ATW, Box 26.

166. Hogg, Diary Note, 14 March 1956, LOC-ATW, Box 26. 
167. Emberson to Seeger, 9 April 1956, LOC-ATW, Box 26.

168. Waterman to diary, 7 February 1956, LOC-ATW, Box 26.

169. The other potential sites were Burkes Garden, VA, Little Meadows, VA, Massanutten Mountain, VA, Green Bank, WV, and Deerfield, VA.

170. Curtis M. Jansky, founder of Jansky and Baily, was Karl Jansky's older brother who had intervened to get Karl a job at Bell Laboratories.

171. Kenwolf (2010) gives a colorful, though sometimes misleading, description of the Green Bank area and the impact of NRAO on the local population.

172. Bok, 7 August 1956, Toward a National Radio Observatory, NAA-NRAO, Founding and Organization, Planning Documents. https://science.nrao. edu/about/publications/open-skies\#section-3

173. Seeger to diary, 21 December 1955, LOC-ATW, Box 26.

174. Seeger to diary, 30 January 1956, LOC-ATW, Box 26.

175. Waterman to diary, 22 December 1955, LOC-ATW, Box 26.

176. Minutes of the AUI Steering Committee Meeting, 13 December 1955, CITAJLG, Box 113, Folder 2.

177. Ibid.

178. Feasibility Report for the National Science Foundation on Construction of a National Radio-Astronomy Facility, 7 May 1955, NAA-NRAO, Founding and Organization, Planning Documents. https://science.nrao.edu/about/publications/open-skies\#section-3

179. Emberson, 16 January 1956 memo to radio astronomy file, NAA-NRAO, Founding and Organization, Correspondence. https://science.nrao.edu/ about/publications/open-skies\#section-3

180. AUI-BOT, 14 April 1955.

181. West Virginia Legislature, Chapter 37A, Article 1, Radio Astronomy Zoning Act, $1956 . \quad$ http://www.wvlegislature.gov/wvcode/code. cfm? chap $=37$ a \&art $=1$

182. Needell (1987) gives a detailed account of the long-lasting conflict between Berkner and Tuve.

183. In spite of the apparent 2-3-day postal delivery time, some of the hastily written letters and responses overlapped in time.

184. Tuve to NSF Panel, 14 June 1956, CITA-JLG, Box 111, Folder 6.

185. Tuve to Stewart, 19 June 1956, CITA-JLG, Box 111, Folder 6.

186. Tuve to Beams, 19 June 1956, CITA-JLG, Box 111, Folder 6.

187. Tuve to Goldberg, 28 June 1956, CITA-JLG, Box 111, Folder 6.

188. Bowen to Tuve, 28 June 1956, CITA-JLG, Box 111, Folder 6.

189. Bok to Tuve, 20 June 1956, NAA-NRAO, Founding and Organization, Correspondence; CITA-JLG, Box 111, Folder 6.

190. Bok to Tuve, 22 June 1956, NAA-NRAO, Founding and Organization, Correspondence; CITA-JLG, Box 111, Folder 6.

191. Bok to Tuve, 5 July 1956, NAA-NRAO, Founding and Organization, Correspondence.

192. Hagen to Tuve, 25 June 1956, NAA-NRAO, Founding and Organization, Correspondence.

193. Greenstein to Tuve, 21 June 1956, CITA-JLG, Box 111, Folder 6. 
194. Purcell to Tuve, 27 June 1956, NAA-NRAO, Founding and Organization, Correspondence; CITA-JLG, Box 111, Folder 6.

195. Houston to Tuve, 26 June 1956, CITA-JLG, Box 111, Folder 6. M. V. (Bill) Houston was a member of the National Science Board from Rice University.

196. Tuve to Bok, 29 June 1956, NAA-NRAO Founding and Organization, Correspondence; CITA-JLG, Box 111, Folder 5.

197. Tuve to NSF Panel, 1 July 1956, CITA-JLG, Box 111, Folder 5.

198. Bok to Tuve, 3 July 1956, NAA-NRAO Founding and Organization, Correspondence; CITA-JLG, Box 111, Folder 5.

199. Ibid.

200. Greenstein to NSF Panel, 5 July 1956, CITA-JLG, Box 111, Folder 5; Greenstein to Tuve, 6 July 1956, CITA-JLG, Box 111, Folder 5.

201. The following discussion of the 11 July meeting is taken from the Minutes of the Conference on Radio Astronomy Facilities, NAA-NRAO, Founding and Organization, Meeting Minutes.

202. Dunbar to Berkner, 2 July 1956, NAA-NRAO, Founding and Organization, Correspondence; AUI-BOTX, 20 July 1956.

203. The enabling legislation which established the NSF states "The Foundation shall not, itself, operate any laboratory or pilot plants." Section 14(c).

204. Heeschen had joined AUI only ten days earlier.

205. Menzel to Tuve, 19 July 1956, CITA-JLG, Box 111, Folder 2.

206. Berkner to Menzel, 24 July 1956, NAA-NRAO, Founding and Organization, Correspondence.

207. Berkner to Waterman, 20 July 1956, Appended to the minutes of BOTXC, 20 July 1956.

208. Minutes of the Joint Meeting of NSF Advisory Panel for Astronomical Observatory and NSF Panel on Radio Astronomy, 23 July 1956, NAA-NRAO, Founding and Organization, Meeting Minutes.

209. Greenstein to Menzel, 27 July 1956, CITA-JLG, Box 111, Folder 5.

210. NSF Press release, 26 July 1956, CITA-JLG, Box 113, Folder 2.

211. Tuve, 25 July 1956, Minutes of the 22-23 July 1956 NSF Advisory Panel on Radio Astronomy, NAA-NRAO, Founding and Organization, Meeting Minutes; CITA-JLG, Box 111, Folder 5.

212. Greenstein to Tuve, 5 November 1956, CITA-JLG Box 113, Folder 2.

213. Minutes of the NSB, 24 August 1956.

214. Hagen to Tuve, 25 July 1956, CITA-JLG, Box 111, Folder 5.

215. Referenced at the start of 8 October 1956 Berkner to Waterman letter appended to AUI-BOTX, 18 October 1956.

216. Appendix to the Minutes of the 16-17 October 1956 meeting of the AUI Advisory Committee, NAA-NRAO, Founding and Organization, Meeting Minutes.

217. Berkner to Waterman, 8 October 1956, Attached to AUI-BOTXC, 18 October 1956.

218. Waterman to Berkner, 12 October 1956, Attached to AUI-BOTXC, 18-19 October 1956.

219. AUI-BOTXC, 21 September 1956.

220. NAA-NRAO, Founding and Organization, Planning Documents. https://science.nrao.edu/about/publications/open-skies\#section-3 


\section{BIBLIOGRAPHY}

\section{REFERENCES}

Baade, W. and Minkowski, R. 1954, Identification of the Radio Sources in Cassiopeia, Cygnus A, and Puppis A, ApJ, 119, 206

Berkner, L.V. 1956, Radio Telescopes, Present and Future - Plan for a National Radio Astronomy Facility, AJ, 61, 165

Bowen, E.G. 1987, Radar Days (Bristol: IOP Publishing)

Bush, V. 1945, Science, The Endless Frontier (Washington: United States Office of Scientific Research and Development)

DeVorkin, D.H. 2000, Who Speaks for Astronomy? How Astronomers Responded to Government Funding after World War II, Historical Studies in the Physical and Biological Sciences, 31 (1), 55

Edmondson, F. 1991, AURA and KPNO: The Evolution of an Idea, 1952-1958, $J H A, 22,68$

Edmondson, F. 1997, AURA and its US National Observatories (Cambridge: Cambridge University Press)

Emberson, R.M. 1959, National Radio Astronomy Observatory, Sci, 130, 1307

England, J.M. 1982, A Patron for Pure Science: The National Science Foundation's Formative Years, 1945-57 (Washington: National Science Foundation)

Goldberg, L. 1983, Founding of Kitt Peak, S\& T, 65 (March), 228

Greenstein, J.L. 1984a, Optical and Radio Astronomers in the Early Years. In The Early Years of Radio Astronomy, ed. W.T. Sullivan III (Cambridge: CUP), 67

Greenstein, J.L. 1984b, An Astronomical Life, ARAA, 22, 1

Greenstein, J.L. 1994, The Early Years of Radio Astronomy at Caltech, $A u J P h, 47,555$

Gunn, J. 2003, Jesse Greenstein (1909-2002), BAAS, 35, 1463

Hagan, J.P. 1954, Radio Astronomy Conference, Sci, 119, 588

Hales, A.L. 1992, Lloyd Viel Berkner, February 1, 1905-June 4, 1967, BMNAS, 61, 3

Hanbury Brown, R., Minnett, H.C., and White, F.W.G. 1992, Edward George Bowen 1911-1991, Historical Records of Australian Science, 9, No. 2, (also appeared in the Biographical Memoirs of Fellows of the Royal Society of London, 1992)

Heeschen, D.S. 1996, The Establishment and Early Years of NRAO, BAAS, 28, 863

Irwin, J.B. 1952, Optimum Location of a Photoelectric Observatory, Sci, 115, 22

Kenwolf, L.G. 2010, A Social and Political History of the National Radio Astronomy Observatory at Green Bank, WV (Morgantown: West Virginia Libraries)

Kraft, R.P. 2005, Jesse Leonard Greenstein, 1909-2002, BMNAS, 86, 1

Leverington, D. 2017, Observatories and Telescopes of Modern Times (Cambridge: Cambridge University Press)

Lockman, F.J., Ghigo, F.D., and Balser, D.S. eds. 2007, But It Was Fun (Green Bank: National Radio Astronomy Observatory)

Lomask, M. 1976, A Minor Miracle: An Informal History of the National Science Foundation (Washington: National Science Foundation)

Malphrus, B. 1996, The History of Radio Astronomy and the National Radio Astronomy Observatory: Evolution toward Big Science (Malabar, Fla.: Krieger Pub.)

McClain, E. 1960, The 600-Foot Radio Telescope, SciAm, 202 (1), 45 
McClain, E. 2007, A View from the Outside. In But It Was Fun, ed. F.J. Lockman, F.D. Ghigo, and D.S. Balser (Green Bank: NRAO)

Munns, D.P.D. 2003, If We Build It, Who Will Come? Radio Astronomy and the Limitations of 'National' Laboratories in Cold War America, Historical Studies in the Physical and Biological Sciences, 34 (1), 95

Munns, D.P.D. 2013, A Single Sky: How an International Community Forged the Science of Radio Astronomy (Cambridge: MIT Press)

Needell, A.E. 1987, Lloyd Berkner, Merle Tuve, and the Federal Role in Radio Astronomy, OSIRIS Ser 2, 3, 261

Needell, A.E. 1991, The Carnegie Institute of Washington and Radio Astronomy: Prelude to an American National Observatory, JHA, 22, 55

Needell, A.E. 2000, Science, Cold War and the American State: Lloyd V. Berkner and the Balance of Professional Ideals (Amsterdam: Harwood Academic)

Reber, G. and Greenstein, J.L. 1947, Radio-frequency Investigations of Astronomical Interest, $O b s, 67,15$

Robertson, P. 1992, Beyond Southern Skies - Radio Astronomy and the Parkes Telescope (Cambridge: CUP)

Rogers, A.E.E. et al. 2005, Deuterium Abundance in the Interstellar Gas of the Galactic Anti-center from the $327 \mathrm{MHz}$ Line, ApJ, 630, L4l

Townes, C. 1995, Making Waves (Washington: American Institute of Physics)

Wang, J. 2012, Physics, Emotion, and the Scientific Self: Merle Tuve's Cold War, Historical Studies in the Natural Sciences, 42(5), 341

Weinreb, S. et al. 1963, Radio Observations of $\mathrm{OH}$ in the Interstellar Medium, Nature, 200, 829

Whipple, F.L. and Greenstein, J.L. 1937, On the Origin of Interstellar Radio Disturbances, PNAS, 23, 177-181

\section{FurThER READING}

Bok, B.J. 1956, A National Radio Observatory, SciAm, 195 (4), 56

Bok, B.J. 1956, Toward a National Radio Observatory, 7 August 1956, NAA-NRAO Founding and Organization, Planning Documents https://science.nrao.edu/ about/publications/open-skies\#section-3

Dick, S.J. 1991, National Observatories - an Overview, JHA, 22, 1

Emberson, R.M. and Ashton, N.L. 1958, The Telescope Program for the National Radio Astronomy Observatory at Green Bank, West Virginia, Proc IRE, 46 (1), 23 
Open Access This chapter is licensed under the terms of the Creative Commons Attribution 4.0 International License (http://creativecommons.org/licenses/ by/4.0/), which permits use, sharing, adaptation, distribution and reproduction in any medium or format, as long as you give appropriate credit to the original author(s) and the source, provide a link to the Creative Commons licence and indicate if changes were made.

The images or other third party material in this chapter are included in the chapter's Creative Commons licence, unless indicated otherwise in a credit line to the material. If material is not included in the chapter's Creative Commons licence and your intended use is not permitted by statutory regulation or exceeds the permitted use, you will need to obtain permission directly from the copyright holder. 